FEDERAL RESERVE BANK OF SAN FRANCISCO

WORKING PAPER SERIES

\title{
Credit Frictions and Optimal Monetary Policy
}

\author{
Vasco Cúrdia \\ Federal Reserve Bank of San Francisco \\ Michael Woodford \\ Columbia University
}

December 2015

Working Paper 2015-20

http://www.frbsf.org/economic-research/publications/working-papers/wp2015-20.pdf

\section{Suggested citation:}

Cúrdia, Vasco, Michael Woodford. 2015. "Credit Frictions and Optimal Monetary Policy.” Federal Reserve Bank of San Francisco Working Paper 2015-20.

http://www.frbsf.org/economic-research/publications/working-papers/wp2015-20.pdf

The views in this paper are solely the responsibility of the authors and should not be interpreted as reflecting the views of the Federal Reserve Bank of San Francisco or the Board of Governors of the Federal Reserve System. 


\title{
Credit Frictions and Optimal Monetary Policy*
}

\author{
Vasco Cúrdia ${ }^{\dagger a}$ and Michael Woodford ${ }^{\ddagger b}$ \\ ${ }^{a}$ Federal Reserve Bank of San Francisco \\ ${ }^{\mathrm{b}}$ Columbia University
}

December 14, 2015

\begin{abstract}
We extend the basic (representative-household) New Keynesian [NK] model of the monetary transmission mechanism to allow for a spread between the interest rate available to savers and borrowers, that can vary for either exogenous or endogenous reasons. We find that the mere existence of a positive average spread makes little quantitative difference for the predicted effects of particular policies. Variation in spreads over time is of greater significance, with consequences both for the equilibrium relation between the policy rate and aggregate expenditure and for the relation between real activity and inflation.

Nonetheless, we find that the target criterion - a linear relation that should be maintained between the inflation rate and changes in the output gap - that characterizes optimal policy in the basic NK model continues to provide a good approximation to optimal policy, even in the presence of variations in credit spreads. Such a "flexible inflation target" can be implemented by a central-bank reaction function that is similar to a forward-looking Taylor rule, but adjusted for changes in current and expected future credit spreads.
\end{abstract}

JEL codes: E44, E52

Keywords: credit spreads, policy rules, target criterion, flexible inflation targeting, quadratic loss function

\footnotetext{
*Revision of a paper prepared for the BIS annual conference, "Whither Monetary Policy?" Lucerne, Switzerland, June 26-27, 2008. We would like to thank Andy Atkeson, Olivier Blanchard, Bill Brainard, V.V. Chari, Fiorella DeFiore, Marco Del Negro, Gauti Eggertsson, Simon Gilchrist, Marvin Goodfriend, Charles Goodhart, Miles Kimball, John Leahy, Bennett McCallum, Tommaso Monacelli, Argia Sbordone, Frank Smets and Oreste Tristani for helpful comments, and the NSF for research support of the second author through a grant to the NBER. The content of this document does not necessarily reflect the views of the Federal Reserve Bank of San Francisco or the Federal Reserve System.

${ }^{\dagger} E$-mail: vasco.curdia@sf.frb.org

$\ddagger E$-mail: michael.woodford@columbia.edu
} 


\section{Credit Frictions and Optimal Monetary Policy}

\section{Introduction}

It is common for theoretical evaluations of alternative monetary policies - most notably, the literature that provides theoretical foundations for inflation targeting - to be conducted using models of the monetary transmission mechanism that abstract altogether from financial frictions. ${ }^{1}$ There is generally assumed to be a single interest rate - "the interest rate" that is at once the policy rate that constitutes the operating target for the central bank, the rate of return that all households and firms receive on savings, and the rate at which anyone can borrow against future income. In models with more complete theoretical foundations, this is justified by assuming frictionless financial markets, in which all interest rates (of similar maturity) must be equal in order for arbitrage opportunities not to exist. It is also common to assume a representative household, and firms that maximize the value of their earnings streams to that household, so that there is no need for credit flows in equilibrium in any event; such models imply that a breakdown of credit markets would have no allocative significance. Many of the quantitative DSGE models developed in central banks and other policy institutions before the recent financial crisis share these features. ${ }^{2}$

Such models abstract from important complications of actual economies, even those that are financially quite sophisticated. Sizeable spreads exist, on average, between different interest rates; moreover, these spreads are not constant over time, especially in periods of financial stress. And "tighter" financial conditions, indicated by increases in the size of credit spreads, are commonly associated with lower levels of real expenditure and employment. This poses obvious questions for the practical application of much work in the theory of monetary policy. ${ }^{3}$ If a model is to be calibrated or estimated using time series data, which actual interest rate should be taken to correspond to "the interest rate" in the model? When the model is used to to give advice about how interest rates should respond to a particular type of shock, which actual interest rate (if any) should be made to respond in the way that "the interest rate" does in the model? How large an error is likely to be made by abstracting from credit frictions, with regard to the model's predictions for the variables that appear in it? Moreover, some questions clearly cannot even be addressed using models that abstract from credit frictions. Most notably, how should a central bank respond to a "financial shock" that increases the size of the spreads resulting from credit frictions?

This paper seeks to address these questions by presenting a simple extension of the basic

\footnotetext{
${ }^{1}$ See, for example, Clarida, Gali and Gertler (1999) or Woodford (2003), among many other references.

${ }^{2}$ The models of Smets and Wouters $(2003,2007)$ provide an especially influential example.

${ }^{3}$ The pre-crisis generation of DSGE models was criticized on this ground by Issing (2006) and Goodhart (2007), among others.
} 


\section{Credit Frictions and Optimal Monetary Policy}

"New Keynesian" model (as developed, for example, in Woodford, 2003) in which a credit friction is introduced, allowing for a time-varying wedge between the interest rate available to households on their savings and the interest rate at which it is possible to borrow. Financial intermediation matters for the allocation of resources due to the introduction of heterogeneity in the spending opportunities currently available to different households. While the model remains highly stylized, it has the advantage of nesting the basic New Keynesian model (extensively used in normative monetary policy analysis) as a special case, and of introducing only a small number of additional parameters, the consequences of which for conclusions about the monetary transmission mechanism and the character of optimal policy can be thoroughly explored. The approach taken also seeks to develop a tractable model, with as small a state space as is consistent with an allowance for financial frictions and heterogeneity, and hence only modestly greater complexity than the basic New Keynesian model.

Among the questions to be addressed are the following: If the parameters determining the degree of heterogeneity and the size of credit frictions are calibrated so as to match both the volume of bank credit and the spread between bank deposit and lending rates in the US economy, how much of a difference does this make (relative to the frictionless baseline) for the model's predictions for the response of the economy to various types of shocks, under a given monetary policy rule? How much of a difference does it make for the implied responses to real disturbances under an optimal monetary policy? How much of a difference does it make for the form of the quadratic stabilization objective that would correspond to the maximization of average expected utility? How much of a difference does it make for the form of the optimal target criterion for monetary stabilization policy? And how should policy optimally respond to a "financial shock"?

The model also provides perspective on "rules of thumb" for policy in times of financial turmoil proposed in the recent literature. For example, McCulley and Toloui (2008) and Taylor (2008) propose that the intercept term in a "Taylor rule" for monetary policy should be adjusted downward in proportion to observed increases in spreads. ${ }^{4}$ Here we use our simple model to ask whether it is correct to say that the "natural" or "neutral" rate of interest is lower when credit spreads increase (assuming unchanged fundamentals otherwise), and to the extent that it is, how the size of the change in the natural rate compares to the size of the change in credit spreads. We also ask whether it is approximately correct to say that a proper response to a "financial shock" is to conduct policy according to the same rule as

\footnotetext{
${ }^{4}$ Similarly, Meyer and Sack (2008) propose, as a possible account of recent U.S. Federal Reserve policy, a Taylor rule in which the intercept - representing the Fed's view of "the equilibrium real funds rate" - has been adjusted downward in response to credit market turmoil, and use the size of increases in spreads in early 2008 as a basis for a proposed magnitude of the appropriate adjustment.
} 


\section{Credit Frictions and Optimal Monetary Policy}

under other circumstances, except with the operating target for the policy rate adjusted by a factor that is proportional to the increase in credit spreads; and again, to the extent that such an approximation is used, we ask what proportion of adjustment should be made. Cúrdia and Woodford (2010) use the framework presented in this paper to evaluate the positive and normative consequences of adopting the proposals of McCulley and Toloui (2008) and Taylor (2008) and find that an adjustment for variations in credit spreads can improve upon the standard Taylor rule, but the optimal size (and direction) of adjustment depends on the source of the variation in credit spreads.

Other authors have argued that if financial disturbances are an important source of macroeconomic instability, a sound approach to monetary policy will have to pay attention to the balance sheets of financial intermediaries. It is sometimes suggested that policy should respond to variations in the growth rate of monetary or credit aggregates, rather than - as in the case of both the Taylor rule and conventional prescriptions for "flexible inflation targeting" — seeking to determine the appropriate level of short-term interest rates purely on the basis of observations of or projections for measures of inflation and real activity. Here we consider two possible interpretations of such proposals: as an argument for targeting monetary and/or credit aggregates, or at least adopting a target criterion that involves such variables along with others; or as an argument for their special value as indicators, so that such variables should receive substantial weight in the central bank's reaction function. We address the first issue by deriving an optimal target criterion for monetary policy, under certain simplifying assumptions, and seeing to what extent it involves either money or credit. We address the second issue, under assumptions that are arguably more realistic, by computing the optimal responses to shocks, and asking what kinds of indicator variables would allow a simple rule of thumb to bring about equilibrium responses of this kind.

Of course, we are not the first to investigate ways in which New Keynesian [NK] models can be extended to allow for financial frictions of one type or another. A number of authors have analyzed DSGE models with financial frictions of one type or another before the recent financial crisis. ${ }^{5}$ Many of the best-known contributions introduce obstacles to the willingness

\footnotetext{
${ }^{5}$ Probably the most influential early example was the model of Bernanke, Gertler and Gilchrist (1999). More recent contributions include Christiano, Motto and Rostagno (2003, 2010), Christiano et al. (2008), Gertler, Gilchrist and Natalucci (2007), and Iacoviello (2005). Faia and Monacelli (2007) consider how two different types of financial frictions affect welfare-based policy evaluation, though from a perspective somewhat different than the one taken here; they compare alternative simple rules, rather than computing optimal policy, as we do, and compute the welfare associated with a particular rule under a complete specification of shocks, rather than considering what a given simple rule implies about the equilibrium responses to shocks considered individually. Cúrdia (2008) considers optimal policy in the spirit of the
} 


\section{Credit Frictions and Optimal Monetary Policy}

of savers to lend to borrowers, but assume that borrowers directly borrow from the suppliers of savings. The recent financial crisis increased interest in models like ours that explicitly introduce intermediaries and allow for a spread between the interest received by savers and that paid by borrowers; early contributions include Hulsewig, Mayer and Wollmershauser (2009), Teranishi (2008), Sudo and Teranishi (2008), and Gerali, Neri and Signoretti (2008). ${ }^{6}$

More recently, Gertler and Kiyotaki (2010) also seek to provide a canonical model of credit market frictions and economic activity. Their work extends the "financial accelerator" framework to the case in which financial intermediaries themselves are exposed to the risk of default and thus face constraints on their ability to attract deposits (unlike Bernanke, Gertler and Gilchrist, 1999). Gertler and Kiyotaki use this model to discuss the consequences to real activity in the case of an imperfect interbank market, in which the banks cannot fully offset their risk exposure by pooling their loans. Their analysis is similar in spirit to ours but less focused on monetary policy. Related recent contributions include those of Meh and Moran (2010), Kiyotaki and Moore (2012), and Jermann and Quadrini (2012).

In general, these models are fairly complex, in the interest of microfoundation and/or quantitative realism, and the results obtained are mostly numerical. Our aim here is somewhat different. While the interest of such analyses is clear, especially to policy institutions seeking quantitative estimates of the effects of particular contemplated actions, we believe that it is also valuable to seek analytical insights of the kind that can only be obtained from analyses of simpler, more stylized models. Here we focus on the consequences for monetary policy analysis of two basic features of economies - heterogeneity of non-financial economic units, of a kind that gives the financial sector a non-trivial role in the allocation of resources; and costs of financial intermediation, that may be subject to random variation for reasons relating largely to developments in the financial sector - in the simplest possible setting, where we do not introduce other departures from the basic NK model.

Two contributions have aims more closely related to ours. Like us, Goodfriend and McCallum (2007) consider a fairly simple NK model, with new model elements limited to those necessary to allow for multiple interest rates with different average levels (including, like us, a distinction between bank lending rates and the policy rate). ${ }^{7}$ As in the present paper, a primary goal is to "investigate quantitatively how much a central bank can be misled by relying on a $[\mathrm{NK}]$ model without money and banking when managing its interbank-rate

present paper, but in a more complex model with features specific to emerging-market economies.

${ }^{6}$ See Gerali, Neri and Signoretti (2008, sec. 2) for a more detailed discussion of early work in this vein. See also Brunnermeier, Eisenbach and Sannikov (2012) for a very extensive survey of the macroeconomic implications of financial frictions of a variety of types.

${ }^{7}$ This paper provides a quantitative analysis of type of model first proposed by Goodfriend (2005). 


\section{Credit Frictions and Optimal Monetary Policy}

policy instrument." De Fiore and Tristani (2011) also propose a simple generalization of the basic NK model in order to introduce a distinction between loan rates and the policy; also like us, they consider how financial frictions affect the "natural rate of interest," and the role of such a concept in inflation determination in an economy with credit frictions.

The approaches taken by these authors nonetheless differ from ours in important respects. In particular, unlike us, Goodfriend and McCallum assume a representative-household model; as a consequence, financial intermediation matters for resource allocation in their model only because they assume that certain liabilities of banks (transactions balances) play a crucial role in facilitating transactions. We instead treat the fact that some (but not all) financial intermediaries finance (some) of their lending by providing accounts that are useful as means of payment as inessential to the primary function of financial intermediaries in the economy; and in our model, for the sake of simplicity, we assume that intermediaries finance themselves entirely by issuing deposits that supply no transactions services at all (so that in equilibrium, deposits must pay the same interest rate as government debt).

De Fiore and Tristani instead have two types of infinite-lived agents ("households" and "entrepreneurs," following Bernanke, Gertler and Gilchrist (1999), one of which saves while the other borrows; but in their model, unlike ours, agents belong permanently to one of these categories, and one is tempted to identify the division between them with the division between households and firms in the flow of funds accounts. This would be desirable, of course, if one thought that the model did adequately capture the nature of that division, as the model would yield additional testable predictions. But in fact, there are both saving units and borrowing units at a given point in time, both in the household sector and in the firm sector; and a saving unit at one point in time need not be a saving unit forever. We accordingly prefer not to introduce a distinction between households and firms (or "households" and "entrepreneurs") at all, and also not to assume that the identities of our savers and borrowers are permanent. ${ }^{8}$ In addition, De Fiore and Tristani, like Goodfriend and McCallum, assume that money must be used in (some) transactions, while we abstract from transactions frictions of this kind altogether in order to simplify our analysis. ${ }^{9}$

\footnotetext{
${ }^{8}$ In fact, De Fiore and Tristani list as an important "undesirable property" of their model the fact that in it, "households and entrepreneurs are radically different agents" (p. 23), as the predicted equilibrium behavior of "households" as a group does not look much like that of the aggregate household sector in actual economies.

${ }^{9}$ Goodfriend and McCallum justify the introduction of a cash-in-advance constraint in their model, stating (footnote 6) that "medium-of-exchange money is implicitly central to our analysis because it is by managing the aggregate quantity of reserves, which banks hold to facilitate transactions, that monetary policy affects interest rates." However, while in their model, banks hold reserves at the central bank only because of a reserve requirement proportional to transactions balances, this need not be true in actual economies, a number of which (such as Canada) have abolished reserve requirements. Moreover, it is possible in principle
} 


\section{Credit Frictions and Optimal Monetary Policy}

With the extensive use of unconventional policies by central banks across the world in response to the financial crisis, models such as the one we discuss have been called to evaluate those policies. That goes beyond the scope of this paper. Cúrdia and Woodford (2011) extend our framework to explicitly evaluate the use of the central bank's balance sheet to stabilize the economy, namely through "credit policy" - the purchase of illiquid assets by the central bank. Gertler and Karadi (2011) also analyze the use of "credit policy" through an extension of Gertler and Kiyotaki (2010).

We develop our model in section 2, and compare its structure with that of the basic NK model. We then consider, in section 3, the implications of the model for the equilibrium effects of a variety of types of exogenous disturbances, under a given assumption about monetary policy (such as that it conform to a "Taylor rule"), and ask to what extent the basic NK model gives incorrect answers to these questions. Section 4 considers optimal monetary policy in the context of our model, defined to mean a policy that maximizes the average expected utility of households, and again considers how different the conclusions are from those derived from the basic NK model. We also discuss the way in which the interest-rate reaction function required to implement a "flexible inflation target" should involve responses to variations in credit spreads. Section 5 summarizes our conclusions.

\section{A New Keynesian Model with Financial Frictions}

Here we sketch a model that introduces heterogeneity of the kind needed in order for financial intermediation to matter for resource allocation, and a limit on the degree of intermediation that occurs in equilibrium, with a minimum of structure. We stress the similarity between the model presented here and the basic New Keynesian model, and show how the standard model is recovered as a special case of the one developed here. This sets the stage for a quantitative investigation of the degree to which credit frictions of an empirically realistic magnitude change the predictions of the model.

for a central bank to control the interest rate in the interbank market for central-bank deposits without there being any demand for such reserves other than as a riskless store of value, as discussed in Woodford (2003, chap. 2). Hence there is no need to introduce a demand for money for transactions purposes in our model, in order for it to be possible to suppose that the central bank controls a short-term nominal interest rate, that will correspond to the rate at which banks can fund themselves. 


\section{Credit Frictions and Optimal Monetary Policy}

\subsection{Financial Frictions and Aggregate Demand}

We depart from the assumption of a representative household in the standard model, by supposing that households differ in their preferences. Each household $i$ seeks to maximize a discounted intertemporal objective of the form

$$
E_{0} \sum_{t=0}^{\infty} \beta^{t}\left[u^{\tau_{t}(i)}\left(c_{t}(i) ; \xi_{t}\right)-\int_{0}^{1} v^{\tau_{t}(i)}\left(h_{t}(j ; i) ; \xi_{t}\right) d j\right]
$$

where $\tau_{t}(i) \in\{b, s\}$ indicates the household's "type" in period $t$. Here $u^{b}(c ; \xi)$ and $u^{s}(c ; \xi)$ are two different period utility functions, each of which may also be shifted by the vector of aggregate taste shocks $\xi_{t}$, and $v^{b}(h ; \xi)$ and $v^{s}(h ; \xi)$ are correspondingly two different functions indicating the period disutility from working. As in the basic NK model, there is assumed to be a continuum of differentiated goods, each produced by a monopolistically competitive supplier; $c_{t}(i)$ is a Dixit-Stiglitz aggegator of the household's purchases of these differentiated goods. The household similarly supplies a continuum of different types of specialized labor, indexed by $j$, that are hired by firms in different sectors of the economy; the additively separable disutility of work $v^{\tau}(h ; \xi)$ is the same for each type of labor, though it depends on the household's type and the common taste shock. ${ }^{10}$

Each agent's type $\tau_{t}(i)$ evolves as an independent two-state Markov chain. Specifically, we assume that each period, with probability $1-\delta$ (for some $0 \leq \delta<1$ ) an event occurs which results in a new type for the household being drawn; otherwise it remains the same as in the previous period. When a new type is drawn, it is $b$ with probability $\pi_{b}$ and $s$ with probability $\pi_{s}$, where $0<\pi_{b}, \pi_{s}<1, \pi_{b}+\pi_{s}=1$. (Hence the population fractions of the two types are constant at all times, and equal to $\pi_{\tau}$ for each type $\tau$.) We assume moreover that

$$
u_{c}^{b}(c ; \xi)>u_{c}^{s}(c ; \xi)
$$

for all levels of expenditure $c$ in the range that occur in equilibrium. (See Figure 1, where these functions are graphed in the case of the calibration discussed below. ${ }^{11}$ ) Hence a change in a household's type changes its relative impatience to consume, ${ }^{12}$ given the aggregate

\footnotetext{
${ }^{10} \mathrm{As}$ in Woodford (2003), the vector $\xi_{t}$ may contain multiple elements, which may or may not be correlated with one another, so that the notation makes no assumption about correlation between disturbances to the utility of consumption and disturbances to the disutility of work.

${ }^{11}$ In the equilibrium discussed below, in the case of small enough disturbances, equilibrium consumption by the two types varies in neighborhoods of the two values $\bar{c}^{b}$ and $\bar{c}^{s}$ shown in the figure.

${ }^{12}$ As explained below, all households have the same expectations regarding their marginal utilities of expenditure far in the future. Hence if type $b$ households have a higher current marginal utility of expenditure, they also have a higher valuation of current (marginal) expenditure relative to future expenditure; thus we
} 


\section{Credit Frictions and Optimal Monetary Policy}

state $\xi_{t}$; in addition, the current impatience to consume of all households is changed by the aggregate disturbance $\xi_{t}$. We also assume that the marginal utility of additional expenditure diminishes at different rates for the two types, as is also illustrated in the figure; type $b$ households (who are borrowers in equilibrium) have a marginal utility that varies less with the current level of expenditure, resulting in a greater degree of intertemporal substitution of their expenditures in response to interest-rate changes. Finally, the two types are also assumed to differ in the marginal disutility of working a given number of hours; this difference is calibrated so that the two types choose to work the same number of hours in steady state, despite their differing marginal utilities of income. For simplicity, the elasticities of labor supply of the two types are not assumed to differ. ${ }^{13}$

The coexistence of the two types with differing impatience to consume creates a social function for financial intermediation. In the present model, as in the basic New Keynesian model, all output is consumed either by households or by the government; ${ }^{14}$ hence intermediation serves an allocative function only to the extent that there are reasons for the intertemporal marginal rates of substitution of households to differ in the absence of financial flows. The present model reduces to the standard representative-household model in the case that one assumes that $u^{b}(c ; \xi)=u^{s}(c ; \xi)$ and $v^{b}(h ; \xi)=v^{s}(h ; \xi)$.

We shall assume that most of the time, households are able to spend an amount different from their current income only by depositing funds with or borrowing from financial intermediaries, and that the same nominal interest rate is available to all savers, and that a (possibly) different nominal interest is available to all borrowers ${ }^{15}$ independent of the quantities that a given household chooses to save or to borrow. (For simplicity, we shall also assume in the present exposition that only one-period riskless nominal contracts with the intermediary are possible for either savers or borrowers.) The assumption that households

may say that they are more impatient to consume.

${ }^{13} \mathrm{As}$ is specified below in our discussion of our calibrated examples, we assume that the function $v^{b}(h ; \xi)$ differs from $v^{s}(h ; \xi)$ only by a multiplicative factor.

${ }^{14}$ The "consumption" variable is therefore to be interpreted as representing all of private expenditure, not only consumer expenditure. In reality, one of the most important reasons for some economic units to wish to borrow from others is that the former currently have access to profitable investment opportunities. Here we treat these opportunities as if they were opportunities to consume, in the sense that we suppose that the expenditure opportunities are valuable to the household, but we abstract from any consequences of current expenditure for future productivity. For discussion of the interpretation of "consumption" in the basic New Keynesian model, see Woodford (2003, pp. 242-243).

${ }^{15}$ Here "savers" and "borrowers" identify households according to whether they choose to save or borrow, and not by their "type". We assume that at any time, each household is able to save or borrow (or both at once, though it would never make sense to do so) at market interest rates. In the equilibrium described below, it turns out that a household $i$ borrows in period $t$ if and only if $\tau_{t}(i)=b$, but this is a consequence of optimization rather than an implication of a participation constraint. 


\section{Credit Frictions and Optimal Monetary Policy}

cannot engage in financial contracting other than through the intermediary sector introduces the financial friction with which the paper is concerned.

Our analysis is simplified (though this may not be immediately apparent!) by allowing for an additional form of financial contracting. We assume that households are able to sign state-contingent contracts with one another, through which they may insure one another against both aggregate risk and the idiosyncratic risk associated with a household's random draw of its type, but that households are only intermittently able to receive transfers from the insurance agency; between the infrequent occasions when a household has access to the insurance agency, it can only save or borrow through the financial intermediary sector mentioned in the previous paragraph. The assumption that households are eventually able to make transfers to one another in accordance with an insurance contract signed earlier means that despite our assumption of infinite-lived households, households' respective marginal utilities of income do not eventually become more and more dispersed as a result of their differing individual type histories. This facilitates aggregation (so that our model still has a low-dimensional state space), and allows us to obtain stationary equilibrium fluctuations and to use local methods to characterize them. At the same time, the fact that households may go for years without access to insurance transfers means that there remains a non-trivial financial friction for the banking sector to partially mitigate. ${ }^{16}$

To simplify the presentation, we assume here that the random dates on which a given household $i$ has access to the insurance agency are the same dates as those on which it draws a new type. Thus with probability $\delta$ each period, household $i$ is unable to receive any insurance transfer in the current period, and also retains the same type as in the previous period. With probability $1-\delta$, it learns at the beginning of the period that it has access to the insurance agency. In this case, it receives a net transfer $T_{t}(i)$ (under the terms of an insurance contract signed far in the past), that may depend on the history of aggregate disturbances through the current period, and also on $i$ 's type history through the previous period (but not on its type in period $t$, which is not yet known). After receiving the insurance transfer, household $i$ learns its new type (an independent drawing as explained above), and then makes its spending, saving and borrowing decisions as in any other period, but taking into account its new type and its post-transfer financial wealth.

Household $i$ 's beginning-of-period (post-transfer) nominal net financial wealth $A_{t}(i)$ is

\footnotetext{
${ }^{16}$ A similar device is commonly used in models of "liquidity," where access to frictionless financial intermediation is assumed to be possible only at discrete points in time, and that only a smaller class of exchanges are possible at interim dates. See, e.g., Lucas and Stokey (1987), Lucas (1990), Fuerst (1992), or Lagos and Wright (2005). Here we use a similar device to facilitate aggregation, but without doing so in a way that implies that the allocative consequences of financial frictions are extremely transitory.
} 


\section{Credit Frictions and Optimal Monetary Policy}

then given by

$$
A_{t}(i)=\left[B_{t-1}(i)\right]^{+}\left(1+i_{t-1}^{d}\right)+\left[B_{t-1}(i)\right]^{-}\left(1+i_{t-1}^{b}\right)+D_{t}^{i n t}+T_{t}(i),
$$

where $B_{t-1}(i)$ is the household's nominal net financial wealth at the end of period $t-1$;

$$
[B]^{+} \equiv \max (B, 0), \quad[B]^{-} \equiv \min (B, 0)
$$

$i_{t}^{d}$ is the (one-period, riskless nominal) interest rate that savers receive at the beginning of period $t+1$ on their savings deposited with intermediaries at the end of period $t$, while $i_{t}^{b}$ is the interest rate at which borrowers are correspondingly able to borrow from intermediaries in period $t$ for repayment at the beginning of period $t+1$; and $D_{t}^{\text {int }}$ represents the distributed profits of the financial intermediary sector. We assume that each household owns an equal share in the intermediary sector, ${ }^{17}$ and so receives an equal share of the distributed profits each period; profits are distributed each period as soon as the previous period's loans and depositors are repaid. Note that the final term $T_{t}(i)$ is necessarily equal to zero in any period in which household $i$ does not have access to the insurance agency. A household's end-of-period nominal net financial wealth $B_{t}(i)$ is correspondingly given by

$$
B_{t}(i)=A_{t}(i)-P_{t} c_{t}(i)+\int W_{t}(j) h_{t}(j ; i) d j+D_{t}+T_{t}^{g},
$$

where $P_{t}$ is the Dixit-Stiglitz price index in period $t$ (and hence the price of the composite consumption good); $W_{t}(j)$ is the wage of labor of type $j$ in period $t ; D_{t}$ represents the household's share in the distributed profits of goods-producing firms; and $T_{t}^{g}$ is the net nominal (lump-sum) government transfer received by each household in period $t$.

Any pair of identically situated households with access to the insurance agency will contract with one another so that if, in any state of the world at some future date, they again each have access to the insurance agency at the same time, a transfer will take place between them that equalizes their marginal utilities of income at that time (if each has behaved optimally in the intervening periods). Given that they have identical continuation problems at that time (before learning their new types), as functions of their post-transfer financial wealths, such an agreement will ensure that their post-transfer financial wealths are identical (again, if each has behaved optimally ${ }^{18}$ ). If we suppose that at some time in

\footnotetext{
${ }^{17}$ We do not allow trading in the shares of intermediaries, in order to simplify the discussion of households' saving and borrowing decisions. Euler equations of the form (2.10)-(2.11) below would still apply, however, even if households could also trade the shares of either banks or goods-producing firms.

${ }^{18} \mathrm{It}$ is important to note, however, that the contractual transfer $T_{t}(i)$ is only contingent on the history of
} 


\section{Credit Frictions and Optimal Monetary Policy}

the past, all households originally started with identical financial wealth and access to the insurance agency, then they should have contracted so that in equilibrium, in each period $t$, all those households with access to the insurance agency in period $t$ will obtain identical post-transfer financial wealth. If we suppose, finally, that transfers through the insurance agency must aggregate to zero each period (because the agency does not accumulate financial assets or borrow), then each household with access to the insurance agency at the beginning of period $t$ must have post-transfer wealth equal to

$$
A_{t}(i)=A_{t} \equiv \int A_{t}(h) d h
$$

The beginning-of-period wealth of households who do not have access to the insurance agency is instead given by (2.1), with $T_{t}(i)$ set equal to zero.

If we let $d_{t}$ denote aggregate real deposits with financial intermediaries at the end of period $t,{ }^{19}$ and $b_{t}$ aggregate real borrowing from intermediaries, then we must have

$$
P_{t} b_{t}=-\int_{\mathcal{B}_{t}} A_{t}(i) d i, \quad p_{t}\left[b_{t}^{g}+d_{t}\right]=\int_{\mathcal{S}_{t}} A_{t}(i) d i
$$

where $\mathcal{B}_{t}$ is the set of households $i$ for which $A_{t}(i)<0, \mathcal{S}_{t}$ is the (complementary) set of households for which $A_{t}(i) \geq 0$, and $b_{t}^{g}$ is real government debt at the end of period $t$. We assume that government debt is held directly by savers, rather than by financial intermediaries, so that the rate of return that must be paid on government debt is $i_{t}^{d}$, the rate paid on deposits at the intermediaries. (For simplicity, we assume here that all government debt also consists of riskless, one-period nominal bonds, so that deposits and government debt are perfect substitutes.) The aggregate beginning-of-period assets $A_{t}$ of households referred to in (2.3) are then given by

$$
A_{t}=\left[\left(d_{t-1}+b_{t-1}^{g}\right)\left(1+i_{t-1}^{d}\right)-b_{t-1}\left(1+i_{t-1}^{b}\right)\right] P_{t-1}+D_{t}^{i n t}
$$

integrating (2.1) over all households $i$.

The supply of government debt evolves in accordance with the government's flow budget

aggregate and individual-specific exogenous states, and not on the actual wealth that household $i$ has at the beginning of period $t$. Thus a spendthrift household is not insured an equal post-transfer wealth as other households, regardless of how much it has spent in past periods.

${ }^{19}$ Here "real" deposits and other real variables are measured in units of the Dixit-Stiglitz composite consumption good, the price of which is $P_{t}$. Deposit contracts, loan contracts, and government debt are actually all assumed to be non-state-contingent nominal contracts. We introduce real measures of the volume of financial intermediation because we assume that the intermediation technology specifies real costs of a given volume of real lending. 


\section{Credit Frictions and Optimal Monetary Policy}

constraint

$$
b_{t}^{g}=b_{t-1}^{g}\left(1+i_{t-1}^{d}\right) / \Pi_{t}+G_{t}+T_{t}^{g} / P_{t}-\tau_{t} Y_{t},
$$

where $\Pi_{t} \equiv P_{t} / P_{t-1}$ is the gross rate of inflation, $G_{t}$ is government purchases of the composite good, $\tau_{t}$ is a proportional tax on sales of goods, ${ }^{20}$ and $Y_{t}$ is the quantity of the composite good produced by firms. Given the sales tax, the distributed profits of firms are equal to

$$
D_{t}=\left(1-\tau_{t}\right) P_{t} Y_{t}-\int W_{t}(j) h_{t}(j) d j,
$$

where $h_{t}(j) \equiv \int h_{t}(j ; i) d i$ is aggregate labor hired of type $j$.

Households take as given the evolution of the two interest rates $i_{t}^{d}$ and $i_{t}^{b}$. In equilibrium, these are linked by a relation of the form

$$
1+i_{t}^{b}=\left(1+i_{t}^{d}\right)\left(1+\omega_{t}\right),
$$

where the credit spread $\omega_{t}$ is determined by a structural relation

$$
\omega_{t}=\omega_{t}\left(b_{t}\right)
$$

reflecting the behavior of competitive intermediaries, explained further in the next section. We allow the credit spread to vary endogenously with the volume of private credit (reflecting capacity limits in the intermediary sector), but we also allow it to vary for exogenous reasons; the latter are the "purely financial disturbances" which will receive particular attention in our analysis.

The other aspect of the intermediary sector that matters for aggregate demand determination in our model is the use of resources by the intermediary sector. As is discussed further in the next section, we assume that the origination of real loans in the quantity $b_{t}$ involves costs $\Xi_{t}\left(b_{t}\right)$. Using this general notation, market-clearing in the goods market requires that

$$
Y_{t}=\int c_{t}(i) d i+G_{t}+\Xi_{t}\left(b_{t}\right)
$$

each period.

We turn now to the implications of optimal household decisions with regard to consumption, saving, and borrowing. A household for which $A_{t}(i)>0$ (i.e., a saver) must satisfy a

\footnotetext{
${ }^{20}$ Note that there are two potential sources of government revenue in our model: variation in the size of the net lump-sum transfers $T_{t}^{g}$, and variation in the tax rate $\tau_{t}$. We introduce the process $\left\{\tau_{t}\right\}$ as an additional source of time-varying supply-side distortions.
} 


\section{Credit Frictions and Optimal Monetary Policy}

first-order condition

$$
\lambda_{t}(i)=\beta\left(1+i_{t}^{d}\right) E_{t}\left[\lambda_{t+1}(i) / \Pi_{t+1}\right]
$$

in period $t$, where $\lambda_{t}(i)=u_{c}\left(c_{t}(i) ; \xi_{t}\right)$ is the household's marginal utility of (real) income in period $t$, while a household for which $A_{t}(i)<0$ (a borrower) must instead satisfy

$$
\lambda_{t}(i)=\beta\left(1+i_{t}^{b}\right) E_{t}\left[\lambda_{t+1}(i) / \Pi_{t+1}\right]
$$

We need not discuss the corresponding first-order condition for a household that chooses $A_{t}(i)=0$ exactly (though this is certainly possible, given the kink in households' budget sets at this point), as no households are in this situation in the equilibria that we describe here.

Under conditions specified in the Appendix, one can show that there is an equilibrium in which every household of type $s$ has positive savings, while every household of type $b$ borrows, in every period. Hence the interest rate that is relevant for a given household's intertemporal tradeoff turns out to be perfectly correlated with the household's type (though this is not due to participation constraints). Moreover, because in equilibrium, households that access the insurance agency in a given period $t$ have the same marginal utility of income at the beginning of that period (before learning their new types), regardless of their past histories, it follows that in any period, all households of a given type have the same marginal utility of income, regardless of their histories. Hence we can write $\lambda_{t}^{\tau}$ for the marginal utility of (real) income of any household of type $\tau$ in period, where $\tau \in\{b, s\}$. Thus the equilibrium evolution of the marginal utility of income for all households can be described by just two stochastic processes, $\left\{\lambda_{t}^{b}, \lambda_{t}^{s}\right\}$.

These two processes satisfy the two Euler equations

$$
\begin{aligned}
& \lambda_{t}^{b}=\beta E_{t}\left[\frac{1+i_{t}^{b}}{\prod_{t+1}}\left\{\left[\delta+(1-\delta) \pi_{b}\right] \lambda_{t+1}^{b}+(1-\delta) \pi_{s} \lambda_{t+1}^{s}\right\}\right] \\
& \lambda_{t}^{s}=\beta E_{t}\left[\frac{1+i_{t}^{d}}{\Pi_{t+1}}\left\{(1-\delta) \pi_{b} \lambda_{t+1}^{b}+\left[\delta+(1-\delta) \pi_{s}\right] \lambda_{t+1}^{s}\right\}\right]
\end{aligned}
$$

in each period. (These follow from (2.10) - (2.11), taking into account the probability of switching type from one period to the next.) It follows that all households of a given type must also choose the same consumption in any period, and, assuming an interior choice for consumption by households of each type, these common consumption levels must satisfy

$$
\lambda_{t}^{b}=u^{b \prime}\left(c_{t}^{b}\right), \quad \lambda_{t}^{s}=u^{s \prime}\left(c_{t}^{s}\right),
$$




\section{Credit Frictions and Optimal Monetary Policy}

which relations can be inverted to yield demand functions

$$
c_{t}^{b}=c^{b}\left(\lambda_{t}^{b} ; \xi_{t}\right), \quad c_{t}^{s}=c^{s}\left(\lambda_{t}^{s} ; \xi_{t}\right) .
$$

Substituting these into (2.9) yields an equilibrium relation

$$
Y_{t}=\pi_{b} c^{b}\left(\lambda_{t}^{b} ; \xi_{t}\right)+\pi_{s} c^{s}\left(\lambda_{t}^{s} ; \xi_{t}\right)+G_{t}+\Xi_{t}\left(b_{t}\right)
$$

linking aggregate demand to the two marginal utilities of income and aggregate borrowing.

The three relations (2.12)-(2.15) generalize the "intertemporal IS relation" of the basic NK model, which can be expressed by an equation relating aggregate demand to the marginal utility of income of the representative household (analogous to (2.15)) and a single equation relating that marginal utility of income to the expected real rate of return implied by the model's single interest rate. The present model implies a similar relation between interest rates and the timing of expenditure as in the basic model. The main differences are (i) that now there are two different interest rates that each affect aggregate demand (though with the same sign), by affecting the expenditure decisions of different economic units, and (ii) that the resources used by the banking sector can also affect aggregate demand.

The presence of two interest rates relevant to aggregate demand determination does not mean there are two independent dimensions of monetary policy. Instead, the two rates must be linked by equations (2.7)-(2.8), determining the equilibrium credit spread. ${ }^{21}$ If we introduce no further frictions, the policy rate (which is a rate at which banks are willing to lend short-term funds to one another) corresponds to the deposit rate $i_{t}^{d .22}$ and we may suppose that the central bank directly controls this rate. ${ }^{23}$ In the case that banking uses no real resources (so that $\Xi_{t}\left(b_{t}\right)=0$ regardless of the volume of lending) and the credit spread $\omega_{t}$ is purely exogenous (i.e., independent of the volume of lending),${ }^{24}$ the system consisting of equations (2.7)-(2.8) and (2.12)-(2.15) gives a complete account of how real aggregate de-

\footnotetext{
${ }^{21}$ Of course, there is an additional, independent dimension of central-bank policy if the central bank has measures, independent of its control of the policy rate, that can influence the financial frictions represented by the functions $\Xi_{t}\left(b_{t}\right)$ or $\chi_{t}\left(b_{t}\right)$ introduced in the next section. We leave this issue for future work.

${ }^{22}$ We could introduce a distinction between the rate that banks pay depositors and the rate banks pay one another for overnight funds, by supposing, as Goodfriend and McCallum (2007) do, that banks must hold unremunerated reserves in proportion to their deposits, while required reserves are not increased by borrowing funds in the interbank market. We abstract from reserve requirements here.

${ }^{23}$ The issues involved in discussing how the central bank actually controls the policy rate are no different here than in the case of the standard NK model. See, for example, Woodford (2003, chap. 2).

${ }^{24}$ The model of the credit spread explained in the next section implies that this would be true in the case that no real resources are used in intermediation, and the default rate is independent of the scale of lending, so that the function $\chi_{t}(b)$ is linear.
} 


\section{Credit Frictions and Optimal Monetary Policy}

mand is determined by the expected path of the policy rate $i_{t}^{d}$ relative to expected inflation. ${ }^{25}$ This predicted relation between aggregate demand and the expected path of future interest rates is of essentially the same kind as in the basic NK model. Hence the introduction of financial frictions, of a kind capable of accounting for the observed average size and variability of spreads between deposit rates and lending rates, need not imply any substantial change in our understanding of the way in which central-bank control of short-term interest rates determines aggregate expenditure.

Indeed, the basic NK model remains nested as a special case of the model proposed here. In the case that both types of households have identical preferences $\left(u^{b}(c ; \xi)=u^{s}(c ; \xi)\right.$ and $\left.v^{b}(h ; \xi)=v^{s}(h: \xi)\right)$, and the wedge between the deposit rate and lending rate is always zero $\left(\omega_{t}(b)=0\right.$ at all times), our model is equivalent to the basic NK model. For in this case $i_{t}^{b}=i_{t}^{d}$ at all times, so that there is a single interest rate; equations (2.12)-(2.13) then imply that $\lambda_{t}^{b}=\lambda_{t}^{s}$ at all times; ${ }^{26}$ and since the functions $c^{b}(\lambda ; \xi)$ and $c^{s}(\lambda ; \xi)$ must be identical in this case, equilibrium must involve $c_{t}^{b}=c_{t}^{s}$ at all times. Equation (2.15) then reduces simply to the standard relation $Y_{t}=c_{t}+G_{t}$, while equations (2.12)-(2.13) imply that the common marginal utility of income of all households satisfies the usual Euler equation. Of course, this parameterization is not the one we regard as most empirically realistic (in particular, it would not account for observed spreads, as discussed below); but since the model has exactly the implications of the basic NK model for some parameter values, it becomes merely a quantitative issue to determine how different its predictions are for other parameter values. In fact, our results reported below suggest that for many questions, a reasonably parameterized version of this model yields predictions quite similar to those of an appropriately parameterized version of the basic NK model.

\subsection{The Intermediary Sector}

Here we further explain our assumptions about the behavior of intermediaries and the determinants of the equilibrium credit spread $\omega_{t}$. We allow for two sources of credit spreads - one of which follows from an assumption that intermediation requires real resources, and the other of which does not - which provide two distinct sources of "purely financial" disturbances in our model.

First, we assume that real resources $\Xi_{t}\left(b_{t}\right)$ are consumed in the process of originating loans

\footnotetext{
${ }^{25}$ To be more precise, the expected path of real interest rates determines only desired current expenditure relative to expected future expenditure, so that current aggregate demand also depends on expected long-run output, just as in the basic NK model (see, e.g., Woodford, 2003, chap. 4). The expected long-run level of output is determined by supply-side factors and by the long-run inflation target.

${ }^{26}$ See the Appendix for demonstration of this.
} 


\section{Credit Frictions and Optimal Monetary Policy}

of real quantity $b_{t}$, and that these resources must be produced and consumed in the period in which the loans are originated. ${ }^{27}$ The function $\Xi_{t}\left(b_{t}\right)$ is assumed to be non-decreasing and at least weakly convex. Strict convexity of $\Xi_{t}(b)$ would indicate increasing costs owing to a capacity constraint, e.g. the scarcity of available managerial time.

In addition, we suppose that in order to originate a quantity of loans $b_{t}$ that will be repaid (with interest) in the following period, it is necessary for an intermediary to also make a quantity $\chi_{t}\left(b_{t}\right)$ of loans that will be defaulted upon, where $\chi_{t}\left(b_{t}\right)$ is also a non-decreasing, weakly convex function. (This function may also be strictly convex, due to reduced accuracy of screening the larger the volume of lending relative to the bank's capacity.)

We assume that the bank cannot tell the legitimate borrowers and fraudulent borrowers apart, and so must treat them equally. However, the bank is able to predict the fraction of its loans that will turn out to be fraudulent, and so correctly predicts that loan repayments in period $t+1$ will total only $P_{t} b_{t}\left(1+i_{t}^{b}\right)$, even though the loans extended had value $P_{t}\left[b_{t}+\chi_{t}\left(b_{t}\right)\right]$. The fact that the same interest rate must be charged for both types of loans means that the existence of the default risk increases the cost of financing projects that are known to the borrower to be riskless; so a credit spread due to this kind of risk represents a barrier to efficient financial intermediation. The opportunity to make a fraudulent loan contract is assumed to arrive randomly to each household with equal probability, regardless of the household's current type. Thus each household has additional real income each period equal to $\chi_{t}\left(b_{t}\right)$, its earnings from fraud. Each household also chooses how many legitimate loan contracts to enter into, understanding that these loans must be repaid; only type $b$ households choose to enter legitimate loan contracts in equilibrium.

A bank collects deposits $d_{t}$ in the largest quantity that can be repaid from the proceeds of its loans (anticipating that a certain fraction of the loans will not be repaid). Any excess funds received from depositors that are not lent out or used to pay the resource costs of loan origination are distributed immediately to the bank's shareholders. Thus real distributions in period $t$ equal

$$
\Pi_{t}^{i n t}=d_{t}-b_{t}-\chi_{t}\left(b_{t}\right)-\Xi_{t}\left(b_{t}\right)
$$

\footnotetext{
${ }^{27}$ This real resource cost can be interpreted in either of two ways: either as a quantity of the composite produced good that is used in the activity of banking, or as a quantity of a distinct type of labor that happens to be a perfect substitute for consumption in the utility of households (so that the value of this labor requirement in units of the composite good is exogenously given). The interpretation that is chosen does not affect the validity of the equations given here, though it affects the interpretation of variables such as " $c$ " in terms of the quantities measured in national income accounts. See the Appendix for further discussion.
} 


\section{Credit Frictions and Optimal Monetary Policy}

Since deposits $d_{t}$ satisfy $\left(1+i_{t}^{d}\right) d_{t}=\left(1+i_{t}^{b}\right) b_{t}$, it follows that

$$
d_{t}=\left(1+\omega_{t}\right) b_{t},
$$

and real distributions by intermediaries equal

$$
\Pi_{t}^{i n t}=\omega_{t} b_{t}-\chi_{t}\left(b_{t}\right)-\Xi_{t}\left(b_{t}\right) .
$$

The income flow to households must also include households' earnings from fraud; hence we write $^{28}$

$$
D_{t}^{i n t}=P_{t}\left[\omega_{t} b_{t}-\Xi_{t}\left(b_{t}\right)\right] .
$$

We assume competition among intermediaries, both in the loan market and the deposit market. Thus a given intermediary takes both $i_{t}^{b}$ and $i_{t}^{d}$ as given, independent of its own scale of operations, and chooses $b_{t}$ to maximize $\prod_{t}^{i n t}$, leading to the first-order condition for optimal credit supply

$$
\omega_{t}-\chi_{t}^{\prime}\left(b_{t}\right)-\Xi_{t}^{\prime}\left(b_{t}\right)=0 .
$$

Hence in equilibrium, competition between banks leads to an equilibrium credit spread

$$
\omega_{t}=\omega_{t}\left(b_{t}\right) \equiv \chi_{t}^{\prime}\left(b_{t}\right)+\Xi_{t}^{\prime}\left(b_{t}\right) .
$$

Thus $\chi_{t}\left(b_{t}\right)$ plays the role of a "markup" factor that can cause credit spreads in excess of the marginal resource cost of loan origination.

Like Goodfriend and McCallum (2007), we simply posit a reduced-form intermediation technology, rather than seeking to provide a deeper behavioral justification for the spread between the interest rate available to savers and the one at which it is possible to borrow. This means that we are unable to consider possible effects of central-bank policy on the efficiency of the banking system. ${ }^{29}$ We can, however, consider the consequences for the

\footnotetext{
${ }^{28}$ The earnings from fraud are not actually collected from the intermediaries as a dividend to shareholders. But like those dividends, we assume that the earnings from fraud are a lump-sum distribution to each household, so there is no harm in combining the two sources of income in a single term. Both sources of income depend on activity in the intermediary sector, though for different reasons.

${ }^{29}$ Certainly we do not deny that at least at certain times, central banks do seek to affect the efficiency of the banking system; this is true most obviously in the case of actions taken in a central bank's capacity as "lender of last resort" during a financial crisis. However, we regard such actions as representing a largely independent dimension of policy from monetary policy, by which we mean control of the supply of centralbank balances to the payments system, and of the overnight interest rate paid for such balances in the interbank market. (Additional lending to intermediaries through the discount window or similar facilities need not imply any increase in the total supply of central-bank deposits, as the actions of the Federal Reserve between September 2007 and September 2008 illustrated.) Here we are concerned solely with the analysis
} 


\section{Credit Frictions and Optimal Monetary Policy}

effects of monetary policy, and for the optimal conduct of monetary policy, of the existence of, and of exogenous variation in, obstacles to fully efficient financial intermediation.

\subsection{The Dynamics of Private Indebtedness}

We allow in general for the possibility that aggregate real borrowing $b_{t}$ from financial intermediaries may affect aggregate demand, by affecting the real resources used by the banking sector (the term $\Xi_{t}\left(b_{t}\right)$ in $(2.15)$ ), by affecting the equilibrium spread between the deposit rate and the lending rate (equation (2.8)), or both. Hence in general a complete model of how interest-rate policy affects aggregate demand requires that we model the evolution of aggregate bank credit, or alternatively, of aggregate household indebtedness.

Integrating (2.1) over all those borrowers in period $t$ who did not have access to the insurance agency in the current period, one finds aggregate net beginning-of-period assets for these households of

$$
-\delta P_{t-1} b_{t-1}\left(1+i_{t-1}^{b}\right)+\delta \pi_{b} D_{t}^{i n t}
$$

Adding to this quantity the beginning-of-period assets ( $A_{t}$ per household) of those households who did receive insurance transfers at the beginning period $t$ and then learned that they are of type $b$, one obtains

$$
\int_{\mathcal{B}_{t}} A_{t}(i) d i=(1-\delta) \pi_{b} A_{t}-\delta P_{t-1} b_{t-1}\left(1+i_{t-1}^{b}\right)+\delta \pi_{b} D_{t}^{\text {int }}
$$

for the aggregate beginning-of-period net assets of borrowers in period $t$. Moreover, integrating (2.2) over all period $t$ borrowers, one obtains

$$
P_{t} b_{t}=-\int_{\mathcal{B}_{t}} A_{t}(i) d i+\pi_{b}\left[P_{t} c_{t}^{b}-w_{t}^{b}-D_{t}-T_{t}^{g}\right]
$$

where $w_{t}^{\tau}$ denotes the real wage income of each household of type $\tau .^{30}$ Finally, using (2.19) to substitute for aggregate beginning-of-period assets, and then using (2.4) to substitute for $A_{t}$, using (2.5) to substitute for $T_{t}^{g}$, using (2.6) to substitute for $D_{t}$, using (2.16) to substitute for $d_{t}$, using (2.7) to substitute for $i_{t}^{b}$, using (2.17) to substitute for $D_{t}^{\text {int }}$, and using (2.15) to

of the central bank's monetary policy decisions, taking as given the evolution of the intermediation frictions (that may reflect other dimensions of central-bank policy, as well as developments elsewhere in the economy).

${ }^{30}$ The fact that each household of a given type has the same labor supply and same wage income follows from the fact that in equilibrium each has the same marginal utility of income; see the further discussion of labor supply below. 


\section{Credit Frictions and Optimal Monetary Policy}

substitute for $Y_{t}$, one obtains

$$
\begin{aligned}
b_{t}= & \delta\left[b_{t-1}+\pi_{s} \omega_{t-1}\left(b_{t-1}\right) b_{t-1}+\pi_{b} \Xi_{t-1}\left(b_{t-1}\right)\right]\left(1+i_{t-1}^{d}\right) / \Pi_{t}-\pi_{b} \Xi_{t}\left(b_{t}\right) \\
& +\pi_{b}\left[\delta b_{t-1}^{g}\left(1+i_{t-1}^{d}\right) / \Pi_{t}-b_{t}^{g}\right]+\pi_{b} \pi_{s}\left[\left(c_{t}^{b}-c_{t}^{s}\right)-\left(w_{t}^{b}-w_{t}^{s}\right)\right],
\end{aligned}
$$

using the notation $\omega_{t}\left(b_{t}\right)$ for the function defined in (2.18).

The dynamics of private indebtedness thus depend, among other things, on the distribution of wage income across households of the two types. Any household $i$, if acting as a wage-taker in the market for labor of type $j$, will supply hours $h_{t}(j ; i)$ to the point at which

$$
v_{h}^{\tau_{t}(i)}\left(h_{t}(j ; i) ; \xi_{t}\right)=\lambda_{t}(i) W_{t}(j) / P_{t}
$$

Aggregation of the labor supply behavior of the two types is facilitated if, as in Benigno and Woodford (2005), we assume the isoelastic functional form

$$
v^{\tau}\left(h ; \xi_{t}\right) \equiv \frac{\psi_{\tau}}{1+\nu} h^{1+\nu} \bar{H}_{t}^{-\nu}
$$

where $\left\{\bar{H}_{t}\right\}$ is an exogenous labor-supply disturbance process; $\psi_{b}, \psi_{s}>0$ are (possibly) different multiplicative coefficients for the two types; and the coefficient $\nu \geq 0$ (inverse of the Frisch elasticity of labor supply) is assumed to be the same for both types. Solving (2.21) for the competitive labor supply of each type and aggregating, we obtain

$$
h_{t}(j)=\bar{H}_{t}\left[\frac{\tilde{\lambda}_{t}}{\psi} \frac{W_{t}(j)}{P_{t}}\right]^{1 / \nu}
$$

for the aggregate supply of labor of type $j$, where

$$
\begin{gathered}
\tilde{\lambda}_{t} \equiv \psi\left[\pi_{b}\left(\frac{\lambda_{t}^{b}}{\psi_{b}}\right)^{1 / \nu}+\pi_{s}\left(\frac{\lambda_{t}^{s}}{\psi_{s}}\right)^{1 / \nu}\right]^{\nu}, \\
\psi \equiv\left[\pi_{b} \psi_{b}^{-1 / \nu}+\pi_{s} \psi_{s}^{-1 / \nu}\right]^{-\nu} .
\end{gathered}
$$

Alternatively, we obtain

$$
W_{t}(j) / P_{t}=\psi \tilde{\lambda}_{t}^{-1}\left(h_{t}(j) / \bar{H}_{t}\right)^{\nu}
$$

for the real wage required if firms are to be able to hire a quantity $h_{t}(j)$ of labor of type j. More generally (and also as in Benigno and Woodford), we allow for the possibility of imperfect competition in the labor market, and suppose that the real wage required to hire 


\section{Credit Frictions and Optimal Monetary Policy}

a given aggregate quantity of labor of type $j$ is given by

$$
W_{t}(j) / P_{t}=\mu_{t}^{w} \psi \tilde{\lambda}_{t}^{-1}\left(h_{t}(j) / \bar{H}_{t}\right)^{\nu},
$$

where $\mu_{t}^{w} \geq 1$ is an exogenous, possibly time-varying markup factor, indicating variations in the market power of labor.

The above theory of labor supply implies that households of type $\tau$ supply fraction $\pi_{\tau}\left(\psi \lambda_{t}^{\tau} / \psi_{\tau} \tilde{\lambda}_{t}\right)^{1 / \nu}$ of all labor of each type $j$, and hence receive that same fraction of aggregate labor income. However, in order to solve for the dynamics of private indebtedness, we must also determine the distribution of national income between labor and capital (since profits are distributed equally to all households, unlike wage income). Once again, aggregation is facilitated by assuming (as in Benigno and Woodford) an isoelastic production function

$$
y_{t}(i)=Z_{t} h_{t}(i)^{1 / \phi}
$$

for each differentiated good $i$, where $\phi \geq 1$ and $Z_{t}$ is an exogenous, possibly time-varying productivity factor, common to all goods. Dixit-Stiglitz preferences (on the part of government as well as households ${ }^{31}$ ) imply that the demand for each differentiated good $i$ is given by

$$
y_{t}(i)=Y_{t}\left(\frac{p_{t}(i)}{P_{t}}\right)^{-\theta},
$$

where $Y_{t}$ is demand for the composite good, $p_{t}(i)$ is the price of good $i, P_{t}$ is the price of the composite good, and $\theta>1$ is the elasticity of substitution across differentiated goods.

Using these relations to solve for the labor demand $h_{t}(i)$ of each firm $i$ as a function of its price, integrating over the firms in each industry $j$ to find the total demand for labor of type $j,{ }^{32}$ solving for the implied real wage for labor of type $j$, and finally integrating over all types of labor, we obtain a total wage bill

$$
\int W_{t}(j) h_{t}(j) d j=\psi \mu_{t}^{w} \frac{P_{t}}{\tilde{\lambda}_{t} \bar{H}_{t}^{\nu}}\left(\frac{Y_{t}}{Z_{t}}\right)^{1+\omega_{y}} \Delta_{t},
$$

\footnotetext{
${ }^{31}$ Dixit-Stiglitz preferences imply that household utility depends only on the quantity purchased of a certain composite good, a CES aggregate of the purchases of the individual goods. We assume that government purchases quantity $G_{t}$ of this same composite good, and that the composition of government purchases minimize the cost of obtaining that quantity of the composite good. We similarly assume that the resources $\Xi_{t}$ used in intermediation are in units of the composite good, and that intermediaries obtain these resources at minimum cost.

${ }^{32}$ Note that we assume, as in Woodford (2003, chap. 3), that all firms in a given industry re-evaluate their prices at the same time, so that the price $p_{t}(i)$ is at each time the same for all firms $i$ in industry $j$.
} 


\section{Credit Frictions and Optimal Monetary Policy}

where $\omega_{y} \equiv \phi(1+\nu)-1 \geq 0$ and

$$
\Delta_{t} \equiv \int\left(\frac{p_{t}(i)}{P_{t}}\right)^{-\theta\left(1+\omega_{y}\right)} d i \geq 1
$$

is a measure of the dispersion of goods prices (taking its minimum possible value, 1 , if and only if all prices are identical). In the Calvo model of price adjustment, this dispersion measure evolves according to a law of motion

$$
\Delta_{t}=h\left(\Delta_{t-1}, \Pi_{t}\right)
$$

where the function $h(\Delta, \Pi)$ is defined in the Appendix.

Using (2.25) for the total wage bill and our conclusion regarding the distribution of the wage bill between households of the two types, we can solve for the wage income of households of each type. This solution, together with the consumption functions (2.14), allows us to write the last term in square brackets in (2.20) as a function of the form $B\left(Y_{t}, \lambda_{t}^{b}, \lambda_{t}^{s}, \Delta_{t} ; \tilde{\xi}_{t}\right)$, defined in the Appendix, where the vector $\tilde{\xi}_{t}$ of exogenous disturbances includes both the vector of preference shocks $\xi_{t}$ and the additional exogenous disturbances $A_{t}$ and $\mu_{t}^{w}$. The law of motion for private indebtedness $b_{t}$ can then be written

$$
\begin{aligned}
b_{t}= & \delta\left[b_{t-1}+\pi_{s} \omega_{t-1}\left(b_{t-1}\right) b_{t-1}+\pi_{b} \Xi_{t-1}\left(b_{t-1}\right)\right]\left(1+i_{t-1}^{d}\right) / \Pi_{t}-\pi_{b} \Xi_{t}\left(b_{t}\right) \\
& +\pi_{b}\left[\delta b_{t-1}^{g}\left(1+i_{t-1}^{d}\right) / \Pi_{t}-b_{t}^{g}\right]+\pi_{b} \pi_{s} B\left(Y_{t}, \lambda_{t}^{b}, \lambda_{t}^{s}, \Delta_{t} ; \tilde{\xi}_{t}\right) .
\end{aligned}
$$

This allows us to describe the evolution of real private debt as a function of its own past level, disturbances to the financial sector (possible exogenous shifts in the functions $\Xi_{t}(b)$ and $\left.\omega_{t}(b)\right)$, the evolution of the policy rate $i_{t}^{d}$ relative to inflation, the evolution of real government debt $b_{t}^{g}$, and the additional aggregate variables $\left(Y_{t}, \lambda_{t}^{b}, \lambda_{t}^{s}, \Delta_{t} ; \tilde{\xi}_{t}\right)$ that determine the relative expenditure and the relative incomes of the two types of households.

The system of equations consisting of (2.7)-(2.8), (2.12)-(2.15), and (2.26)-(2.27), together with a monetary-policy reaction function (such as a Taylor rule) to specify $i_{t}^{d}$ (as a function of variables such as inflation and real activity) and a fiscal rule to specify the real public debt $b_{t}^{g}$ (also possibly as a function of variables such as inflation and real activity), then comprise a complete "aggregate demand block" for our model, that suffices to determine the evolution of the variables $\left\{\lambda_{t}^{b}, \lambda_{t}^{s}, i_{t}^{b}, i_{t}^{d}, \Pi_{t}, \Delta_{t}, b_{t}\right\}$ given the evolution of $\left\{Y_{t}\right\}$ and the exogenous disturbances. It remains to specify the model's "aggregate supply block," that determines aggregate output $Y_{t}$ for any given evolution of inflation and other vari- 


\section{Credit Frictions and Optimal Monetary Policy}

ables, in order to have a complete general-equilibrium model of the monetary transmission mechanism.

A noteworthy property of this system is that when credit frictions matter, Ricardian equivalence generally does not obtain. Even if we consider alternative paths for $\left\{b_{t}^{g}\right\}$ while holding the path of distorting taxes $\left\{\tau_{t}\right\}$ constant, so that contemplated changes in the path of government debt are achieved entirely through changes in the size of lump-sum transfers, a change in the path of the public debt will generally require a different equilibrium evolution of real activity, interest rates and inflation, contrary to the implication of the basic NK model. ${ }^{33}$ For (2.27) implies that in the absence of any offsetting changes in the paths of other endogenous variables, a change in the path of $\left\{b_{t}^{g}\right\}$ will require an offsetting change in the path of $\left\{b_{t}\right\}$; essentially, government borrowing crowds out private borrowing, in the absence of changes in macroeconomic conditions that increase aggregate private saving. ${ }^{34}$ In the special case considered at the end of the previous section (when $\Xi_{t}=0$ and $\omega_{t}$ is independent of the level of private debt), this change in the path of private indebtedness still has no consequences for the determination of aggregate output, interest rates or inflation, or for the allocation of consumption or labor effort between the two types of households, and so Ricardian equivalence still obtains. However, except in this special case, a change in the path of private indebtedness has consequences for aggregate demand determination, by changing the spread between the lending rate and the deposit rate, by changing the resources used by intermediaries, or both.

\subsection{Aggregate Supply}

It remains to specify the aggregate supply side of the model. This part of the model remains the same as the basic NK model (as expounded, for example, in Benigno and Woodford, 2005), except that in modelling the cost of supplying a given quantity of output (and hence

\footnotetext{
${ }^{33} \mathrm{Crucial}$ to this result is our assumption here that the government can borrow from the private sector at a rate more favorable than that available to private non-financial borrowers: the rate $i_{t}^{d}$ at which intermediaries are able to obtain funding, rather than the rate $i_{t}^{b}$ paid by households that must borrow from intermediaries. In effect, when the public debt is increased the government is (among other things) borrowing at this lower rate on behalf of households that would like to borrow at this rate but are assumed to be unable to do so on their own account. This increases aggregate demand in somewhat the same way as a reduction in credit spreads does.

${ }^{34}$ In the simple case in which $\omega_{t}\left(b_{t}\right)=\Xi_{t}\left(b_{t}\right)=0,(2.27)$ determines the evolution of an aggregate credit variable, $b_{t}+\pi_{b} b_{t}^{g}$, in a way that is independent of the composition of that variable, so that a unit increase in $b_{t}^{g}$ requires a reduction of $b_{t}$ by precisely $\pi_{b}$ units, so that each borrowing household must borrow exactly one unit less for each unit that is borrowed (per capita) by the government. The relation between the evolution of the two variables is more complex when private indebtedness increases credit frictions while government debt does not, but the most important effect of government borrowing remains the "crowding out" of private borrowing.
} 


\section{Credit Frictions and Optimal Monetary Policy}

the incentives of price-setters) we must take account of the differing labor supply behavior of savers and borrowers. The model of labor supply explained above implies that the equilibrium real marginal cost of supplying output in any industry $j$ is equal to

$$
s_{t}(j)=\frac{\phi \psi \mu_{t}^{w}}{Z_{t}^{1+\omega_{y}} \bar{H}_{t}^{\nu}} \frac{y_{t}(j)^{\omega_{y}}}{\tilde{\lambda}_{t}} .
$$

This differs from the expression in Benigno and Woodford only in that the factor $\tilde{\lambda}_{t}$ in the denominator is no longer the marginal utility of income of a representative household, and so is no longer so simply related to aggregate real expenditure.

As in the basic NK model, we assume staggered price adjustment of the kind first hypothesized by Calvo (1983). This implies an inflation equation of the form

$$
\Pi_{t}=\Pi\left(z_{t}\right)
$$

where $z_{t}$ is a vector of two forward-looking variables, recursively defined by a pair of relations of the form

$$
z_{t}=G\left(Y_{t}, \lambda_{t}^{b}, \lambda_{t}^{s} ; \tilde{\xi}_{t}\right)+E_{t}\left[g\left(\Pi_{t+1}, z_{t+1}\right)\right],
$$

where the vector-valued functions $G$ and $g$ are defined in the Appendix. (Among the arguments of $G$, the vector of exogenous disturbances $\tilde{\xi}_{t}$ now includes the sales tax rate $\tau_{t}$, in addition to the disturbances already mentioned; this is relevant to firms' pricing decisions, as they balance after-tax marginal revenue with the marginal cost of supplying more

These relations are of exactly the same form as in the basic NK model, except that two distinct marginal utilities of income are here arguments of $G$; in the case that $\lambda_{t}^{b}=\lambda_{t}^{s}=\lambda_{t}$, the relations (2.29) reduce to exactly the ones in Benigno and Woodford (2005). The system (2.28)-(2.29) indicates the nature of the short-run aggregate-supply trade-off between inflation and real activity at a point in time, given expectations regarding the future evolution of inflation and of the variables $\left\{z_{t}\right\}$. (The precise nature of the implied aggregate-supply relation is discussed further in section 2.1.) Equations (2.7)-(2.8), (2.12)-(2.15), (2.26)-(2.27), and (2.28)-(2.29), together with equations specifying interest-rate policy and the evolution of the public debt, then comprise a complete system of equations for determination of the endogenous variables $\left\{Y_{t}, \lambda_{t}^{b}, \lambda_{t}^{s}, i_{t}^{b}, i_{t}^{d}, z_{t}, \Pi_{t}, \Delta_{t}, b_{t}\right\}$, given the evolution of the exogenous disturbances. 


\section{Credit Frictions and Optimal Monetary Policy}

\section{Credit Frictions and the Propagation of Disturbances}

We have shown that it is possible to generalize the basic NK model in a fairly straightforward way to incorporate credit frictions - more specifically, a spread between the deposit rate and the lending rate, that may be large or small, constant or variable, and exogenous or endogenous, depending how we choose to parameterize the model. This shows, at the very least, that the inherent structure of NK models does not in some way require one to ignore the existence of such frictions. But how much does this generalization change the implications of the resulting model?

In this section, we consider the effects on the economy of a variety of types of exogenous disturbances, including monetary policy shocks, under simple specifications of monetary policy. Our goal is not yet to compare monetary policies, but rather to compare the predictions of alternative model specifications; we wish to determine to what extent our conclusions about the consequences of a given monetary policy are affected by the introduction of heterogeneity and credit frictions.

\subsection{Log-Linearized Structural Relations}

To approach this question, we log-linearize the structural relations of our model around steady-state values of the various endogenous variables that represent a perfect foresight equilibrium in the case of no random variation in any of the exogenous disturbance processes, as discussed further in the Appendix. The solution to these linear equations under a correspondingly log-linear specification of monetary policy provides a linear approximation to the equilibrium responses to the various types of disturbances, in the case that these random variations are small enough. The linearity of the solution allows us to discuss the equilibrium responses to individual shocks independently of whether other exogenous variables change concurrently, and to discuss the size of the responses relative to the size of the shock without caring about the size of the shock that is considered.

We first summarize the structure of the log-linearized model, as these equations themselves provide considerable insight into the model's implications, and the similarities and differences between the predictions of the generalized model and those of the basic NK model (which is itself most familiar in its log-linearized form). We log-linearize the structural relations of the previous section around a steady state with zero inflation $(\bar{\Pi}=1)$. This means that in our analysis, we shall restrict attention to monetary policy rules that imply an inflation rate of zero, or one not far from zero, in the absence of stochastic disturbances. This simplification is familiar in the standard NK literature, and we follow it here in order 


\section{Credit Frictions and Optimal Monetary Policy}

to focus solely on the new complications introduced by heterogeneity and credit frictions. Moreover, we show in section 3 that according to the present model, optimal monetary policy has this property; hence the approximation adopted here suffices for the study of monetary policies that are close enough to optimal policy.

We turn first to the model's "aggregate demand" block. Log-linearization of equations (2.12)-(2.13) yields

$$
\begin{aligned}
& \hat{\lambda}_{t}^{b}=\hat{\imath}_{t}^{b}-E_{t} \pi_{t+1}+\chi_{b} E_{t} \hat{\lambda}_{t+1}^{b}+\left(1-\chi_{b}\right) E_{t} \hat{\lambda}_{t+1}^{s}, \\
& \hat{\lambda}_{t}^{s}=\hat{\imath}_{t}^{d}-E_{t} \pi_{t+1}+\chi_{s} E_{t} \hat{\lambda}_{t+1}^{s}+\left(1-\chi_{s}\right) E_{t} \hat{\lambda}_{t+1}^{b} .
\end{aligned}
$$

Here we introduce the notation $\hat{\lambda}_{t}^{\tau} \equiv \log \left(\lambda_{t}^{\tau} / \bar{\lambda}^{\tau}\right)$ for $\tau=b, s ; \hat{\imath}_{t}^{m} \equiv \log \left(1+i_{t}^{m} / 1+\bar{\imath}^{m}\right)$ for $m=b, d$; and $\pi_{t} \equiv \log \Pi_{t}$ for the rate of inflation. (In each case, a variable with a bar indicates the steady-state value of the corresponding variable, discussed in the Appendix.) The coefficients $0<\chi_{b}, \chi_{s}<1$ are defined by

$$
\chi_{\tau}=\beta\left(1+\bar{r}^{\tau}\right)\left[\delta+(1-\delta) \pi_{\tau}\right]
$$

for $\tau=b, s$.

Log-linearization of (2.7) similarly yields

$$
\hat{\imath}_{t}^{b}=\hat{\imath}_{t}^{d}+\hat{\omega}_{t}
$$

where $\hat{\omega}_{t} \equiv \log \left(1+\omega_{t} / 1+\bar{\omega}\right)$. We can similarly log-linearize (2.8) to obtain $\hat{\omega}_{t}$ as a linear function of $\hat{b}_{t}$, where we define $\hat{b}_{t} \equiv \log \left(b_{t} / \bar{b}\right)$.

Subtracting (3.2) from (3.1) then implies that

$$
\hat{\Omega}_{t}=\hat{\omega}_{t}+\hat{\delta} E_{t} \hat{\Omega}_{t+1}
$$

where $\hat{\Omega}_{t} \equiv \hat{\lambda}_{t}^{b}-\hat{\lambda}_{t}^{s}$ is a measure of the inefficiency of financial intermediation, insofar as the marginal utilities of the two (ex ante identical) types would be equated if financial markets were frictionless, and

$$
\hat{\delta} \equiv \chi_{b}+\chi_{s}-1<1
$$




\section{Credit Frictions and Optimal Monetary Policy}

Because $\hat{\delta}<1,{ }^{35}$ (3.4) can be "solved forward" to yield

$$
\hat{\Omega}_{t}=\sum_{j=0}^{\infty} \hat{\delta}^{j} E_{t} \hat{\omega}_{t+j}
$$

The system consisting of (3.1)-(3.2) can then equivalently be expressed by (3.4) and a single additional equation that relates the average marginal utility of income to interest rates and the expected marginal utilities of income in the following period. The most useful equation of the latter sort is the one that involves the particular average of $\hat{\lambda}_{t}^{b}$ and $\hat{\lambda}_{t}^{s}$ that determines aggregate demand $\hat{Y}_{t}$.

Log-linearization of (2.15) yields

$$
\hat{Y}_{t}=s_{c} \bar{c}_{t}-\bar{\sigma}\left(\hat{\lambda}_{t}+s_{\Omega} \hat{\Omega}_{t}\right)+\hat{G}_{t}+\hat{\Xi}_{t}
$$

where we define $\hat{Y}_{t} \equiv \log \left(Y_{t} / \bar{Y}\right), \hat{G}_{t} \equiv\left(G_{t}-\bar{G}\right) / \bar{Y}$, and $\hat{\Xi}_{t} \equiv\left(\Xi_{t}-\bar{\Xi}\right) / \bar{Y} ;{ }^{36} \hat{\lambda}_{t} \equiv \pi_{b} \hat{\lambda}_{t}^{b}+$ $\pi_{s} \hat{\lambda}_{t}^{s}$ is the average $(\log )$ marginal utility of income; and the exogenous disturbance $\bar{c}_{t}$ is a weighted average of changes in the impatience to consume of the two types of households. The coefficient $\bar{\sigma}$ measures the (appropriately weighted) average ${ }^{37}$ sensitivity of households' expenditure decisions to variations in the marginal utility of income (or equivalently, their interest-sensitivity);

$$
\bar{\sigma} \equiv \pi_{b} s_{b} \sigma_{b}+\pi_{s} s_{s} \sigma_{s}>0
$$

where $\sigma_{\tau}$ is each type's intertemporal elasticity of substitution and $s_{\tau} \equiv \bar{c}^{\tau} / \bar{Y}$ is the steadystate share of each type's purchases in aggregate national expenditure. The coefficient

$$
s_{\Omega} \equiv \pi_{b} \pi_{s} \frac{s_{b} \sigma_{b}-s_{s} \sigma_{s}}{\bar{\sigma}}
$$

indicates the degree to which aggregate demand is affected by heterogeneity in the marginal utility of income, given the average marginal utility of income; this depends on the degree to which the expenditure decisions of borrowers are more interest-elastic than those of savers.

\footnotetext{
${ }^{35}$ See the Appendix for proof.

${ }^{36}$ We do not define these last two hat variables as log deviations from the steady-state value, so that we can discuss calibrations in which $\bar{G}$ or $\bar{\Xi}$ may equal zero, though we still consider small non-zero values of the corresponding disturbances.

${ }^{37}$ Definition (3.6) implies that $\bar{\sigma}$ is only actually an average of $\sigma_{b}$ and $\sigma_{s}$ in the case that $\bar{G}=\bar{\Xi}=0$. More generally, $\bar{\sigma}$ is $s_{c}$ times the average household intertemporal elasticity of substitution, where $s_{c} \equiv \pi_{b} s_{b}+\pi_{s} s_{s}$ is the share of private expenditure in aggregate expenditure. In terms of the notation used in Woodford (2003, pp. 80, 243), $\bar{\sigma}$ is the coefficient analogous to $\sigma$ in the representative-household model, while the coefficients $\sigma_{\tau}$ are analogous to the intertemporal elasticity of substitution $\sigma_{C}$.
} 


\section{Credit Frictions and Optimal Monetary Policy}

(More precisely, what matters is how much the aggregate reduction in borrowing by borrowers, per percentage point increase in the interest rate that they face, exceeds the aggregate increase in saving by savers in response to an interest-rate increase of the same size.)

Solving (3.5) for $\hat{\lambda}_{t}$ as a function of aggregate expenditure, and substituting for $\hat{\lambda}_{t}$ in the corresponding weighted average of (3.1) and (3.2), we obtain an "intertemporal IS relation"

$$
\begin{gathered}
\hat{Y}_{t}=-\bar{\sigma}\left(\hat{\imath}_{t}^{a v g}-E_{t} \pi_{t+1}\right)+E_{t} \hat{Y}_{t+1}-E_{t} \Delta g_{t+1}-E_{t} \Delta \hat{\Xi}_{t+1} \\
-\bar{\sigma} s_{\Omega} \hat{\Omega}_{t}+\bar{\sigma}\left(s_{\Omega}+\psi_{\Omega}\right) E_{t} \hat{\Omega}_{t+1}
\end{gathered}
$$

where

$$
\hat{\imath}_{t}^{a v g} \equiv \pi_{b} \hat{\imath}_{t}^{b}+\pi_{s} \hat{\imath}_{t}^{d}
$$

is the average of the interest rates that are relevant (at the margin) for all of the savers and borrowers in the economy, $g_{t} \equiv \hat{G}_{t}+s_{c} \bar{c}_{t}$ is a composite "autonomous expenditure" disturbance as in Woodford (2003, pp. 80, 249),

$$
\psi_{\Omega} \equiv \pi_{b}\left(1-\chi_{b}\right)-\pi_{s}\left(1-\chi_{s}\right)
$$

and $\Delta$ indicates a first difference.

Note that the first four terms on the right-hand side of (3.8) are exactly as in the basic NK model (with appropriate generalizations of the definitions of variables and coefficients to allow for heterogeneity), while the final two terms exist only in the case of credit frictions. An important difference between this relation and the standard "IS relation" is that the interest rate appearing in it is no longer the policy rate. Instead, (3.3) together with (3.9) imply that the policy rate $\hat{\imath}_{t}^{d}$ and the rate that is relevant for the IS relation are linked by the equilibrium relation

$$
\hat{\imath}_{t}^{a v g}=\hat{\imath}_{t}^{d}+\pi_{b} \hat{\omega}_{t}
$$

indicating that the spread between them increases when credit spreads increase.

The complete aggregate demand block developed in section 1.1 can then be summarized (in our log-linear approximation) by the intertemporal IS relation (3.8), together with (3.10) connecting the average interest rate with the policy rate, the log-linear version of (2.8) for the determination of the credit spread, and (3.4) for the determination of the marginal-utility gap $\hat{\Omega}_{t}$. In the case that either $\hat{\omega}_{t}$ or $\hat{\Xi}_{t}$ depends (to first order) on the evolution of $\hat{b}_{t}$, completion of the system of equilibrium relations requires a law of motion for aggregate private indebtedness. Log-linearizing (2.27), and using the same method as above to substitute for $\hat{\lambda}_{t}^{b}$ and $\hat{\lambda}_{t}^{s}$, we obtain an equation for $\hat{b}_{t}$ as a linear function of $\hat{b}_{t-1}, \hat{\imath}_{t-1}^{d}-\pi_{t}, \hat{Y}_{t}, \hat{\Omega}_{t}, \hat{b}_{t}^{g}, \hat{b}_{t-1}^{g}$, 


\section{Credit Frictions and Optimal Monetary Policy}

and the exogenous disturbances. (See the Appendix for details.)

Log-linearization of the aggregate-supply block consisting of equations (2.28)-(2.29) yields the log-linear aggregate-supply relation

$$
\pi_{t}=\xi\left[\omega_{y} \hat{Y}_{t}-\hat{\tilde{\lambda}}_{t}-\nu \bar{h}_{t}-\left(1+\omega_{y}\right) \hat{Z}_{t}+\hat{\mu}_{t}^{w}+\hat{\tau}_{t}\right]+\beta E_{t} \pi_{t+1}
$$

through calculations explained in the Appendix, where we define $\hat{\tilde{\lambda}}_{t} \equiv \log \left(\tilde{\lambda}_{t} / \overline{\tilde{\lambda}}\right), \bar{h}_{t} \equiv$ $\log \left(\bar{H}_{t} / \bar{H}\right), \hat{Z}_{t} \equiv \log \left(Z_{t} / \bar{Z}\right), \hat{\mu}_{t}^{w} \equiv \log \left(\mu_{t}^{w} / \bar{\mu}^{w}\right), \hat{\tau}_{t} \equiv-\log \left(1-\tau_{t} / 1-\bar{\tau}\right)$, and

$$
\xi \equiv \frac{1-\alpha}{\alpha} \frac{1-\alpha \beta}{1+\omega_{y} \theta}>0
$$

(where $0<\alpha<1$ is the fraction of prices that remain unchanged from one period to the next) determines the sensitivity of the inflation rate to variation in average marginal costs. Note that (3.11) takes exactly the same form as in the basic NK model, except that here $\hat{\tilde{\lambda}}_{t}$ replaces the marginal utility of income of the representative household.

It is also important to note that the "average" marginal utility of income $\hat{\tilde{\lambda}}_{t}$ that enters the aggregate-supply relation is in general not exactly the same as the one that enters the aggregate-demand relation (3.5). The two are related through the identity

$$
\hat{\tilde{\lambda}}_{t}=\hat{\lambda}_{t}+\left(\gamma_{b}-\pi_{b}\right) \hat{\Omega}_{t},
$$

where

$$
\gamma_{b} \equiv \pi_{b}\left(\frac{\psi \bar{\lambda}^{b}}{\psi_{b}}\right)^{1 / \nu} .
$$

Using this to substitute for $\hat{\tilde{\lambda}}_{t}$ in (3.11), and then using (3.5) to substitute for $\hat{\lambda}_{t}$ as in the derivation of (3.8), we obtain an aggregate-supply relation

$$
\pi_{t}=\kappa\left(\hat{Y}_{t}-\hat{Y}_{t}^{n}\right)+u_{t}+\xi\left(s_{\Omega}+\pi_{b}-\gamma_{b}\right) \hat{\Omega}_{t}-\xi \bar{\sigma}^{-1} \hat{\Xi}_{t}+\beta E_{t} \pi_{t+1}
$$

with a slope

$$
\kappa \equiv \xi\left(\omega_{y}+\bar{\sigma}^{-1}\right)>0 .
$$

Here the composite exogenous disturbance term $\hat{Y}_{t}^{n}$ (the "natural rate of output") is a linear combination of the disturbances $\bar{c}_{t}, \hat{G}_{t}, \bar{h}_{t}$, and $\hat{Z}_{t}$ (sources of variation in the flexible-price equilibrium level of output that, in the absence of steady-state distortions or financial frictions, correspond to variations in the efficient level of output, as discussed further in section 


\section{Credit Frictions and Optimal Monetary Policy}

3); the additional exogenous term $u_{t}$ (the "cost-push shock") is instead a linear combination of the disturbances $\hat{\mu}_{t}^{w}$ and $\hat{\tau}_{t}$ (sources of variation in the flexible-price equilibrium level of output that do not correspond to any change in the efficient level of output). This is identical to the "new Keynesian Phillips curve" of the basic NK model, with the exception of the terms proportional to $\hat{\Omega}_{t}$ and $\hat{\Xi}_{t}$, indicating "cost-push" effects of the credit frictions in our extended model.

Equations (3.8) and (3.12) are thus direct analogs of two of the equations of the canonical "three-equation model"; the third equation (a central-bank reaction function, such as a Taylor rule, for the policy rate as a function of inflation and output) is unchanged by the existence of credit frictions. In the case that both $\left\{\hat{\omega}_{t}\right\}$ and $\left\{\hat{\Xi}_{t}\right\}$ can be treated as exogenous processes (so that $\left\{\hat{\Omega}_{t}\right\}$ is exogenous as well), these same three equations again provide a complete system for the determination of equilibrium inflation, output and interest rates, except that one must adjoin equation (3.10) to connect the interest rate that appears in the IS relation to the policy rate. If one substitutes the central-bank reaction function for $\hat{\imath}_{t}^{d}$ in (3.10), in order to derive the implied response of the average interest rate - or if one supposes that the central bank uses the average interest rate as its operating target, a policy proposal that we analyze further in section 3 - then one again obtains a three-equation model directly analogous to the basic NK model. For example, if the central bank follows a Taylor rule of the form

$$
\hat{\imath}_{t}^{d}=\phi_{\pi} \pi_{t}+\phi_{y} \hat{Y}_{t}+\epsilon_{t}^{m},
$$

then the complete model would consist of (3.8), (3.12), and

$$
\hat{\imath}_{t}^{a v g}=\phi_{\pi} \pi_{t}+\phi_{y} \hat{Y}_{t}+\pi_{b} \hat{\omega}_{t}+\epsilon_{t}^{m} .
$$

The only differences relative to the basic NK model are that the interest rate appearing in this three-equation system is not the only relevant interest rate and may not correspond to the policy rate; that the numerical values of the coefficients $\bar{\sigma}$ and $\kappa$ must take appropriate account of the different degrees of interest-sensitivity of expenditure of different units in the economy; and that time-varying financial frictions are an additional source of disturbance terms in all three equations.

It follows that at least in this case, inflation and output determination can be understood in exactly the same way as in the basic NK model, regardless of the average size of credit frictions, or their degree of variability. For example, in the case that the monetary policy equation involves no response to lagged variables (or to any endogenous variables other than inflation, output, or forecasts of these), and the policy implies a determinate rational- 


\section{Credit Frictions and Optimal Monetary Policy}

expectations equilibrium, that equilibrium will make inflation, output and interest rates all a function solely of the economy's current state - to be precise, the current values of $\hat{Y}_{t}^{n}, g_{t}, u_{t}, \hat{\omega}_{t}, \hat{\Xi}_{t}$, and the monetary policy disturbance, and current information about the expected future evolution of these variables. (As has often been remarked of the basic NK model, the model is thus "purely forward-looking," and cannot explain inflation persistence other than as a consequence of persistence in the exogenous disturbances just mentioned.)

In the simple case of a monetary policy described by (3.13), the conditions for determinacy of equilibrium remain exactly the same as in the basic NK model; in the case that $\phi_{\pi}, \phi_{y} \geq$ 0 , these amount simply to the requirement that the policy rule conform to the "Taylor Principle" (Woodford, 2003, p. 254), i.e., that the response coefficients satisfy

$$
\phi_{\pi}+\frac{1-\beta}{\kappa} \phi_{y}>1
$$

If this condition is satisfied, one can solve for inflation as a function of current and expected future values of the disturbance processes in exactly the same way as is explained in Woodford (2003, chap. 4, secs. 2.2, 2.4), and the coefficients on current and expected future values of the disturbances $\bar{c}_{t}, \hat{G}_{t}, \bar{h}_{t}, a_{t}, \hat{\mu}_{t}^{w}, \hat{\tau}^{t}$, or $\epsilon_{t}^{m}$ at all horizons are identical to the predictions of the basic NK model, if the latter model is calibrated to have the same values for the coefficients $\beta, \xi, \bar{\sigma}$, and $\omega_{y}{ }^{38}$ The only difference in the solution is that shocks to the current or expected future values of the financial disturbances $\hat{\omega}_{t}$ and $\hat{\Xi}_{t}$ will affect equilibrium inflation as well.

Moreover, not only does the model predict the same numerical responses to non-financial disturbances, under given monetary-policy coefficients $\left(\phi_{\pi}, \phi_{y}\right)$ - so that one's conclusions about the desirability of a particular choice of those coefficients, from the point of view of how they effect the economy's response to non-financial disturbances, will be unchanged - but the predicted responses to financial disturbances do not really involve any new considerations (beyond the mere fact that such disturbances can occur and ought to be measured in order to properly conduct policy). The effects of variations in the processes $\left\{\hat{\omega}_{t}, \hat{\Xi}_{t}\right\}$ on inflation and output are predicted to be the same as the effects that other kinds of disturbances have, when they shift the three equations to a similar extent and with a similar expected degree of persistence. Thus the effects of financial shocks on inflation can be decomposed into three

\footnotetext{
${ }^{38}$ Of course, the numerical values of some of these coefficients may be different, owing to the existence of credit frictions, than they would be in an economy without such frictions, owing, for example, to an effect of steady-state distortions resulting from credit spreads on the steady-state level of output, and hence the point at which various elasticities are evaluated. This would not, however, affect the accuracy of predictions made by the NK model if it were correctly parameterized to match the elasticities observed in an actual economy.
} 


\section{Credit Frictions and Optimal Monetary Policy}

types of effects that are already present in the basic NK model: the effects of a disturbance to the "natural rate of interest" (a shift in the real average interest rate consistent with a zero output gap), the effects of a "cost-push shock" (a shift in the size of output gap required for price stability), and the effects of a "monetary policy shock" (a change in the average interest rate relative to what would ordinarily follow from the current inflation rate and output gap, in this case due to a change in the credit spread rather than a change in the policy rate). Financial disturbances typically have effects of all three types; but their consequences can be easily understood if the consequences of those three general types of disturbances are already understood.

The case in which $\left\{\hat{\omega}_{t}, \hat{\Xi}_{t}\right\}$ are both completely exogenous processes is, of course, a fairly special one. If one or both of them depends on the volume of bank lending, as allowed for in our exposition above, a larger system of equations, including the law of motion for private debt, is needed in order to predict the evolution of inflation, output and interest rates. We do not seek to present analytical results for this more complex case, but instead offer some illustrative numerical results.

\subsection{Model Calibration}

The numerical values for parameters that are used in our calculations are explained in the Appendix. Many of the model's parameters are also parameters of the basic NK model, and in the case of these parameters we assume similar numerical values as in the numerical analysis of the basic NK model in Woodford (2003). The new parameters that are also needed for the present model are those relating to heterogeneity or to the specification of the credit frictions. The parameters relating to heterogeneity are the fraction $\pi_{b}$ of households that are borrowers, the degree of persistence $\delta$ of a household's "type", the steady-state expenditure level of borrowers relative to savers, $s_{b} / s_{s}$, and the interest-elasticity of expenditure of borrowers relative to that of savers, $\sigma_{b} / \sigma_{s} \cdot{ }^{39}$

In the calculations reported here, we assume that $\pi_{b}=\pi_{s}=0.5$, so that there are an equal number of borrowers and savers. We assume that $\delta=0.975$, so that the expected time until a household has access to the insurance agency (and its type is drawn again) is 10 years. This means that the expected path of the spread between lending and deposit rates for 10 years or so into the future affects current spending decisions, but that expectations

\footnotetext{
${ }^{39}$ Another new parameter as a consequence of heterogeneity is the steady-state level of government debt relative to GDP, $\bar{b}^{g} / \bar{Y}$. This parameter need not be specified in the representative-household basic NK model, since changes in it simply imply a different steady-state level of net transfers, and the size of these does not affect any of the equilibrium relations. In the model with heterogeneity, it does matter, because of the failure of Ricardian equivalence noted above. But in our baseline calculations, we assume that $\bar{b}^{g}=0$.
} 


\section{Credit Frictions and Optimal Monetary Policy}

regarding the spread several decades in the future are nearly irrelevant.

We calibrate the degree of heterogeneity in the steady-state expenditure shares of the two types so that the implied steady-state debt $\bar{b}$ is equal to 80 percent of annual steady-state output. ${ }^{40}$ This value matches the median ratio of private (non-financial, non-government, non-mortgage) debt to GDP over the period 1986-2008. ${ }^{41}$ This requires a ratio $s_{b} / s_{s}=1.27$. We calibrate the value of $\sigma_{b} / \sigma_{s}$ to equal 5 . This is an arbitrary choice, though the fact that borrowers are assumed to have a greater willingness to substitute intertemporally is important, as this results in the prediction that an exogenous tightening of monetary policy (a positive value of the residual $\epsilon_{t}^{m}$ in (3.13)) results in a reduction in the equilibrium volume of credit $b_{t}$ (see Figures 2 and 5 below). This is consistent with VAR evidence on the effects of an identified monetary policy shock on household borrowing. ${ }^{42}$

It is also necessary to specify the steady-state values of the functions $\omega(b)$ and $\Xi(b)$ that describe the financial frictions, in addition to making clear what kinds of random perturbations of these functions we wish to consider when analyzing the effects of "financial shocks." We here mainly present results for two cases. In each case, we assume that there is no steady-state default risk $(\bar{\chi}(b)=0)$, so that the steady-state credit spread is due entirely to the marginal resource cost of intermediation. But we do allow for exogenous shocks to the default rate (which then becomes slightly positive); specifically, we assume that

$$
\chi_{t}(b)=\tilde{\chi}_{t} b,
$$

where $\left\{\tilde{\chi}_{t}\right\}$ is an exogenous disturbance process taking non-negative values. The "financial shock" in Figure 15 below is an exogenous increase in $\tilde{\chi}_{t} \cdot{ }^{43}$

We consider two cases that differ in the specification of the (time-invariant) intermediation technology $\Xi(b)$. In the case of a linear intermediation technology (not shown), we suppose that $\Xi(b)=\bar{\omega} b$, while in the case of a convex intermediation technology (shown in Figure 15), we assume that

$$
\Xi(b)=\tilde{\Xi} b^{\eta}
$$

\footnotetext{
${ }^{40}$ In our quarterly model, this means that $\bar{b} / \bar{Y}=3.2$.

${ }^{41}$ We exclude mortgage debt when calibrating the degree of heterogeneity of preferences in our model, since mortgage debt is incurred in order to acquire an asset, rather than to consume current produced goods in excess of current income.

${ }^{42}$ See, for example, Den Haan, Sumner and Yamashiro (2010).

${ }^{43}$ In treating the "financial shock" as involving an increase in markups but no increase in the real resources used in banking, we follow Gerali, Neri and Signoretti (2008). These authors cite the Eurosystem's quarterly Bank Lending Survey as showing that since October 2007, banks in the euro area had "strongly increased the margins charged on average and riskier loans" (p. 24).
} 


\section{Credit Frictions and Optimal Monetary Policy}

for some $\eta>1 .{ }^{44}$ In both cases, in our numerical analyses we assume a steady-state credit spread $\bar{\omega}$ equal to 2.0 percentage points per annum, ${ }^{45}$ following Mehra, Piguillem and Prescott (2008). ${ }^{46}$ (Combined with our assumption that "types" persist for 10 years on average, this implies a steady-state "marginal utility gap" $\bar{\Omega} \equiv \bar{\lambda}^{b} / \bar{\lambda}^{s}=1.22$, so that there would be a non-trivial welfare gain from transferring further resources from savers to borrowers.) In the case of the convex technology, we set $\eta$ so that a one-percent increase in the volume of credit increases the credit spread by one percentage point (per annum). ${ }^{47}$ The assumption that $\eta>1$ allows our model to match the prediction of VAR estimates that an unexpected tightening of monetary policy is associated with a slight reduction in credit spreads (see, e.g., Lown and Morgan, 2002). We have chosen a rather extreme value for this elasticity in our calibration of the convex-technology case, in order to make more visible the difference that a convex technology makes for our results. (In the case of a smaller value of $\eta$, the results for the convex technology are closer to those for the linear technology, and in fact are in many respects similar to those for an economy with no financial frictions at all.)

As a first exercise, we consider the implied equilibrium responses of the model's endogenous variables to the various kinds of exogenous disturbances, under the assumption that monetary policy is described by a Taylor rule of the form (3.13). The coefficients of the monetary policy rule are assigned the values $\phi_{\pi}=2$ and $\phi_{y}=0.25$ as in Woodford (2003, chap. 4 ), allowing comparison between our quantitative results here and those presented there for a calibrated representative-household model. Among other disturbances, we consider the effects of random disturbances to the error term $\epsilon_{t}^{m}$ in the monetary policy rule. Later, we consider the predicted dynamics under optimal monetary policy.

\footnotetext{
${ }^{44}$ One interpretation of this function is in terms of a monitoring technology of the kind assumed in Goodfriend and McCallum (2007). Suppose that a bank produces monitoring according to a Cobb-Douglas production function, $k^{1-\eta^{-1}} \Xi_{t}^{\eta^{-1}}$, where $k$ is a fixed factor ("bank capital"), and must produce a unit of monitoring for each unit of loans that it manages. Then the produced goods $\Xi_{t}$ required as inputs to the monitoring technology in order to manage a quantity $b$ of loans will be given by a function of the form (3.15), where $\tilde{\Xi}=k^{1-\eta}$. A sudden impairment of bank capital, treated as an exogenous disturbance, can then be represented as a random increase in the multiplicative factor $\tilde{\Xi}$. This is another form of "financial shock", with similar, though not identical, effects as the default rate shock considered in the numerical results presented below; see the Appendix for further discussion.

${ }^{45}$ In our quarterly numerical model, this means that we choose a value such that $(1+\bar{\omega})^{4}=1.02$.

${ }^{46}$ Mehra et al. argue for this calibration by dividing the net interest income of financial intermediaries (as reported in the National Income and Product Accounts) by a measure of aggregate private credit (as reported in the Flow of Funds). As it happens, this value also corresponds to the median spread between the FRB index of commercial and industrial loan rates and the federal funds rate, over the period 1986-2007.

${ }^{47}$ This requires that $\eta=51.6$.
} 


\section{Credit Frictions and Optimal Monetary Policy}

\subsection{Numerical Results}

We begin by considering the predicted responses to aggregate disturbances of a kind that also exist in the basic NK model, in order to determine how accurate that model's answers are about the questions to which it gives answers. We first consider the case of a linear intermediation technology. In this case, the credit spread $\omega_{t}$ evolves exogenously, as assumed in the discussion at the end of section 1.1 , but $\Xi_{t}$ is no longer independent of $b_{t}$. Nonetheless, in this case we continue to find that for a reasonable parameterization of the quantity of resources used in intermediation, the existence of credit frictions makes virtually no difference for the predicted equilibrium responses to shocks.

This is illustrated in Figures 2-4 for three particular types of exogenous disturbances. In Figure 2 we consider the equilibrium responses to a contractionary monetary policy shock, represented by a unit (one percentage point, annualized) increase in $\epsilon_{t}^{m}$. We furthermore assume that the policy disturbance is persistent; specifically, $\epsilon_{t}^{m}$ is assumed to follow an $\operatorname{AR}(1)$ process with coefficient of autocorrelation $\rho=0.75$. The separate panels of the figure indicate the impulse responses of output, inflation, ${ }^{48}$ the deposit rate, the lending rate, ${ }^{49}$ and aggregate private debt respectively. Figure 3 illustrates the equilibrium responses of the same variables to a unit positive innovation in the productivity factor, where the disturbance is again assumed to have an autocorrelation of 0.75 , and monetary policy is conducted in accordance with (3.13) with no random term. Figure 4 shows the corresponding equilibrium responses in response to an increase in government purchases by an amount equal to one percent of total output.

In each figure, the predicted impulse responses under our model with financial frictions (the case labeled 'FF' in each figure) are contrasted with those under two variant parameterizations of the model. The case labeled 'NoFF' corresponds to an otherwise identical model in which $\omega_{t}(b) \equiv 0$ and $\Xi_{t}(b) \equiv 0$, but we retain the heterogeneity in preferences, parameterized in the same way as in the ' $\mathrm{FF}$ ' model. The case labeled ' $\mathrm{RepHH}$ ' is one in which in addition to assuming zero credit frictions, we assume identical preferences for the two types; this model is equivalent to a representative-household model (specifically, to the basic NK model as presented in Woodford, 2003, chap. 4). Comparison of these three cases allows us

\footnotetext{
${ }^{48} \mathrm{In}$ the plots, both the inflation rate and the interest rates are reported as annualized rates, so that 0.10 means an increase in the inflation rate of 10 basis points per annum. In terms of our quarterly model, what is plotted is not the response of $\pi_{t}$, but rather the response of $4 \pi_{t}$.

${ }^{49}$ In the present model, the spread between the deposit rate and the lending rate is exogenously fixed, and so these two variables necessarily respond by exactly the same amount, except in the case of a shock to the exogenous credit spread itself. However, we include both panels as we use the same format for the figures to follow, when inclusion of both is no longer redundant.
} 


\section{Credit Frictions and Optimal Monetary Policy}

to separately consider the degree to which credit frictions as opposed to heterogeneity make a difference.

In each of Figures 2 through 4, we observe that the impulse responses of output, inflation, and the two interest rates are virtually identical under all three parameterizations of the model. (The same is true for the other aggregate disturbances that have analogs in the representative-household model - a common disturbance to the impatience to consume of all households, a disturbance to the disutility of work, a shock to government purchases, a shock to the tax rate, or a shock to the wage markup - though we do not include these figures here.) We have already explained in section 2.1 why this would be true in the case that the resources used in intermediation are independent of the volume of lending. Our numerical results indicate that even when we assume that intermediation uses resources (and indeed that credit spreads are entirely due to the marginal resource cost of making additional loans), and that the required resources are proportional to the volume of lending, heterogeneity and the existence of a steady-state credit spread (of a realistic magnitude) still make only a negligible difference. This is because the contribution of the banking sector to the overall variation in the aggregate demand for produced goods and services is still quite small. ${ }^{50}$

Financial frictions matter somewhat more for equilibrium dynamics if we also assume that credit spreads vary endogenously with the volume of lending. Figures 5-9 show equilibrium responses of the same aggregate variables to a variety of types of exogenous disturbances, in the case of the "convex intermediation technology" calibration discussed in section 2.2. Figures 5-7 show responses to the same three kinds of shocks as in Figures 2-4 respectively, but for the alternative intermediation technology. Figure 8 shows the corresponding responses to an exogenous increase in the impatience to consume of savers; and Figure 9 shows responses to an exogenous increase in real government debt by an amount equal to 1 percent of GDP. In each case, the disturbance is modeled as an $\mathrm{AR}(1)$ process with autoregressive coefficient 0.75 .

In the case of the monetary policy shock (Figure 5), we again find that the equilibrium responses of output and inflation are nearly the same in all three models, though the 'FF model' is no longer quite so indistinguishable from the 'NoFF' model. The most important effect of allowing for endogeneity of the credit spread is on the implied responses of interest rates to the shock. Because credit contracts in response to this shock (as noted earlier, though

\footnotetext{
${ }^{50}$ Note that in each of Figures 2-4, the existence of the credit frictions in the 'FF' model makes a substantial difference for the equilibrium evolution of credit $b_{t}$ relative to the prediction of the 'NoFF' model. However, this change in the size of the banking sector does not have substantial consequences for aggregate output, employment, or inflationary pressure.
} 


\section{Credit Frictions and Optimal Monetary Policy}

now by less than in Figure 2), the spread between the lending rate and the deposit rate decreases, in accordance with the empirical finding of Lown and Morgan (2002). This means that the deposit rate need no longer decline as much as does the lending rate. Moreover, because the reduced spread has an expansionary effect on aggregate demand, output declines slightly less in response to the shock than in the 'NoFF' model; this is also a reason for the deposit rate to decline less. Thus the most visible effect is on the predicted response of the deposit rate, which is visibly smaller in the 'FF model.' The effects of financial frictions are similarly mainly on the path of the deposit rate in the case of a shock to the sales tax rate $\tau_{t}$ (not shown).

The effects of financial frictions are not quite as trivial in the case of the technology shock (Figure 6). Though again the largest effect is on the path of the deposit rate, in this case the endogeneity of the credit spread also has non-negligible effects on the equilibrium response of output. (The primary reason for the difference is that this shock has a larger immediate effect on the path of credit, and hence a larger immediate effect on the equilibrium spread in the case of the convex technology.) Because an increase in productivity leads to an expansion of credit, credit spreads now increase in the 'FF model'; this is has a contractionary effect on aggregate demand, so that output increases less than in the 'NoFF model'. Similar effects of financial frictions are observed in the case of a disturbance to the disutility of working (an exogenous increase in the multiplicative factor $\bar{H}_{t}$ in (2.23)). The effects of an increase in the wage markup $\mu_{t}^{w}$ or the tax rate $\tau_{t}$ are likewise similar, but with opposite signs to the effects shown in Figure 6.

The effects of financial frictions are even more significant in the case of a shock to government purchases (Figure 7) or to the consumption demand of savers (Figure 8). ${ }^{51}$ These are both disturbances that crowd out the expenditure of private borrowers (as the most interest-sensitive category of expenditure) to a significant extent, and so substantially reduce equilibrium borrowing and credit spreads. In each case, the reduction in spreads has a further expansionary effect on aggregate demand, so that output increases by more than in the 'NoFF' model.

Note that the effect would be quite different in the case of a shock to the consumption demand of borrowers rather than savers (not shown). In this case, private credit would increase rather than decreasing, and by less than in Figure 8, because of the greater interestelasticity of the demand of borrowers; this would imply a small increase in spreads, making the disturbance slightly less expansionary, but with a less dramatic effect than in Figure $8 .{ }^{52}$

\footnotetext{
${ }^{51}$ The shock considered here increases the value of $c^{s}(\lambda)$ by one percent for each possible value of $\lambda$.

${ }^{52}$ The effect of financial frictions in this case is somewhat similar to the case of the technology shock shown
} 


\section{Credit Frictions and Optimal Monetary Policy}

The aggregate effects of financial frictions are even smaller in the case of a uniform increase in the consumption demand of both types of households, since in this case the effects of the two types of expenditure on equilibrium credit spreads partially offset one another.

Finally, the consequences of financial frictions are of particular qualitative significance in the case of a disturbance to the path of government debt (Figure 9). Here we consider a disturbance to fiscal policy that temporarily increases the level of government debt, through a lump-sum transfer to households, which is then gradually taken back over a period of time, so that the path of real government debt is eventually the same as it would have been in the absence of the shock. In the case of the 'NoFF model', Ricardian equivalence holds, as in the representative household model; and so in these cases, the fiscal shock has no effect on output, inflation, or interest rates. However, an increase in government borrowing crowds out private borrowing, and in the case of the convex intermediation technology, the reduced private borrowing implies a reduction in spreads. This has an expansionary effect on aggregate demand, with the consequence that both output and inflation increase, as shown in the figure. ${ }^{53}$

To sum up, we find that under an empirically realistic calibration of the average size of credit spreads, the mere existence of a positive credit spread does not imply any substantial quantitative difference for our model's predictions, either about the effects of a monetary policy shock or about the effects of other kinds of exogenous disturbances under a given systematic monetary policy. ${ }^{54}$ What matters somewhat more is the degree to which there is variation in credit spreads. If spreads vary endogenously (as in our model with a convex intermediation technology), then the effects of disturbances are somewhat different, especially in the case of types of disturbances - such as variations in government borrowing, or changes in the relative spending opportunities available to savers as opposed to borrowers - that particularly affect the evolution of the equilibrium volume of private credit.

Another important difference of the model with credit frictions is the possibility of exogenous disturbances to the banking sector itself, represented by exogenous variation in either the intermediation technology $\Xi_{t}(b)$ or the default rate $\chi_{t}(b)$. Again, these disturbances mat-

in Figure 6. See the Appendix for the corresponding figure.

${ }^{53}$ Ricardian equivalence does not hold precisely in the ' $\mathrm{FF}$ model' even in the case of the linear intermediation technology. However, in this case (not shown) there is no reduction in credit spreads in response to the shock, and the only consequence for aggregate demand comes from the reduction in the resources used by the banking sector, so that shock is actually (very slightly) contractionary in this case. (See the Appendix for the corresponding figure.) But there is very little difference in the predictions of the 'NoFF' and ' $F F$ ' models in the case of that technology, so that we omit the figure here.

${ }^{54}$ The Appendix includes figures with the equilibrium responses to all the exogenous disturbances considered, for both the exogenous spread (linear technology) and the endogenous spread (convex technology) cases. 


\section{Credit Frictions and Optimal Monetary Policy}

ter to the determination of aggregate output, inflation and interest rates primarily to the extent that they imply variation in credit spreads. The equilibrium effects of disturbances of this kind under alternative monetary policies are considered further below (see Figure 15).

\section{Optimal Monetary Stabilization Policy}

We turn now to the implications of credit frictions for optimal monetary policy. We shall suppose that the objective of policy is to maximize the average ex ante expected utility of the households. This implies an objective of the form

$$
E_{0} \sum_{t=0}^{\infty} \beta U\left(Y_{t}, \lambda_{t}^{b}, \lambda_{t}^{s}, \Delta_{t} ; \tilde{\xi}_{t}\right)
$$

where

$$
\begin{aligned}
U\left(Y_{t}, \lambda_{t}^{b}, \lambda_{t}^{s}, \Delta_{t} ; \tilde{\xi}_{t}\right) \equiv & \pi_{b} u^{b}\left(c^{b}\left(\lambda_{t}^{b} ; \xi_{t}\right) ; \xi_{t}\right)+\pi_{s} u^{s}\left(c^{s}\left(\lambda_{t}^{s} ; \xi_{t}\right) ; \xi_{t}\right) \\
& -\frac{\psi}{1+\nu}\left(\frac{\tilde{\lambda}_{t}}{\tilde{\Lambda}_{t}}\right)^{-\frac{1+\nu}{\nu}} \bar{H}_{t}^{-\nu}\left(\frac{Y_{t}}{Z_{t}}\right)^{1+\omega} \Delta_{t}
\end{aligned}
$$

and

$$
\tilde{\Lambda}_{t} \equiv \psi^{\frac{1}{1+\nu}}\left[\pi_{b} \psi_{b}^{-\frac{1}{\nu}}\left(\lambda_{t}^{b}\right)^{\frac{1+\nu}{\nu}}+\pi_{s} \psi_{s}^{-\frac{1}{\nu}}\left(\lambda_{t}^{s}\right)^{\frac{1+\nu}{\nu}}\right]^{\frac{\nu}{1+\nu}}
$$

Again, the derivation is provided in the Appendix. Note that the final term in (4.2) represents the average disutility of working, averaging both over the entire continuum of types of labor $j$ and over the two types of households, using the model of equilibrium labor supply discussed in section 1.2 .

While one might reasonably consider the optimal use of fiscal policy for stabilization purposes as well, we shall here consider only the optimal conduct of monetary policy, taking as given the state-contingent evolution of the fiscal variables $\left\{\tau_{t}, b_{t}^{g}\right\}$. The problem with which we are concerned is thus the choice of state-contingent paths for the endogenous variables $\left\{Y_{t}, \lambda_{t}^{b}, \lambda_{t}^{s}, i_{t}^{b}, i_{t}^{d}, z_{t}, \Pi_{t}, \Delta_{t}, b_{t}\right\}$, consistent with the structural relations (2.7)-(2.8), (2.12)-(2.15), (2.26)-(2.27), and (2.28)-(2.29), so as to maximize (4.1). Note that there is one fewer structural relations per period than endogenous variables, so that there is one dimension of variation of monetary policy each period, which may be thought of as the central bank's choice of the policy rate $i_{t}^{d}$.

We can analyze the solution to this optimization problem, by differentiating a Lagrangian 


\section{Credit Frictions and Optimal Monetary Policy}

to obtain a system of first-order conditions, that take the form of nonlinear (expectational) stochastic difference equations. (Details are given in the Appendix.) A first important conclusion, demonstrated in the Appendix, is that when there are no stochastic disturbances (i.e., each of the exogenous variables in $\tilde{\xi}_{t}$ takes a constant value), the first-order conditions for optimality admit a stationary (or steady state) solution, in which the rate of inflation is zero. Hence under an optimal policy commitment, in the absence of stochastic disturbances the inflation rate will eventually converge to zero; ${ }^{55}$ and in the case of small enough stochastic disturbances, the optimal policy commitment will involve an inflation rate that fluctuates asymptotically around zero. To the extent that the disturbances are small enough for a linear approximation to the equilibrium relations to provide an adequate approximation to the equilibrium dynamics, optimal policy involves a long-run average inflation rate of zero, even in the stochastic case.

This result generalizes the one obtained by Benigno and Woodford (2005) for the case with representative-household, and implies that the optimal inflation target is independent of the (average) severity of the distortions resulting from credit frictions, just as it is independent of the severity of the steady-state distortions resulting from market power in the goods or labor markets or from distorting taxes. This indicates a first important respect in which conclusions about optimal policy derived from a model that abstracts from financial frictions continue to apply when one allows for such frictions. The result also justifies our attention here only to the consequences of alternative policies that imply a long-run average inflation rate near zero (as in our analysis of the consequences of a Taylor rule in section 2); since we know that the optimal policy commitment involves inflation fluctuations around zero, we can restrict our analysis to policies with that property, both when seeking to further characterize optimal policy, and when investigating the desirability of simple policy rules that are intended to approximate optimal policy.

\footnotetext{
${ }^{55}$ Under a once-and-for-all commitment chosen to maximize the objective (4.1) at some initial date, under no constraints other than those required for a perfect foresight equilibrium from the time of adoption of the policy commitment onward - the "Ramsey" policy problem - a higher inflation rate will be chosen initially, in order to exploit the short-run aggregate-supply trade-off without having to take account of any consequences of anticipation of such inflation in the period prior to adoption of the policy; but the policy will involve a commitment to eventually reduce the inflation rate to zero, since the long-run inflation commitment internalizes the consequences of anticipation of the inflation rate in prior periods. (See Woodford, 2003, chap. 7, for discussion of this in the context of the basic NK model.) Optimal policy "from a timeless perspective," in the sense defined in Woodford (2003, chapter 7) and Benigno and Woodford (2005), instead involves zero inflation at all times, in the absence of stochastic disturbances.
} 


\section{Credit Frictions and Optimal Monetary Policy}

\subsection{Linear-Quadratic Analysis}

Under certain simplifying assumptions, we can obtain an analytical solution for the optimal state-contingent policy - or more precisely, for a linear approximation to optimal policy, in the case of small enough fluctuations around the optimal (zero-inflation) long-run steady state - using the method of linear-quadratic approximation introduced in Rotemberg and Woodford (1997) and further expounded by Benigno and Woodford (2012). ${ }^{56}$ Under these assumptions, we can derive a quadratic loss function for monetary stabilization policy with the property that minimization of the loss function is equivalent (in the case of small enough disturbances) to maximization of the utility-based objective (4.1). The linear policy rule that minimizes the quadratic loss function subject to the linear constraints obtained by log-linearizing the model structural relations (as in section 2.1) then provides a linear approximation to optimal policy.

We begin by using structural relation (2.15) together with the definition $\Omega_{t} \equiv \lambda_{t}^{b} / \lambda_{t}^{s}$ to solve for $\lambda_{t}^{b}$ and $\lambda_{t}^{s}$ as functions of $Y_{t}, \Omega_{t}, \Xi_{t}$, and the exogenous disturbances. Substituting these solutions into (4.2), we obtain a period utility function $\tilde{U}\left(Y_{t}, \Omega_{t}, \Xi_{t}, \Delta_{t} ; \tilde{\xi}_{t}\right)$ to replace the function $U$ defined in (4.2). We then compute a quadratic (Taylor-series) approximation to the function $\tilde{U}$ around the values of its arguments in the zero-inflation steady state, $(\bar{Y}, \bar{\Omega}, \Xi, 1 ; 0)$. This takes an especially simple form under the following special assumptions: (i) the steady-state tax distortion $\bar{\tau}$ exactly cancels the distortion resulting from market power in the goods markets $\left(1-\tau=\mu^{p} \equiv \theta /(\theta-1)\right)$, so that in the zero-inflation steady state, price is equal to marginal cost; (ii) there is no steady-state wage markup $\left(\bar{\mu}^{w}=1\right)$; (iii) the steady-state credit spread $\bar{\omega}=0$ (which, because of relation (3.4), implies that $\bar{\Omega}=1$ as well); and (iv) there are no resources consumed by the intermediary sector in steady state $(\bar{\Xi}=0)$. Note that the assumed absence of steady-state distortions of any of these kinds does not mean that we cannot consider the effects of these distortions; as with the other exogenous disturbances, we consider the effects of small departures from the steady-state values. But in the special case considered in this section, each of these distortions is assumed to be of order $\mathcal{O}(\|\xi\|)$ in the notation of Woodford (2003, chap. 6). Finally, we also assume (v) that the gradient $\bar{\Xi}_{b}=0$ in steady state as well, so that any endogenous variation in the resources used by the banking sector is of at most second order, though we allow for variations in the

\footnotetext{
${ }^{56}$ These simplifying assumptions are not required in order to compute a valid LQ approximation to our policy problem, as explained in Benigno and Woodford (2012). However, in general, the algebraic expression of the solution to the LQ problem will be complex, so we discuss it here only in a special case allowing a solution of a simple form. The same general method is used, however, to approximately characterize optimal policy in the numerical results presented below, that do not rely upon the simplifying assumptions introduced in this section.
} 


\section{Credit Frictions and Optimal Monetary Policy}

intercept $\Xi_{t}(\bar{b})$ that are of order $\mathcal{O}(\|\xi\|){ }^{57}$

In this special case, the Taylor series approximation to the period utility function takes the simple form

$$
\tilde{U}_{t}=-\frac{\bar{\lambda} \bar{Y}}{2}\left\{\left(\bar{\sigma}^{-1}+\omega_{y}\right)\left(\hat{Y}_{t}-\hat{Y}_{t}^{*}\right)^{2}+\tilde{\lambda}_{\Omega} \hat{\Omega}_{t}^{2}+\left(2 / 1+\omega_{y}\right) \hat{\Delta}_{t}\right\}-\bar{\lambda} \Xi_{t}+\text { t.i.p. }+\mathcal{O}\left(\|\xi\|^{3}\right),
$$

where the term "t.i.p." collects terms that are independent of monetary policy (because they depend only on exogenous disturbances) and the residual is of at most third order in the amplitude of the disturbances. Here

$$
\hat{Y}_{t}^{*} \equiv \hat{Y}_{t}^{n}+\frac{\bar{\sigma}^{-1}}{\bar{\sigma}^{-1}+\omega_{y}} \widehat{\widetilde{\Xi}}_{t}
$$

where $\hat{Y}_{t}^{n}$ is defined as in (3.12), and $\widehat{\Xi}_{t}$ measures the departure of the exogenous factor $\tilde{\Xi}_{t}$ from its steady-state value. ${ }^{58}$ Thus the target level of output $\hat{Y}_{t}^{*}$ is a function solely of exogenous disturbances, and indicates the optimal common level of production of each good given the current values of those disturbances, if one takes as given the marginal utility gap $\hat{\Omega}_{t}$ (which determines the way in which a given aggregate consumption level must be allocated across the two types of households) and the quantity of resources $\Xi_{t}$ that are consumed by the intermediary sector. ${ }^{59}$ Moreover, $\bar{\lambda}$ is the common steady-state marginal utility of income of all households (under a calibration in which $\bar{\Omega}=1$ ); $\bar{\sigma}$ is the "aggregate" intertemporal elasticity of substitution defined in (3.6) above; the coefficient $\tilde{\lambda}_{\Omega}>0$ is defined in the Appendix; and hats denote percentage deviations from the steady-state values of the various variables, as in section 2.1 .

Taking a discounted sum of these terms, and using a second-order Taylor series approximation to (2.26) to substitute for the $\hat{\Delta}_{t}$ terms in terms of inflation, we obtain a quadratic

\footnotetext{
${ }^{57}$ This last assumption is not necessary in order for the approximation (4.3) to average utility to be valid, but it is necessary in order for the terms in (4.3) that depend on policy to be purely quadratic, i.e., for them to include no linear terms. This last condition is necessary in order for the loss function to be evaluated to second order under alternative policies using only linear approximations to the model's structural relations, as discussed in Woodford (2003, chap. 6) and Benigno and Woodford (2012).

${ }^{58}$ Note that $\hat{Y}_{t}^{*}$ is a modified version of $\hat{Y}_{t}^{n}$ in which the term $\hat{G}_{t}$ is replaced by $\hat{G}_{t}+\widehat{\Xi}_{t}$. Effectively, exogenous variations in $\Xi_{t}(\bar{b})$ have an effect like that of variations in $G_{t}$, insofar as both represent variations in "autonomous expenditure" by sectors other than the private non-financial sector (represented by the "households" of our model). See the Appendix for details.

${ }^{59}$ In a version of the model without financial frictions - so that $\hat{\Omega}_{t}=\Xi_{t}=\widehat{\tilde{\Xi}}_{t}=0$ at all times $-\hat{Y}_{t}^{n}$ is the efficient level of output of each good, given current preferences and technological possibilities, as remarked earlier.
} 


\section{Credit Frictions and Optimal Monetary Policy}

objective

$$
\sum_{t=0}^{\infty} \beta^{t} \tilde{U}_{t}=-K \sum_{t=0}^{\infty} \beta^{t} L_{t}+\text { t.i.p. }+\mathcal{O}\left(\|\xi\|^{3}\right),
$$

where $K>0$ and the period loss function is of the form

$$
L_{t}=\pi_{t}^{2}+\lambda_{y}\left(\hat{Y}_{t}-\hat{Y}_{t}^{*}\right)^{2}+\lambda_{\Omega} \hat{\Omega}_{t}^{2}+\lambda_{\Xi} \Xi_{b t} \hat{b}_{t},
$$

for certain weights $\lambda_{y}, \lambda_{\Omega}, \lambda_{\Xi}>0$ defined in the Appendix. Maximization of average expected utility is thus equivalent (to the order of approximation required here) to minimization of the expected discounted value of the loss function (4.6). And because the terms in (4.6) are purely quadratic, the loss function can be evaluated to second order using only a log-linear approximation to the equilibrium dynamics of the endogenous variables under a given policy. Hence it is possible to use the log-linearized structural relations (derived in section 2.1) as the constraints in our (approximate) optimal policy problem. We thus obtain a linear-quadratic (LQ) problem, the solution to which provides a log-linear (approximate) characterization of optimal policy.

It is noteworthy that in (4.6), both the effects of the various types of exogenous disturbances (other than the "purely financial" disturbance $\widehat{\widetilde{\Xi}}_{t}$ ) on the "target" level of output $\hat{Y}_{t}^{*}$ and the relative weight $\lambda_{y}$ placed on the output-gap stabilization objective are identical (as functions of the model parameters) to those in the corresponding derivation for the basic NK model, modulo the need to "average" the preferences of the two types of households in defining both the elasticity $\bar{\sigma}$ and the composite disturbance to "autonomous expenditure" $g_{t}$. In particular, not only is the output gap appearing here the same one that appears in the aggregate-supply relation (3.12) - again except for the effect of the purely financial disturbance $\widehat{\widetilde{\Xi}}_{t}$ - just as in the basic NK model; but in addition the weight is given by $\lambda_{y}=\kappa / \theta$, where $\kappa$ is the slope of the inflation/output-gap tradeoff in (3.12), again as in the basic NK model. Thus in the special case that there are no financial frictions (i.e., $\omega_{t}=\tilde{\Xi}_{t}=\Xi_{t}=0$ at all times), so that the last two terms in (4.6) vanish, along with the non-standard terms in (3.12), and $\hat{Y}_{t}^{*}$ is simply equal to $\hat{Y}_{t}^{n}$, both the welfare-based loss function and the aggregate-supply relation (that defines the available trade-off between dynamic paths for the two variables in the loss function) are of exactly the same form as in the basic NK model, once one defines "average" variables appropriately. The existence of preference heterogeneity of the kind assumed in the present model - heterogeneity both with respect to the interest-sensitivity of different units' expenditure decisions and with respect to the time variation in their opportunities for productive expenditure - does not in itself require 


\section{Credit Frictions and Optimal Monetary Policy}

any substantial modification of the theory of optimal monetary stabilization policy.

If we instead allow for time-varying financial frictions (though no steady-state distortions, as explained above), but assume that there is no endogenous variation in these frictions - i.e., that $\left\{\omega_{t}, \Xi_{t}\right\}$ are exogenous processes, independent of the evolution of private indebtedness ${ }^{60}$ - we continue to obtain a very simple characterization of optimal policy. In this case, the final term in (4.6) is zero, and the penultimate term is independent of policy (to second order), since the log-linear approximate structural relation (3.4) implies that if $\left\{\omega_{t}\right\}$ is an exogenous process, $\left\{\Omega_{t}\right\}$ is also an exogenous process, at least up to a residual that is at most of second order, so that $\hat{\Omega}_{t}^{2}$ is exogenous, at least up to a residual of order $\mathcal{O}\left(\|\xi\|^{3}\right)$. Hence the loss function can be written (ignoring terms independent of policy) in the standard New Keynesian form, which is to say, as

$$
E_{0} \sum_{t=0}^{\infty} \beta^{t}\left[\pi_{t}^{2}+\lambda_{y} x_{t}^{2}\right],
$$

where $x_{t} \equiv \hat{Y}_{t}-\hat{Y}_{t}^{*}$ is the welfare-relevant output gap. In this case, the appropriate objectives of stabilization policy remain as in the basic NK model; the only differences made by financial frictions relate to the feasible paths for inflation and the output gap, and to the path for the policy rate required to implement given paths for inflation and the output gap.

Time-variation in financial frictions does matter for the optimal conduct of monetary policy, because they shift both the IS relation (3.8) and the aggregate-supply relation (3.12)). However, only the latter relation represents a constraint upon the set of achievable outcomes for the target variables, inflation and the output gap. And the only effect of financial frictions on this relation is the presence of an additional additive disturbance term. The first-order conditions that characterize the solution to the LQ problem of minimizing (4.7) subject to the constraint that (3.12) hold each period are unaffected by the additional disturbance terms, and so is the optimal target criterion that expresses the linear relation that must exist between the evolution of inflation and of the output gap in order for the first-order conditions for optimality to be satisfied. Just as in the basic NK model, the optimal target criterion is of the form ${ }^{61}$

$$
\pi_{t}+\left(\lambda_{y} / \kappa\right)\left(x_{t}-x_{t-1}\right)=0 .
$$

\footnotetext{
${ }^{60}$ For example, we may assume that (i) no real resources are used in intermediation, so that $\Xi_{t}(b)=0$, and the credit spread $\omega_{t}$ is due entirely to default risk; and (ii) the default rate $\tilde{\chi}_{t}$ evolves exogenously, and is unaffected by the volume of bank lending.

${ }^{61}$ See Woodford (2003, chap. 7) for derivation of this characterization of optimal policy in the case of the basic NK model, and for further discussion of the implementation of optimal policy using a target criterion.
} 


\section{Credit Frictions and Optimal Monetary Policy}

While the state-contingent paths for inflation and the output gap that satisfy this criterion are different in the case of a time-varying credit spread, the criterion that the central bank should use at each point in time to determine if policy remains on track is unchanged. Not only can optimal policy still be characterized as "flexible inflation targeting," but the optimal target criterion is of an identical form to what is optimal in the absence of credit frictions.

\subsection{Implementing the Optimal Policy}

The implementation of an optimal policy does require the central bank to monitor the varying size of the credit frictions - more precisely, the varying size of credit spreads - in order to determine how it must act in order to ensure fulfillment of the target criterion (4.8). These matter for two reasons. First, the paths of inflation and the output gap consistent with (4.8) depend in general on the evolution of credit spreads, because of the effect of those spreads on the aggregate-supply trade-off (3.12). And second, the path of policy rates required to implement given (feasible) paths for inflation and output depends on the path of credit spreads, because of their effects on both the relation (3.8) between average interest rates and expenditure and the relation (3.10) between the policy rate and the relevant "average" interest rate.

The required adjustment of the policy rate follows from standard treatments (e.g., Clarida, Gali and Gertler, 1999; Woodford, 2003, chap. 7) of the optimal interest-rate response to "cost-push shocks" and variations in the natural rate of interest in the context of the basic NK model. Variations in credit spreads result in a total cost-push term in the aggregatesupply relation equal to ${ }^{62}$

$$
u_{t}^{F F}=u_{t}+\xi s_{\Omega} \hat{\Omega}_{t}
$$

where $u_{t} \equiv \xi\left(\hat{\mu}_{t}^{w}+\hat{\tau}_{t}\right)$ is the cost-push term in the absence of financial frictions (but taking account of preference heterogeneity), and the coefficient $s_{\Omega}$ is defined as in (3.7); and they similarly result in a natural rate of interest (understood to mean the real value of the relevant average rate of interest that would be required to maintain a zero output gap at all times) equal to

$$
r_{t}^{n, F F}=r_{t}^{n}+s_{\Omega} E_{t} \Delta \hat{\Omega}_{t+1}-\left(\bar{\sigma}+\omega_{y}^{-1}\right)^{-1} E_{t} \Delta \widehat{\widetilde{\Xi}}_{t},
$$

where $r_{t}^{n}$ is similarly the natural rate of interest in the absence of financial frictions (but

\footnotetext{
${ }^{62}$ The cost-push effect of variations in $\hat{\Omega}_{t}$ here has a simpler expression than in (3.12), because of the assumption in this section that $\bar{\Omega}=1$, which implies that $\gamma_{b}=\pi_{b}$. The effect of variations in $\hat{\Omega}_{t}$ on the natural rate of interest given below is similarly simpler than the one indicated in (3.8), because $\psi_{\Omega}=0$ in the special case in which $\bar{\Omega}=1$.
} 


\section{Credit Frictions and Optimal Monetary Policy}

taking account of preference heterogeneity). The standard theory of how "the interest rate" should be adjusted in response to exogenous variations in the processes $\left\{u_{t}, r_{t}^{n}\right\}$ continues to apply under this extension of the basic NK model, but it now should be understood to determine the optimal operating target for the average interest rate $\hat{\imath}_{t}^{a v g}$. The required adjustment of the central bank's policy rate $i_{t}^{d}$ is then given by (3.10), and this relation is also shifted when credit spreads change.

A useful description of the ultimate implications for interest-rate policy can be given by solving equilibrium relations (3.8), (3.10) and (3.12) for the policy rate required in order for the equilibrium values of $\pi_{t}$ and $x_{t}$ to satisfy the target criterion (4.8). In this exercise we take as given the values of the expectations $E_{t} \pi_{t+1}$ and $E_{t} x_{t+1}$, as well as the values of all predetermined or exogenous variables; solve for the implied values of $\pi_{t}$ and $x_{t}$ conditional upon the choice of $i_{t}^{d}$; substitute these solutions for $\pi_{t}$ and $x_{t}$ into the target criterion; and then solve for the value of $i_{t}^{d}$ that implies that (4.8) should be satisfied. The resulting interest-rate reaction function is what Evans and Honkapohja (2006) call an "expectationsbased reaction function." Because it responds directly to (observed) current expectations, such a policy ensures that the target criterion is satisfied regardless of whether expectations are those consistent with the optimal equilibrium. Such an approach to the implementation of policy has important advantages; in particular, it ensures both that the optimal equilibrium is the only (non-explosive) rational-expectations equilibrium consistent with the central bank's reaction function, and that this equilibrium is "E-stable," facilitating convergence to the rational-expectations equilibrium under least-squares learning dynamics. ${ }^{63}$

In the case of the model developed here (under the assumptions used to derive (4.8), this reaction function takes the form

$$
\begin{aligned}
i_{t}^{d}= & r_{t}^{n}+\phi_{u} u_{t}+\left[1+\beta \phi_{u}\right] E_{t} \pi_{t+1}+\bar{\sigma}^{-1} E_{t} x_{t+1}-\phi_{x} x_{t-1} \\
& -\left[\pi_{b}+\hat{\delta}^{-1} s_{\Omega}\right] \hat{\omega}_{t}+\left[\left(\hat{\delta}^{-1}-1\right)+\phi_{u} \xi\right] s_{\Omega} \hat{\Omega}_{t} \\
& -\left(\bar{\sigma}+\omega_{y}^{-1}\right)^{-1} E_{t} \Delta \widehat{\tilde{\Xi}}_{t+1}
\end{aligned}
$$

where

$$
\phi_{u} \equiv \frac{\kappa}{\bar{\sigma}\left(\kappa^{2}+\lambda_{y}\right)}>0, \quad \phi_{x} \equiv \frac{\lambda_{y}}{\bar{\sigma}\left(\kappa^{2}+\lambda_{y}\right)}>0 .
$$

The terms on the first line of (4.9) are exactly the reaction function derived by Evans and Honkapohja (2006) for the basic NK model; note that the rule can be viewed as a forwardlooking variant of a "Taylor rule." The second and third lines contain the additional terms

\footnotetext{
${ }^{63}$ See Evans and Honkapohja (2006), Preston (2008), and Woodford (2003, chap. 7).
} 


\section{Credit Frictions and Optimal Monetary Policy}

that must be added in the case of credit frictions, taking into account the effects of credit spreads and of the resources used in intermediation on the effective natural rate of interest, the cost-push effects of credit spreads, and the consequences of spreads for the gap between the policy rate and the average interest rate. (We have written the terms on the second line in terms of $\hat{\omega}_{t}$ and $\hat{\Omega}_{t}$ rather than $\hat{\Omega}_{t}$ and $E_{t} \hat{\Omega}_{t+1}$, by using (3.4) to eliminate the expected gap term. This makes it easiest to contrast the effects of transitory as opposed to more persistent variations in credit spreads.)

Because the coefficient multiplying $\hat{\omega}_{t}$ is negative, while the term multiplying $\hat{\Omega}_{t}$ is positive (under the assumption that $s_{b} \sigma_{b}>s_{s} \sigma_{s}$ ), the appropriate adjustment of the intercept of the reaction function is generally negative in the case of a transitory increase in credit spreads, but less negative (for any given size of increase in credit spreads) the more persistent the increase is expected to be. It is furthermore worth noting that in the limiting case in which $s_{b} \sigma_{b}>s_{s} \sigma_{s}$ and $\delta$ approaches 1 , the coefficient on $\hat{\omega}_{t}$ in (4.9) approaches -1 . Since the coefficient on $\hat{\Omega}_{t}$ is also fairly small under a realistic calibration (about 0.03 in the calibration used above), it follows that the optimal reduction in the policy rate (relative to what the reaction function would otherwise call for) in response to a purely transitory increase in credit spreads will equal nearly 100 percent of the increase in spreads, as proposed by Taylor (2008) and McCulley and Toloui (2008). In this limiting case, it is really only the interest rate faced by borrowers that matters for aggregate demand, and thus it is only the consequence of the policy rate for the rate that will be faced by borrowers that matters for fulfillment of the target criterion; in this case the reasoning of Taylor and of McCulley and Toloui is essentially correct.

Even in the case of a less extreme parameterization of the structural model and a more persistent disturbances to credit markets, the optimal adjustment can easily be a large fraction of the size of the increase in credit spreads. For example, in the case of the calibration discussed above and in the case of a financial shock with the degree of persistence assumed in Figures 15 below (i.e., an autoregressive coefficient of 0.75 ), the reduction in the intercept of the central-bank reaction function will be by about 85 basis points for each percentage point increase in credit spreads. However, under a parameterization in which the expenditure decisions of borrowers are not so largely responsible for the interest sensitivity of aggregate expenditure, the optimal reduction in the policy rate in response to an increase in credit spreads would be smaller. For example, in the case that $s_{b} \sigma_{b}=s_{s} \sigma_{s}$, the coefficient on $\hat{\omega}_{t}$ is equal to exactly $-\pi_{b}$, while the coefficient on $\hat{\Omega}_{t}$ is zero. In this case, it is only optimal to reduce the policy rate by $\pi_{b}$ percentage points for every percentage point increase in credit spreads; in this case, the optimal reaction function is most simply expressed in terms of an 


\section{Credit Frictions and Optimal Monetary Policy}

operating target for $i_{t}^{a v g}$, rather than either $i_{t}^{d}$ or $i_{t}^{b}$. (It is also interesting to note that in this case, the optimal response is independent of the degree of persistence of the disturbance to credit markets.)

These analytical results depend, of course, on a number of simplifying assumptions. Matters are more complicated, in particular, if we assume that either the resources used in financial intermediation, the size of credit spreads, or both depend on the volume of bank lending. Rather than seek analytical results in the more general case, we present some illustrative numerical calculations of optimal policy in calibrated examples, and investigate the degree to which the insights suggested by the analysis of this simple case continue to apply.

\subsection{Numerical Analysis}

In order to check the degree to which the results obtained above for a special case continue to hold, at least approximately, under more general assumptions, we numerically analyze optimal policy in the calibrated economies for which we have already analyzed the consequences of a simple Taylor rule in section 2. Under assumptions more general than those used in the previous section, we can characterize the optimal responses to exogenous disturbances of various sorts by deriving the first-order conditions that characterize optimal (Ramsey) policy - the problem of maximizing (4.1) subject to constraints (2.7)-(2.8), (2.12)-(2.15), (2.26)-(2.27), and (2.28)-(2.29) - and then log-linearizing them around the zero-inflation optimal steady state. The resulting log-linear equations can be solved for log-linear optimal dynamic responses of the various endogenous variables to (small enough) random shocks to each of the exogenous disturbance processes.

A useful question about these optimal responses is the degree to which they can be achieved through one or another rule for the conduct of monetary policy. Given our results for the special case treated in the previous section, one obvious candidate for a rule is flexible inflation targeting, here understood to mean a commitment to adjust the policy rate as necessary to ensure that the target criterion (4.8) holds at all times. ${ }^{64}$ Other simple

\footnotetext{
${ }^{64}$ More precisely, the target criterion that we assume is the one that characterizes optimal policy in the representative-household model. The target criterion discussed in the previous section corresponded to optimal policy in a representative household model in which the steady-state level of output is efficient, which required that $1-\tau=\mu^{p} \equiv \theta /(\theta-1)$. More generally, the optimal target criterion for the representativehousehold model continues to be of the form (4.8), but the definition of the output gap $x_{t}$ and the relative weight $\lambda_{y}$ are slightly different, as explained in Benigno and Woodford (2005). To be precise, in our numerical solutions under the "flexible inflation targeting rule" (4.8), we define the variable $x_{t}$ as in Benigno and Woodford, except that the exogenous level of government purchases $\hat{G}_{t}$ is replaced by $\hat{G}_{t}+\widehat{\Xi}_{t}$, as in (4.4).
} 


\section{Credit Frictions and Optimal Monetary Policy}

proposals that we shall consider include the simple Taylor rule analyzed in section 2, and a strict inflation targeting rule, under which monetary policy stabilizes the inflation rate regardless of the type of disturbance that occurs.

The equilibrium responses of the endogenous variables to a technology shock (of exactly the same kind previously considered in Figures 3 and 6) under each of these alternative monetary policies are shown in Figure 10. (The model parameterization is again the one with a convex intermediation technology, as in Figures 5-9.) The solid line (labeled 'Optimal') indicates the equilibrium responses to the increase in productivity under the optimal policy. The dashed line (labeled 'PiStab') instead indicates responses under a policy that fully stabilizes inflation (i.e., strict inflation targeting); the line marked with + signs (labeled 'Taylor') indicates responses under policy conducted in accordance with the Taylor rule; and the line marked with x's (labeled 'FlexTarget') indicates responses under the flexible inflation targeting policy.

In the case of this kind of shock, the aggregate-supply relation (3.12) implies that there is little inconsistency between inflation stabilization and output-gap stabilization; and as a consequence strict inflation targeting and flexible inflation targeting are barely distinguishable policies. ${ }^{65}$ They are also both very close to the optimal policy, confirming that in this respect the analytical results of the previous section continue to provide a good approximation. The Taylor rule is instead much less close to an optimal policy, because it requires policy to be tightened in response to the output increase, even when this does not represent high output relative to the natural rate (which is increased by the technology shock). Similar results are obtained in the case of exogenous shocks to the disutility of labor, the demand of borrowers, or to the path of government debt (none of which are shown here): in each case, there is sufficiently little tension between the requirements of inflation stabilization and of output-gap stabilization that flexible inflation targeting and strict inflation targeting are similar policies, and both are fairly close to optimal policy (while the Taylor rule is much less close).

Figure 11 shows the corresponding equilibrium responses in the case of a shock to the wage markup $\mu_{t}^{w}$, under the same four alternative policies. This case is interesting because it is one in which strict inflation targeting is clearly not an optimal policy, even in the representative-household model, owing to the substantial "cost-push" effect of such a shock. (However, even in this case, strict inflation targeting is still more similar to optimal policy than is adherence to the Taylor rule.) The figure shows that in the case of this kind of shock,

\footnotetext{
${ }^{65}$ In fact, if we did not allow for endogeneity of the credit spread, as in the model with a linear intermediation technology, they would not differ at all.
} 


\section{Credit Frictions and Optimal Monetary Policy}

as with other "supply shocks" such as disturbances to the disutility of labor supply or to the tax rate, flexible inflation targeting is nonetheless quite a close approximation to optimal policy.

Figure 12 shows the corresponding equilibrium responses to a shock to the level of government purchases (of the kind previously assumed in Figures 4 and 7); and Figure 13 shows the responses to a shock to the demand of savers (of the kind previously assumed in Figure 8). In the case of a shock to government purchases, strict inflation targeting is again not optimal, ${ }^{66}$ and in at least some respects the Taylor rule is in this case closer to the optimal policy than would be strict inflation targeting. ${ }^{67}$ Nonetheless, once again flexible inflation targeting is the closest to optimal policy of the set of simple policy rules considered here, though optimal policy would be slightly tighter in the period of the shock. In the case of a shock to the demand of savers as well, flexible inflation targeting is the closest to optimal policy, though again optimal policy would be slightly tighter in the period of the shock. Flexible inflation targeting is nonetheless a slightly tighter policy (initially) in response to the expansionary shock than strict inflation targeting would be, though it is not excessively tight in the way that the simple Taylor rule is.

Figure 14 instead considers equilbrium responses to a shock to the demand of borrowers (again, the shock increases their purchases by one percent for a given marginal utility of income). In this case, the way in which the strict inflation targeting policy is suboptimal is opposite to the case of two "demand shocks" just considered: under an optimal policy, inflation would be allowed to rise slightly in response to the shock. But again the flexible inflation targeting policy deviates from strict inflation targeting in the correct direction, while both targeting rules are substantially better than the simple Taylor rule.

Finally, Figure 15 shows the corresponding equilibrium responses in the case of a shock to the default rate $\tilde{\chi}_{t}$, of a size sufficient to increase the credit spread $\omega_{t}$ by four percentage points (annualized). This kind of shock (not discussed in section 2.3 because there is no analogous shock in the models without financial frictions) would be quite contractionary if monetary policy were conducted in accordance with an unadjusted Taylor rule. ${ }^{68}$ But as in the case of a productivity shock (shown in Figure 10) or a shock to the disutility of labor supply, either kind of inflation targeting is much closer to optimal policy. Yet even in this case, flexible inflation targeting is not quite an equivalent policy to strict inflation targeting,

\footnotetext{
${ }^{66}$ This would be true even in the representative-household model, given the existence of steady-state distortions, as discussed by Benigno and Woodford (2005).

${ }^{67}$ The response of output is more nearly optimal under the Taylor rule.

${ }^{68}$ This effect could be substantially mitigated, of course, by a spread-adjusted Taylor rule of the kind proposed by Taylor (2008). See Cúrdia and Woodford (2010) for numerical analysis of rules of that kind.
} 


\section{Credit Frictions and Optimal Monetary Policy}

and is closer to the optimal policy.

Overall, our conclusion is that while the additional distortions that were omitted in the special case for which we were able to give an analytical characterization of optimal policy in section 3.1 are of at least some significance in our calibrated model, the flexible inflation targeting rule (4.8) continues to provide a fairly good approximation to optimal policy, in response to each of the variety of types of exogenous disturbances discussed above. ${ }^{69}$ Since this is also the rule that characterizes optimal policy in the basic NK model, in at least this sense the basic NK model remains quite a good guide to policy in the kind of environment that we consider. Of course, it is important to remember that the policy prescription provided by (4.8) is not a complete description of the way in which the policy rate should be adjusted: it is still necessary to use a model of the transmission mechanism to determine what adjustments of the policy rate are needed to ensure that the target criterion is satisfied. And the model used for this latter purpose needs to be one that takes account of the credit frictions - in particular, that takes account of the variations over time in the size of credit spreads. But the target criterion around which monetary policy deliberations are structured may not need to be changed in response to the existence of credit frictions.

\section{Conclusions}

With regard to the most general question raised in our introduction - implications for models for policy analysis - our results suggest that the basic view of the way in which monetary policy influences aggregate expenditure and inflation presented in New Keynesian models need not be modified in any fundamental way as a consequence of the observation that substantial spreads exist on average between different interest rates in the economy, or that these spreads are not always constant over time. We have exhibited a simple extension of the basic NK model in which a time-varying positive spread exists between the interest rate available to savers and the interest rate at which borrowers can borrow. Yet in at least the simplest version of this model, the monetary transmission mechanism is virtually identical to that of the basic NK model: monetary policy can be viewed purely as central-bank control of a short-term nominal interest rate (the deposit rate $i_{t}^{d}$ ), and the ways in which aggregate expenditure and inflation are determined by the expected central-bank reaction function for the policy rate (e.g., a Taylor rule specification) are nearly identical to those in the basic NK model. Hence the fundamental lessons implied by that framework for monetary policy

\footnotetext{
${ }^{69}$ The Appendix includes figures with the equilibrium responses to all the exogenous disturbances considered, under the alternative policies discussed.
} 


\section{Credit Frictions and Optimal Monetary Policy}

analysis continue to apply (for example, the conclusion that central banks influence the aggregate economy primarily by affecting the expected future path of short-run real rates of return, rather than through their control of the current short rate as such, the conclusion that optimal policy is history-dependent, and so on).

This does not mean that financial frictions are irrelevant to output and inflation determination. Even in the simplest case of the present model, time-variation in credit spreads affects both the "IS relation" between the expected path of the real policy rate and aggregate expenditure and the "AS relation" between aggregate output and inflation. However, in the simplest version of the model, these spreads simply contribute additional additive terms to these relations, corresponding to a new form of exogenous disturbance, in addition to the real sources of variation in the natural rate of interest and natural rate of output, and the "cost-push" disturbances allowed for in the basic NK model. The occurrence of such additional disturbances matters: successful monetary policy requires appropriate adjustment of the policy rate in response to disturbances, and this requires monitoring them in real time and correctly identifying their character as they occur. But the effects of "financial shocks" in the simplest version of our model with credit frictions are not fundamentally different than the effects of a certain linear combination of types of shocks that are already considered in the standard NK literature, and the appropriate response to them (from the point of view of stabilization of inflation and/or real activity) is the same as would be appropriate in the case of that combination of familiar shocks.

Among other things, allowing for credit spreads need not require any reconsideration of the often-noted de-emphasis of measures of the money supply and sources of money demand in standard NK models. ${ }^{70}$ We have shown that it is possible to extend the basic NK model to incorporate time-varying credit frictions, without making any reference to money or introducing a transactions role for money. This can be interpreted as a "cashless" model in which there actually are no transactions balances and no government liabilities that are held other than for their pecuniary returns. But as usual, the model can also be interpreted as one in which money does supply liquidity services and earns a correspondingly lower return than government debt, and in which the central bank implements its interest-rate target by adjusting the supply of money. It remains the case, under this latter interpretation, that

\footnotetext{
${ }^{70}$ Critics of the omission of a fundamental role for monetary aggregates in NK models (e.g., Issing, 2006; Goodhart, 2007) often point to the absence of multiple interest rates and of any role for financial intermediaries as a ground for suspecting the empirical relevance of such models. Goodhart, in particular, proposes that the absence of financial frictions in such models may account for the absence of an essential role for money: "by basing their model on [frictionless financial markets], the Neo-Keynesians are turning their model into an essentially non-monetary model. So it is no surprise that monetary variables are inessential in it" (p. 11).
} 


\section{Credit Frictions and Optimal Monetary Policy}

what matters about monetary policy is the intended reaction function for interest rates, and not the adjustments of the supply of money that are required in order to achieve the interestrate targets, and that, under a plausible calibration of the size of monetary frictions, the existence of such frictions is of negligible quantitative significance for the predicted evolution of aggregate activity and inflation. ${ }^{71}$

Yet while our results suggest that in the case of many types of aggregate disturbances (both disturbances that are ordinarily thought of as "demand" disturbances, and others that are considered "supply" disturbances), the effects of shocks on the evolution of output, inflation and interest rates under a conventional specification of monetary policy are not too greatly changed by the introduction of credit frictions, this is not uniformly the case. One example is the effects of changes in the path of government debt owing to shifts in fiscal policy. While the path of government debt has no effects on inflation, output or interest-rate determination in the basic NK model (if distorting tax rates are assumed not to change, so that the changed path of government borrowing corresponds only to a change in the time path of net lump-sum transfers from the government) - that is, "Ricardian equivalence" obtains - in the presence of credit frictions of the kind modeled here, this is no longer the case (even under the special assumption about tax rates). This suggests that the integration of fiscal variables into models used in central banks for monetary policy analysis may deserve a higher place on the research agenda.

Another important consequence of allowing for credit spreads, of course, is the possibility of considering how a central bank should respond to observed variation in such spreads. It is often argued that widening credit spreads provide a prima facie case for the appropriateness of lowering the central bank's policy rate. The argument commonly given is that when spreads increase, the terms on which it is possible to borrow are tightened, even in the absence of any increase in the policy rate. If it was not desired to tighten monetary conditions, it is therefore necessary to lower the policy rate, to the extent required in order to preserve the original cost

\footnotetext{
${ }^{71}$ Of course, our analysis here does not prove that it is not of value to model the evolution of a suitably defined monetary aggregate. In the model proposed by Woodford (2015), for example, the quantity of "money-like" liabilities issued by private intermediaries is an important state variable, because the amount of funding of this kind determines the amount of assets that such intermediaries will be forced to liquidate in the event that they are unable to roll over their short-term funding, and this in term determines the extent to which asset prices will be depressed in such a crisis. Such a model allows for a type of financial friction that we abstract from here. But even in the model of Woodford (2015), the relevant aggregate is not a traditional monetary aggregate, but rather the quantity of privately issued short-term safe instruments, such as repos or asset-backed commercial paper; and the reason it matters is not because of the ability of such assets to substitute for some uses of government-supplied money, as in traditional monetarist theory, but because of the consequences of the adjustment of the asset side of bank's balance sheets that may be required if the demand for such liabilities suddenly changes.
} 


\section{Credit Frictions and Optimal Monetary Policy}

of borrowing. Authors such as McCulley and Toloui (2008) suggest a one-for-one reduction in the policy rate in response to increases in particular credit spreads.

In our model, it is certainly right that the policy rate is not the only interest rate that matters in assessing the degree to which financial conditions are expansionary. On the other hand, it is not true (except in a rather special limiting case) that only the interest rate faced by borrowers matters, either; so a full offset of the observed increase in credit spreads would generally be a larger interest-rate reduction than is optimal. (A decline in the interest rate received by savers, with no change in the interest rate faced by borrowers, represents a loosening of financial conditions, insofar as saving decisions are also interest-elastic to some extent.) Moreover, the justification of a reduction in the policy rate in response to an increase in credit spreads depends on an expectation that the lower policy rate will be passed through to the interest rates at which intermediaries are willing to lend; if such passthrough is incomplete, this would further reduce the extent to which it is optimal for the policy rate to adjust in response to a change in credit spreads. And even in the case of an exogenous credit spread (so that changes in the policy rate are passed through one-for-one to lending rates), the optimal adjustment of the policy rate to an increase in the credit spread is generally less than the full size of the increase in the spread, and the optimal adjustment is smaller the more persistent the increase in the credit spread is expected to be.

Still less would our model justify the view, which sometimes appears to be assumed in popular discussions of the appropriate response to strains in credit markets, that the persistence of higher-than-average credit spreads means that interest rates have not been cut enough. (This is evidently what is assumed when commentators seek to judge whether policy rates have been cut by the right amount by looking at whether spreads remain unusually large, rather than asking whether borrowing rates are actually high.)

It is true that an increase in spreads is a source of deadweight loss in our model, so that a reduction of spreads to normal levels, if this could be done without changing anything else, would be desirable. But it is not necessarily true that monetary policy can do anything to undo an increase in credit spreads - this is certainly the case in our simplest model, where the credit spread is determined entirely by exogenous factors - and lowering interest rates will instead certainly have collateral effects. Even if monetary policy can influence spreads, it is not obvious that this will be beneficial. For example, in the case that spreads are endogenous because they depend on the volume of bank lending, monetary policy can lower spreads to the extent that it can lead to a contraction of bank lending; but that would not necessarily increase efficiency, even if a reduction in the spread associated with a given

volume of lending would enhance efficiency (by allowing more lending). A better principle 


\section{Credit Frictions and Optimal Monetary Policy}

may well be to use monetary policy to mitigate the distortions caused by an increase in credit spreads, to the extent that this is possible, rather than seeking to use policy to influence the level of spreads as such.

A policy rule that directs the central bank to adjust its policy rate as necessary to satisfy a "flexible inflation target" will automatically require the central bank to adjust the policy rate to take account of changes in the severity of financial frictions, without any need to modify the target criterion that the bank aims to conform with. In our model of the transmission mechanism, it is the level and expected future path of the average interest rate, rather than the policy rate, that determines whether the evolution of output and inflation should satisfy the target criterion. When the relation between this average rate and the policy rate changes owing to a change in the size of interest-rate spreads, the level and expected path of the policy rate required for conformity with the target criterion will obviously change. The required policy rate will similarly change as a result of the effects of changing credit spreads on the "IS relation" and aggregate-supply relation discussed in section 2.

When the policy rule is specified in terms of a target criterion, it is not obvious that the target criterion that should be chosen depends much on the importance of credit frictions. In a particularly simple case of a model with time-varying credit frictions, we have shown that the optimal target criterion remains exactly the same as in the basic NK model: the central bank should seek to stabilize a weighted average of the inflation rate and the rate of growth of the output gap (or alternatively, to stabilize an output-gap-adjusted price level). Under more general assumptions, this exact equivalence does not obtain. Nonetheless, the target criterion that would be optimal in the case of the model without credit frictions seems still to provide a fairly good approximation to optimal policy in the model with credit frictions, when these are parameterized to be of an empirically realistic magnitude. Because of the advantages (for example, from the point of view of communication) of commitment to a simple criterion, and because of the degree to which any attempt to refine the rule would depend on fine details of the specification of the financial frictions, about which there is likely to be uncertainty in any event, our results suggest that maintaining a commitment to the same target criterion as would be optimal in the absence of financial frictions is not a bad idea.

This suggests that a central bank should not change its target criterion - what it regards as acceptable paths of inflation and real activity - at all in times of financial stress, but instead should take account of those developments only as a result of the changes that they imply for the links between the policy rate and the evolution of the target variables, and hence for the path of the policy rate that is required to satisfy the target criterion. As we 


\section{Credit Frictions and Optimal Monetary Policy}

have shown, this will generally mean lowering the policy rate in response to a disturbance that increases credit spreads; but the exact size of the appropriate response will involve balancing each of several economic effects of the change in the anticipated path of credit spreads.

The present analysis represents merely a first attempt at exploration of what is obviously a very rich terrain. Among other obvious limitations of the present analysis, we have allowed for only one, very simple form of possible endogeneity of credit spreads. ${ }^{72}$ Further analysis will be necessary before we can judge how robust the conclusions of the present analysis are to variations in this aspect of our model of the monetary transmission mechanism.

\section{References}

Araújo, Aloísio, Susan Schommer, and Michael Woodford. 2015. "Conventional and Unconventional Monetary Policy with Endogenous Collateral Constraints." American Economic Journal: Macroeconomics, 7: 1-43.

Benigno, Pierpaolo, and Michael Woodford. 2005. "Inflation Stabilization and Welfare: The Case of a Distorted Steady State." Journal of the European Economic Association, 3(6): 1185-1236.

Benigno, Pierpaolo, and Michael Woodford. 2012. "Linear-Quadratic Approximation of Optimal Policy Problems." Journal of Economic Theory, 147(1): 1-42.

Bernanke, Ben S., Mark Gertler, and Simon Gilchrist. 1999. "The Financial Accelerator in a Quantitative Business Cycle Framework." In Handbook of Macroeconomics. Vol. 1C, ed. John B. Taylor and Michael Woodford, Chapter 21, 1341-93. Amsterdam:North-Holland.

Brunnermeier, Markus K., Thomas M. Eisenbach, and Yuliy Sannikov. 2012. "Macroeconomics with Financial Frictions: A Survey." NBER Working Paper No. 18102.

\footnotetext{
${ }^{72}$ For example, we abstract from the possible dependence of loan rates on borrowers' net worth stressed in the "financial accelerator" model of Bernanke, Gertler and Gilchrist (1999); from the stickiness of loan rates stressed by Hulsewig, Mayer and Wollmershauser (2009), Teranishi (2008), Sudo and Teranishi (2008), and Gerali, Neri and Signoretti (2008); and from endogenous variation in the extent to which collateral constraints on borrowers bind, as emphasized by both Araújo, Schommer and Woodford (2015) and Woodford (2015).
} 
Calvo, Guillermo. 1983. "Staggered Prices in a Utility-Maximizing Framework." Journal of Monetary Economics, 12.

Christiano, Lawrence J., Cosmin Ilut, Roberto Motto, and Massimo Rostagno. 2008. "Monetary Policy and Stock-Market Boom-Bust Cycles." ECB Working Paper No. 955.

Christiano, Lawrence J., Roberto Motto, and Massimo Rostagno. 2003. "The Great Depression and the Friedman-Schwartz Hypothesis." Journal of Money, Credit and Banking, 35: 1119-1198.

Christiano, Lawrence J., Roberto Motto, and Massimo Rostagno. 2010. "Financial Factors in Business Cycles." ECB Working Paper No. 1192.

Clarida, Richard, Jordi Gali, and Mark Gertler. 1999. "The Science of Monetary Policy: A New Keynesian Perspective." Journal of Economic Literature, 37: 1661-1707.

Cúrdia, Vasco. 2008. "Optimal Monetary Policy under Sudden Stops." FRBNY Staff Report No. 323.

Cúrdia, Vasco, and Michael Woodford. 2010. "Credit Spreads and Monetary Policy." Journal of Money Credit and Banking, 42(s1): 3-35.

Cúrdia, Vasco, and Michael Woodford. 2011. "The Central-Bank Balance Sheet as an Instrument of Monetary Policy." Journal of Monetary Economics, 58(1): 54-79.

De Fiore, Fiorella, and Oreste Tristani. 2011. "Credit and the Natural Rate of Interest." Journal of Money, Credit and Banking, 43(2-3): 407-440.

Den Haan, Wouter, Steven W. Sumner, and Guy Yamashiro. 2010. "Bank Loan Components and the Time-Varying Effects of Monetary Policy Shocks." Economica, 78: 593-617.

Evans, George W., and Seppo Honkapohja. 2006. "Monetary Policy, Expectations and Commitment." Scandinavian Journal of Economics, 108: 15-38.

Faia, Ester, and Tommaso Monacelli. 2007. "Optimal Interest-Rate Rules, Asset Prices, and Credit Frictions." Journal of Economic Dynamics and Control, 31: 3228-3254.

Fuerst, Timothy S. 1992. "Liquidity, Loanable Funds, and Real Activity." Journal of Monetary Economics, 29: 3-24. 


\section{Credit Frictions and Optimal Monetary Policy}

Gerali, Andrea, Stefano Neri, and Federico M. Signoretti. 2008. "Credit and Banking in a DSGE Model." Unpublished.

Gertler, Mark, and Nobuhiro Kiyotaki. 2010. "Financial Intermediation and Credit Policy in Business Cycle Analysis." Unpublished.

Gertler, Mark, and Peter Karadi. 2011. "A Model of Unconventional Monetary Policy." Journal of Monetary Economics, 58: 17-34.

Gertler, Mark, Simon Gilchrist, and Fabio Natalucci. 2007. "External Constraints on Monetary Policy and the Financial Accelerator." Journal of Money, Credit and Banking, 39: 295-330.

Goodfriend, Marvin. 2005. "Narrow Money, Broad Money, and the Transmission of Monetary Policy." Board of Governors of the Federal Reserve System.

Goodfriend, Marvin, and Bennett T. McCallum. 2007. "Banking and Interest Rates in Monetary Policy Analysis: A Quantitative Exploration." Journal of Monetary Economics, 54: 1480-1507.

Goodhart, Charles A.E. 2007. "Whatever Became of the Monetary Aggregates?" LSE Financial Markets Group Special Paper 172.

Hulsewig, Oliver, Eric Mayer, and Timo Wollmershauser. 2009. "Bank Behavior, Incomplete Interest-Rate Pass-Through, and the Cost Channel of Monetary Policy Transmission." Economic Modelling, 26(6): 1310-1327.

Iacoviello, Matteo. 2005. "Housing Prices, Borrowing Constraints, and Monetary Policy in the Business Cycle." American Economic Review, 95: 739-764.

Issing, Otmar. 2006. "The ECB's Monetary Policy Strategy: Why Did We Choose a Two Pillar Approach?" Speech at the Fourth ECB Central Banking Conference "The Role of Money: Money and Monetary Policy in the Twenty-First Century".

Jermann, Urban, and Vincenzo Quadrini. 2012. "The Macroeconomic Effects of Financial Shocks." American Economic Review, 102(1): 238-71.

Kiyotaki, Nobuhiro, and John Moore. 2012. "Liquidity, Business Cycles, and Monetary Policy." NBER Working Paper No. 17934. 


\section{Credit Frictions and Optimal Monetary Policy}

Lagos, Ricardo, and Randall Wright. 2005. "A Unified Framework for Monetary Theory and Policy Analysis." Journal of Political Economy, 113: 463-484.

Lown, Cara S., and Donald P. Morgan. 2002. "Credit Effects in the Monetary Mechanism." Federal Reserve Bank of New York Economic Policy Review, 8(1): 217-235.

Lucas, Robert E., Jr. 1990. "Liquidity and Interest Rates." Journal of Economic Theory, 50: $237-264$.

Lucas, Robert E., Jr., and Nancy Stokey. 1987. "Money and Interest in a Cash-inAdvance Economy." Econometrica, 55: 491-513.

McCulley, Paul, and Ramin Toloui. 2008. "Chasing the Neutral Rate Down: Financial Conditions, Monetary Policy, and the Taylor Rule." PIMCO Global Central Bank Focus February 20.

Meh, Césaire, and Kevin Moran. 2010. "The Role of Bank Capital in the Propagation of Shocks." Journal of Economic Dynamics and Control, 34(3): 555-576.

Mehra, Rajnish, Facundo Piguillem, and Edward C. Prescott. 2008. "Intermediated Quantities and Returns." Federal Reserve Bank of Minneapolis Staff Report No. 405.

Meyer, Laurence H., and Brian P. Sack. 2008. "Updated Monetary Policy Rules: Why Don't They Explain Recent Monetary Policy?" Monetary Policy Insights. Macroeconomic Advisors, March 7.

Preston, Bruce. 2008. "Adaptive Learning and the Use of Forecasts in Monetary Policy." Journal of Economic Dynamics and Control, 32(11): 3661-3681.

Rotemberg, Julio J., and Michael Woodford. 1997. "An Optimization-Based Econometric Framework for the Evaluation of Monetary Policy." NBER Macroeconomics Annual, 12: $297-346$.

Smets, Frank R., and Raf Wouters. 2003. "An Estimated Dynamic Stochastic General Equilibrium Model of the Euro Area." Journal of the European Economics Association, 5: $1123-1175$.

Smets, Frank R., and Raf Wouters. 2007. "Shocks and Frictions in US Business Cycles: A Bayesian DSGE Approach." American Economic Review, 97: 586-606. 


\section{Credit Frictions and Optimal Monetary Policy}

Sudo, Nao, and Yuki Teranishi. 2008. "Optimal Monetary Policy under Heterogeneous Banks." Unpublished, Bank of Japan.

Taylor, John B. 2008. "Monetary Policy and the State of the Economy." Testimony before the Committee on Financial Services, U.S. House of Representatives, February 26.

Teranishi, Yuki. 2008. "Optimal Monetary Policy under Staggered Loan Contracts." Unpublished, Columbia University.

Woodford, Michael. 2003. Interest and Prices: Foundations of a Theory of Monetary Policy. Princeton:Princeton University Press.

Woodford, Michael. 2015. "Quantitative Easing and Financial Stability." Unpublished, Columbia University. 


\section{Credit Frictions and Optimal Monetary Policy}

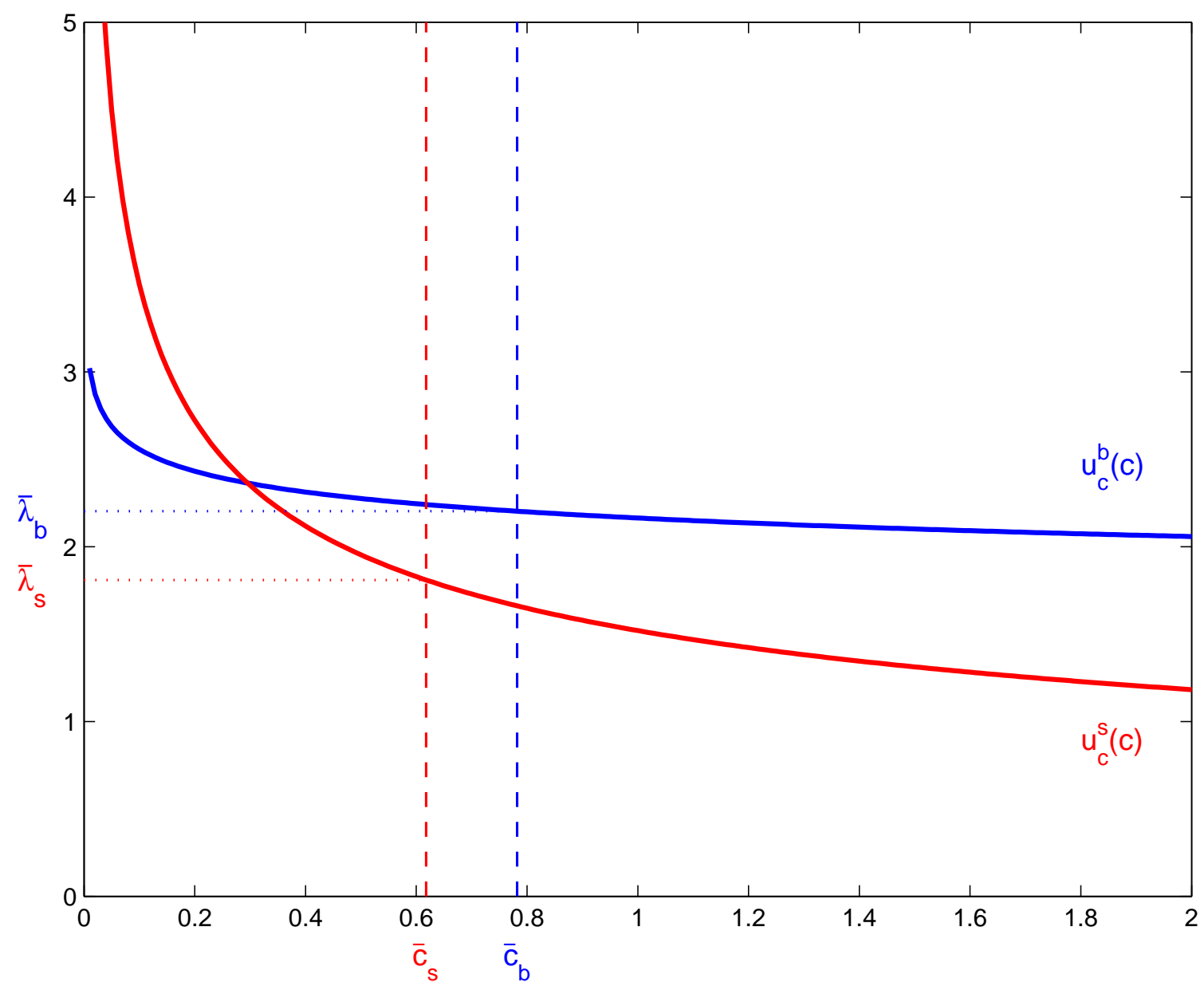

Figure 1: Marginal utilities of consumption for households of the two types. The values $\bar{c}^{s}$ and $\bar{c}^{b}$ indicate steady-state consumption levels of the two types, and $\bar{\lambda}^{s}$ and $\bar{\lambda}^{b}$ their corresponding steady-state marginal utilities. 


\section{Credit Frictions and Optimal Monetary Policy}
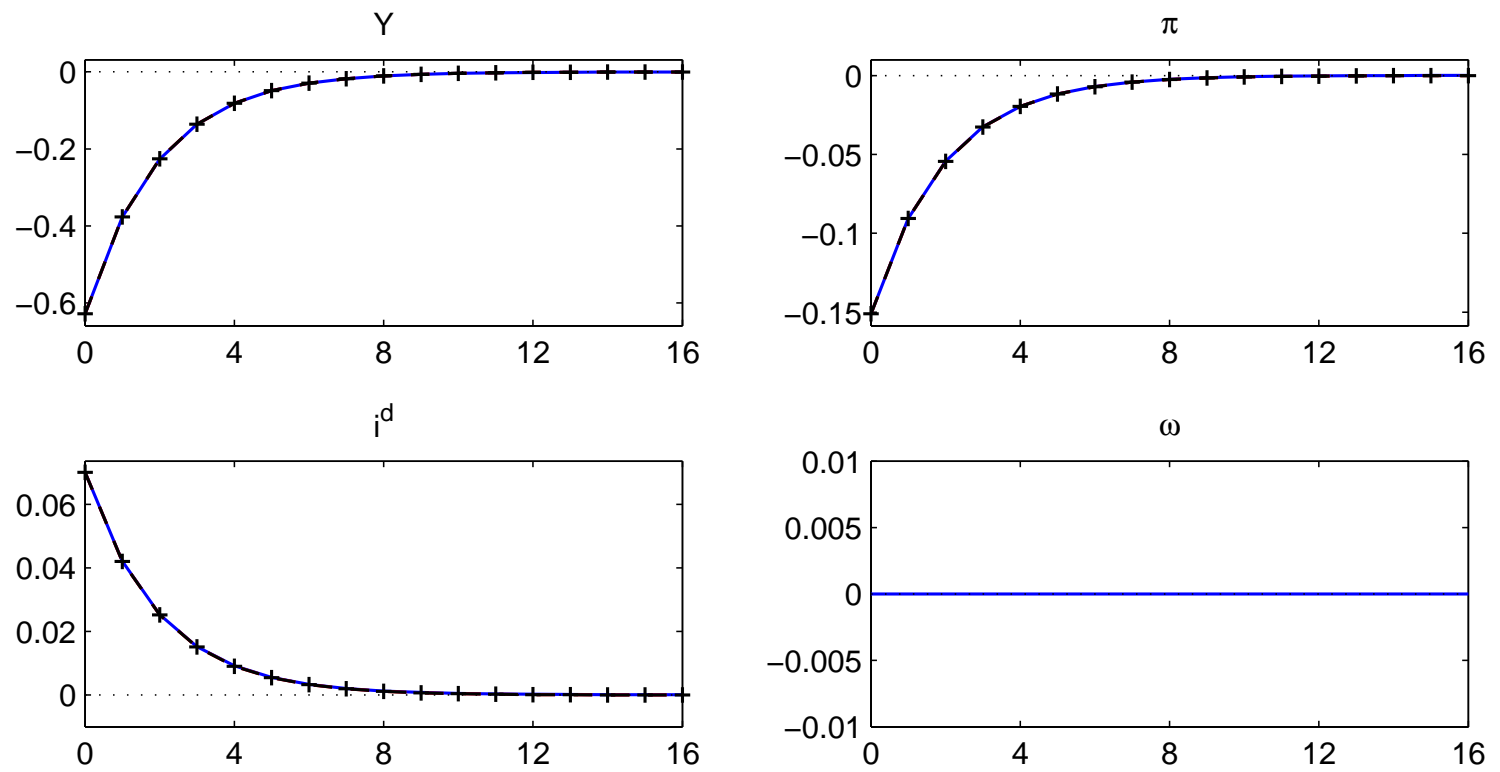

b
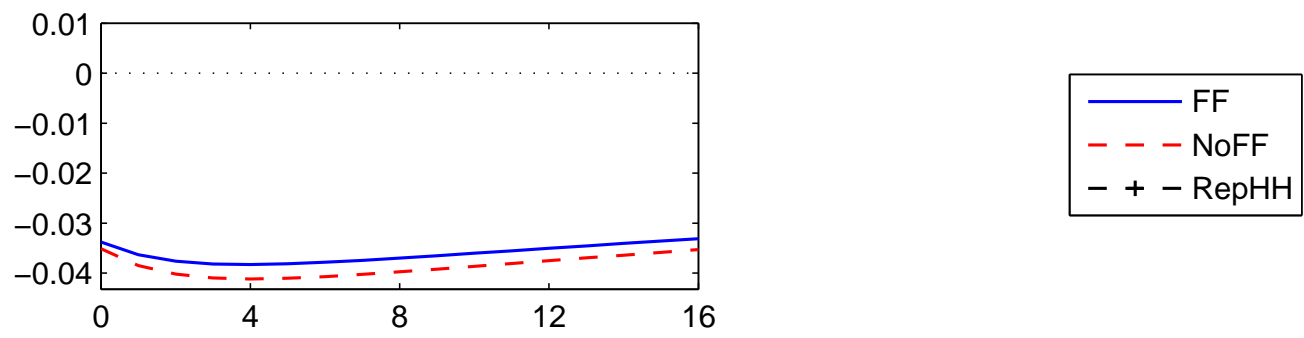

Figure 2: Impulse responses to a 1 percent (annualized) shock to $\epsilon_{t}^{m}$, in three different models with a linear intermediation technology. 


\section{Credit Frictions and Optimal Monetary Policy}
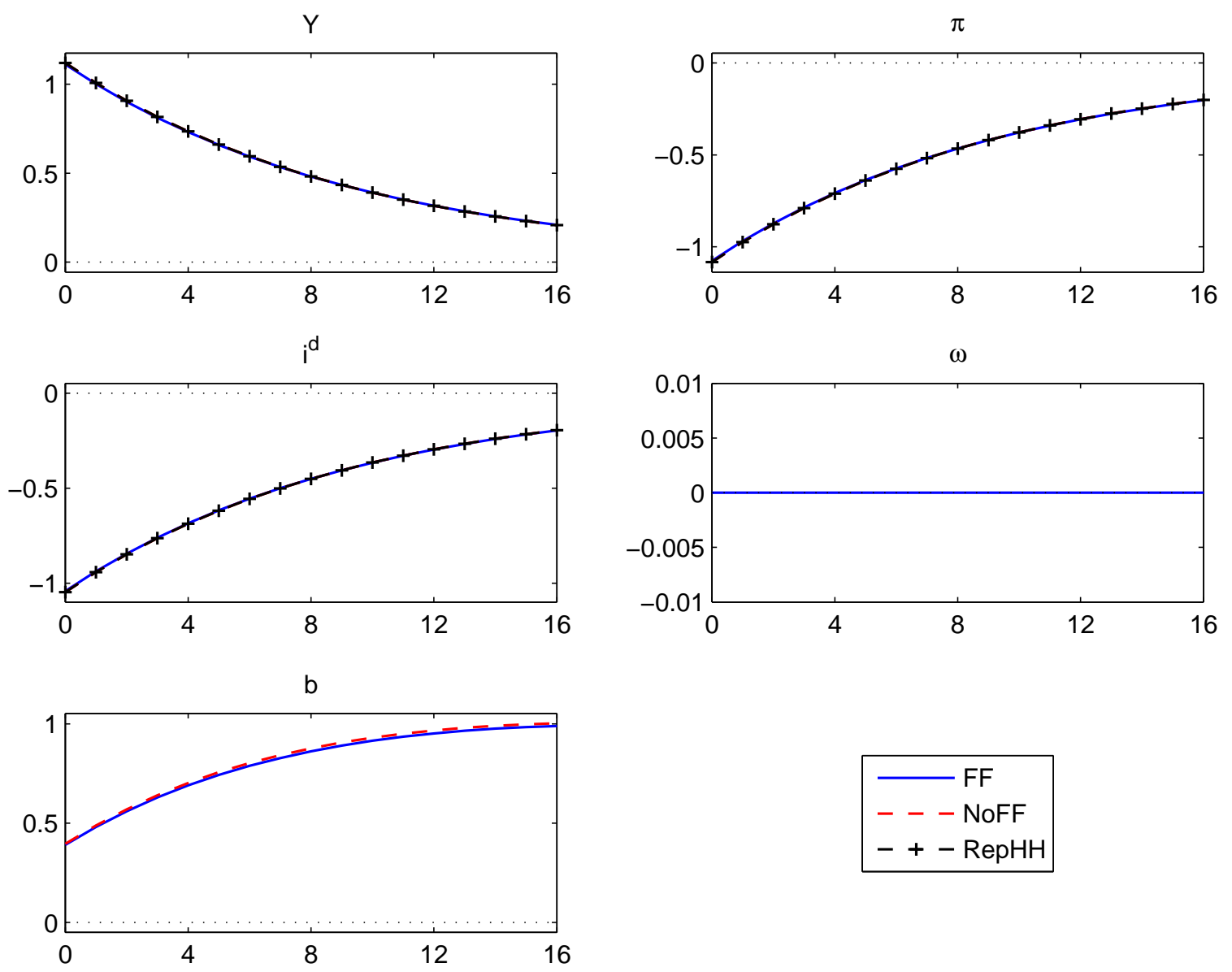

Figure 3: Impulse responses to a 1 percent shock to $Z_{t}$, in three different models with a linear intermediation technology. 


\section{Credit Frictions and Optimal Monetary Policy}
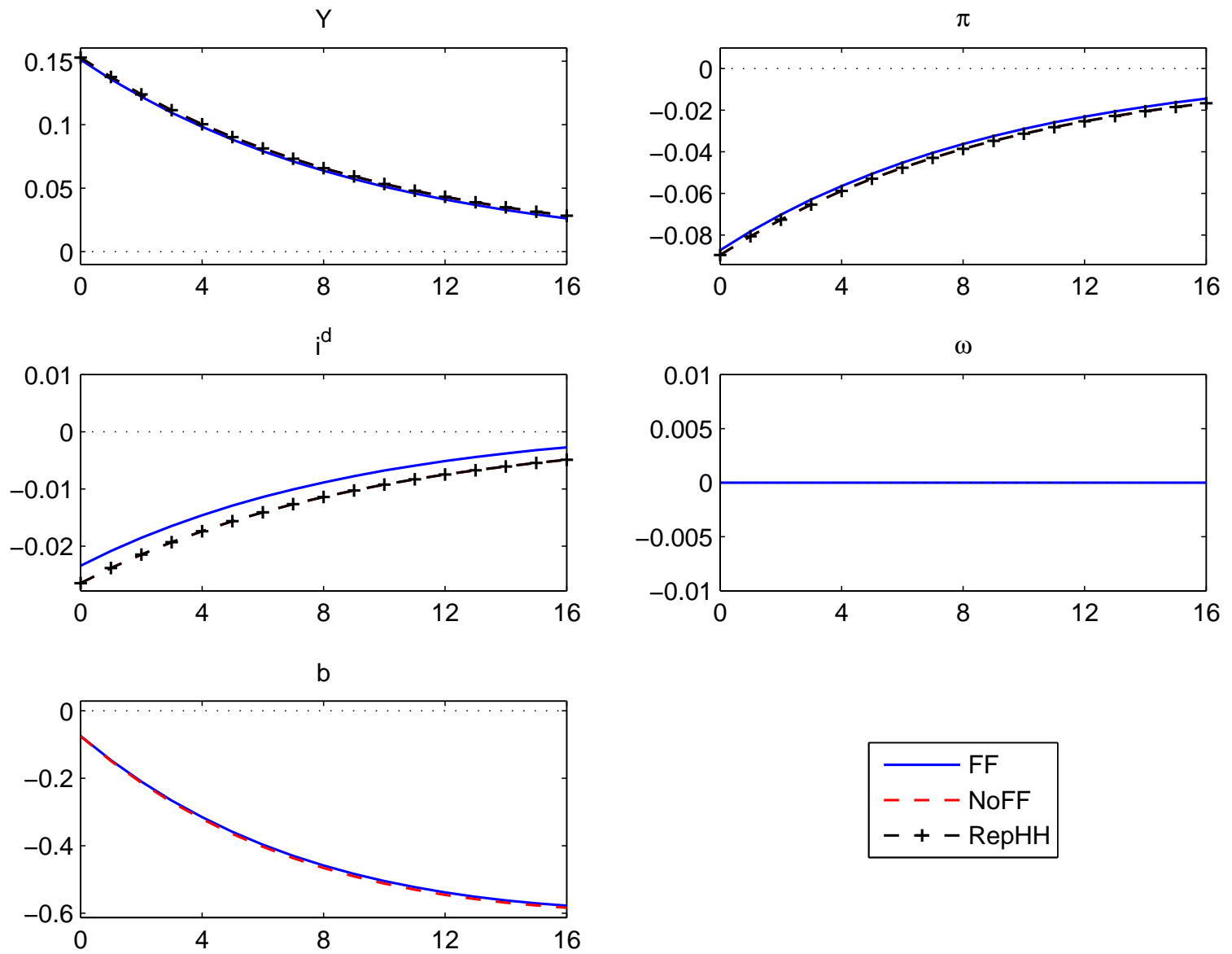

Figure 4: Impulse responses to a shock to $G_{t}$ equal to 1 percent of steady-state output, in three different models with a linear intermediation technology. 


\section{Credit Frictions and Optimal Monetary Policy}
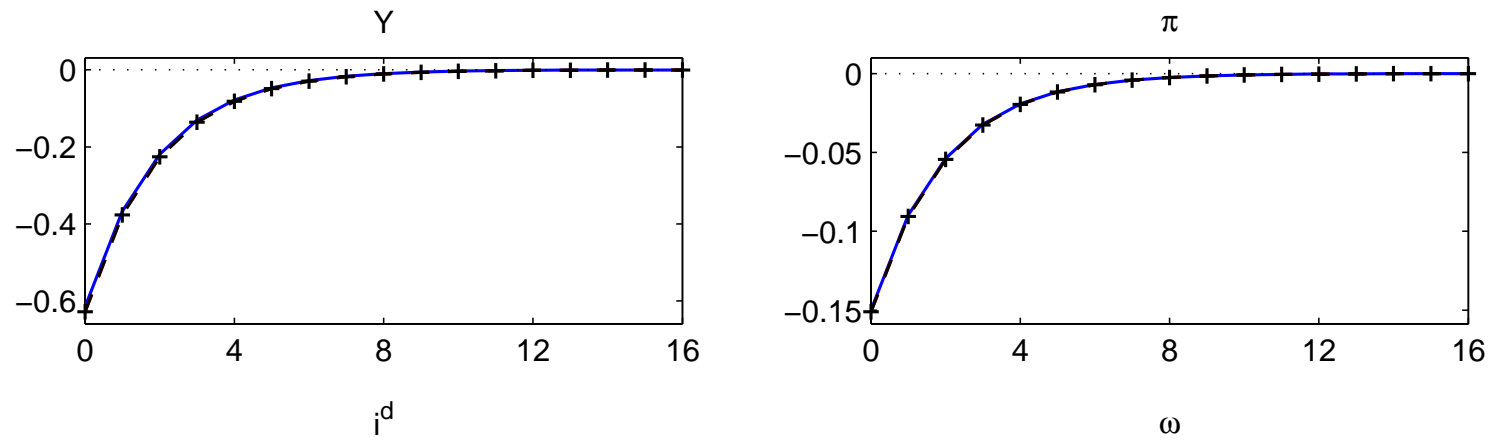

$\omega$
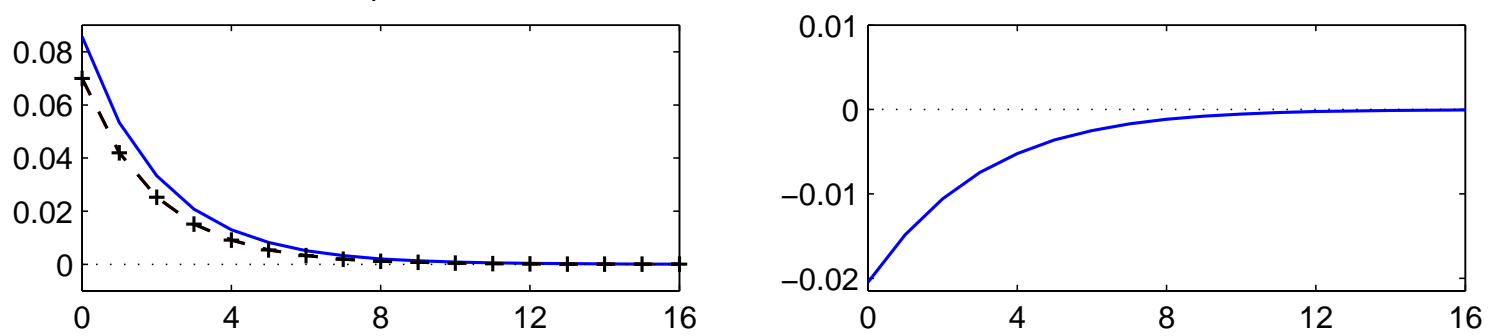

b
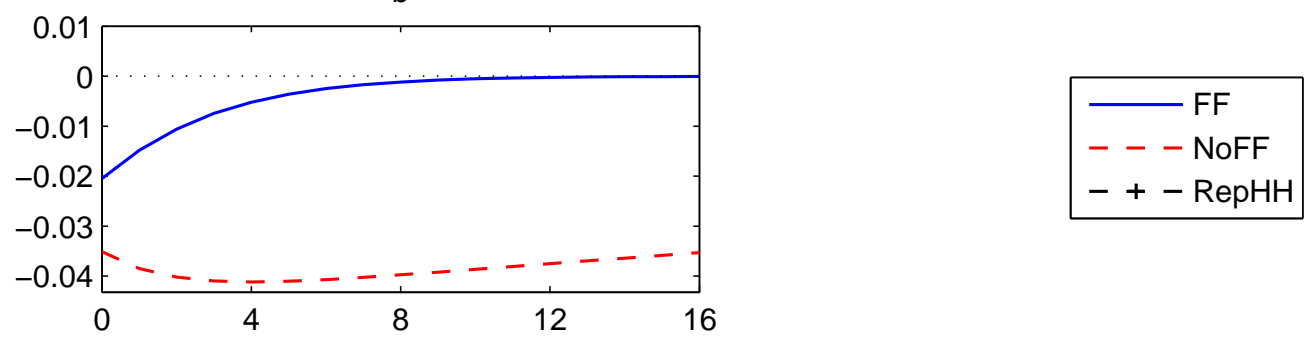

Figure 5: Impulse responses to a 1 percent (annualized) shock to $\epsilon_{t}^{m}$, in three different models with a convex intermediation technology. 


\section{Credit Frictions and Optimal Monetary Policy}
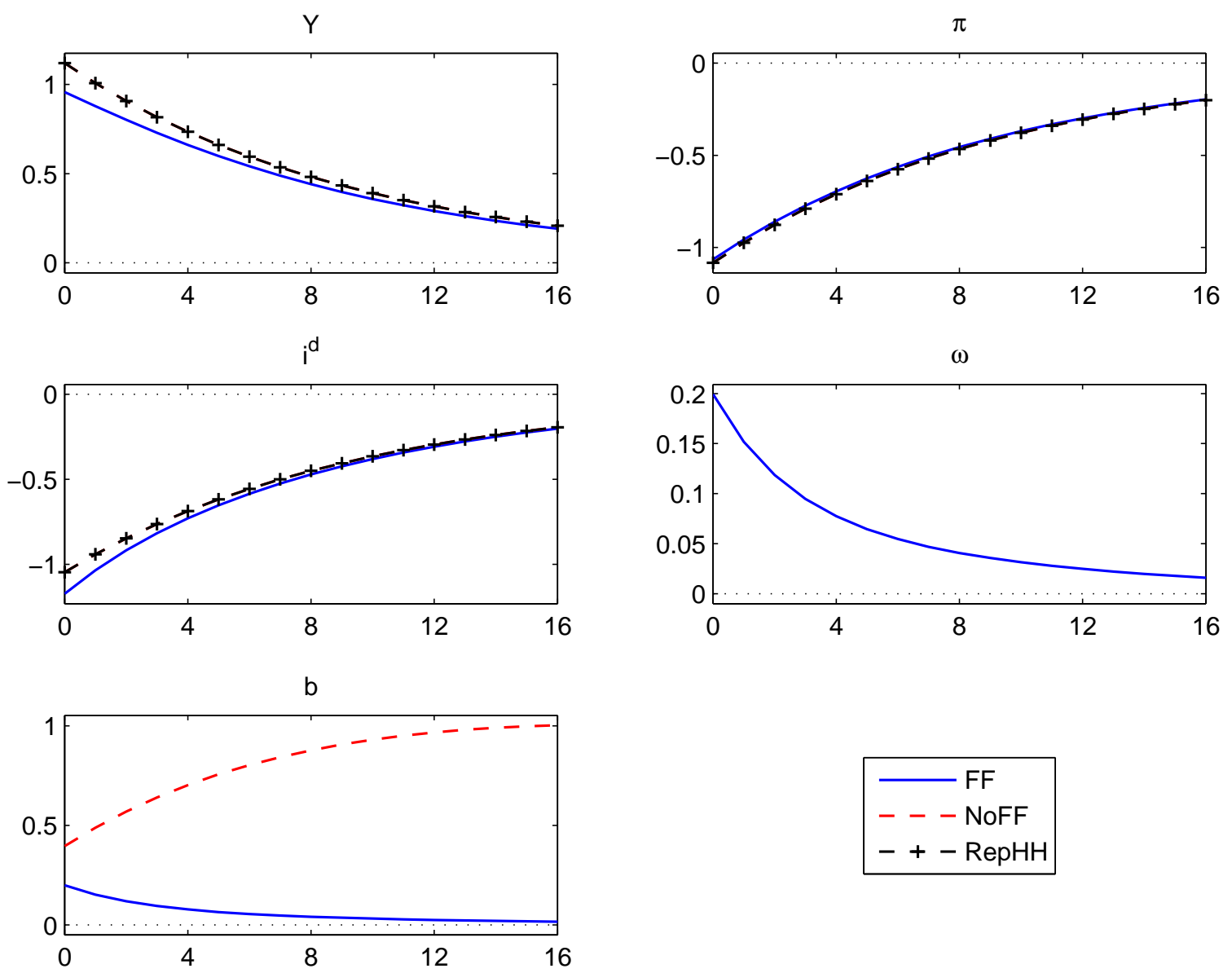

Figure 6: Impulse responses to a 1 percent shock to $Z_{t}$, in three different models with a convex intermediation technology. 


\section{Credit Frictions and Optimal Monetary Policy}
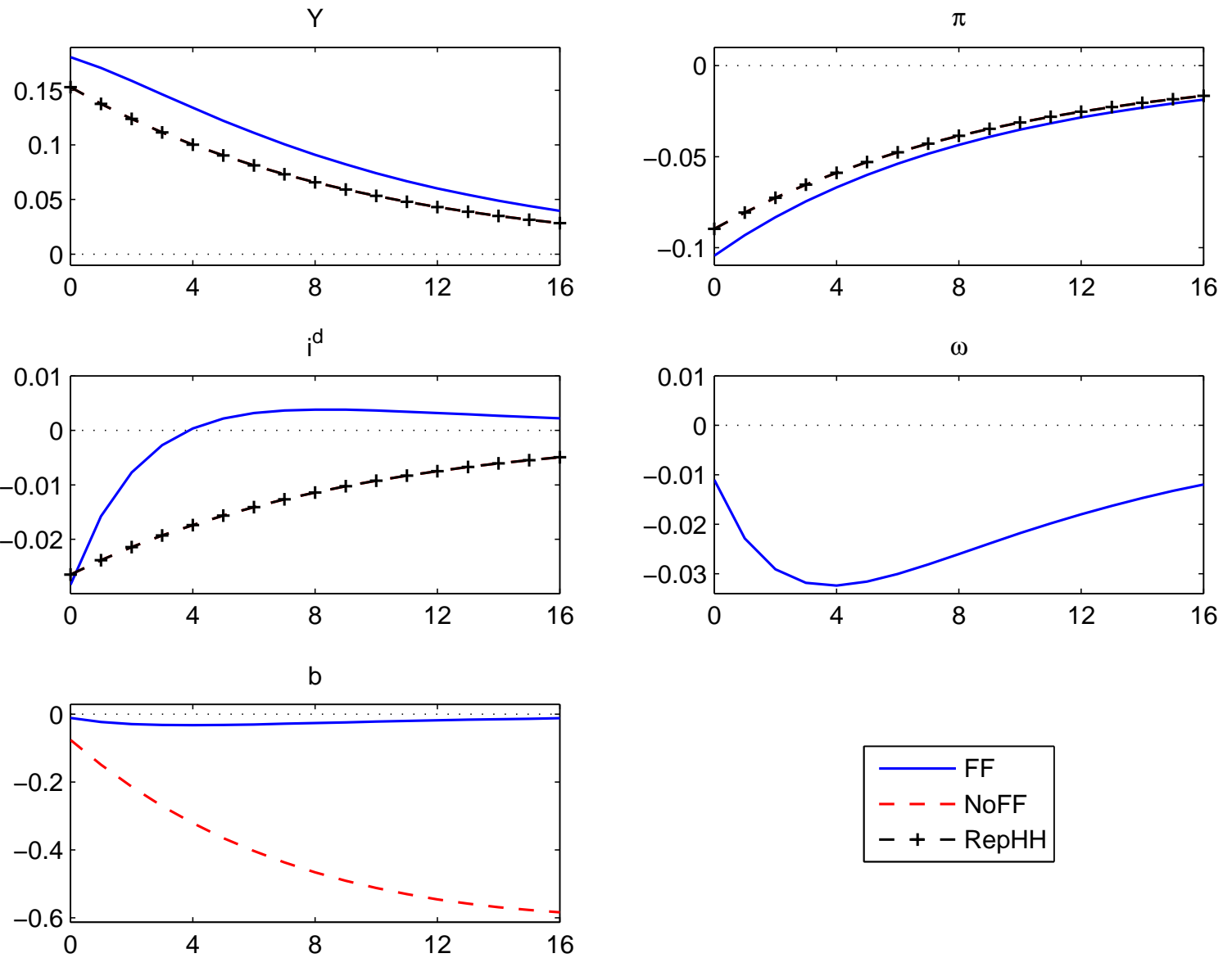

Figure 7: Impulse responses to a shock to $G_{t}$ equal to 1 percent of steady-state output, in three different models with a convex intermediation technology. 


\section{Credit Frictions and Optimal Monetary Policy}
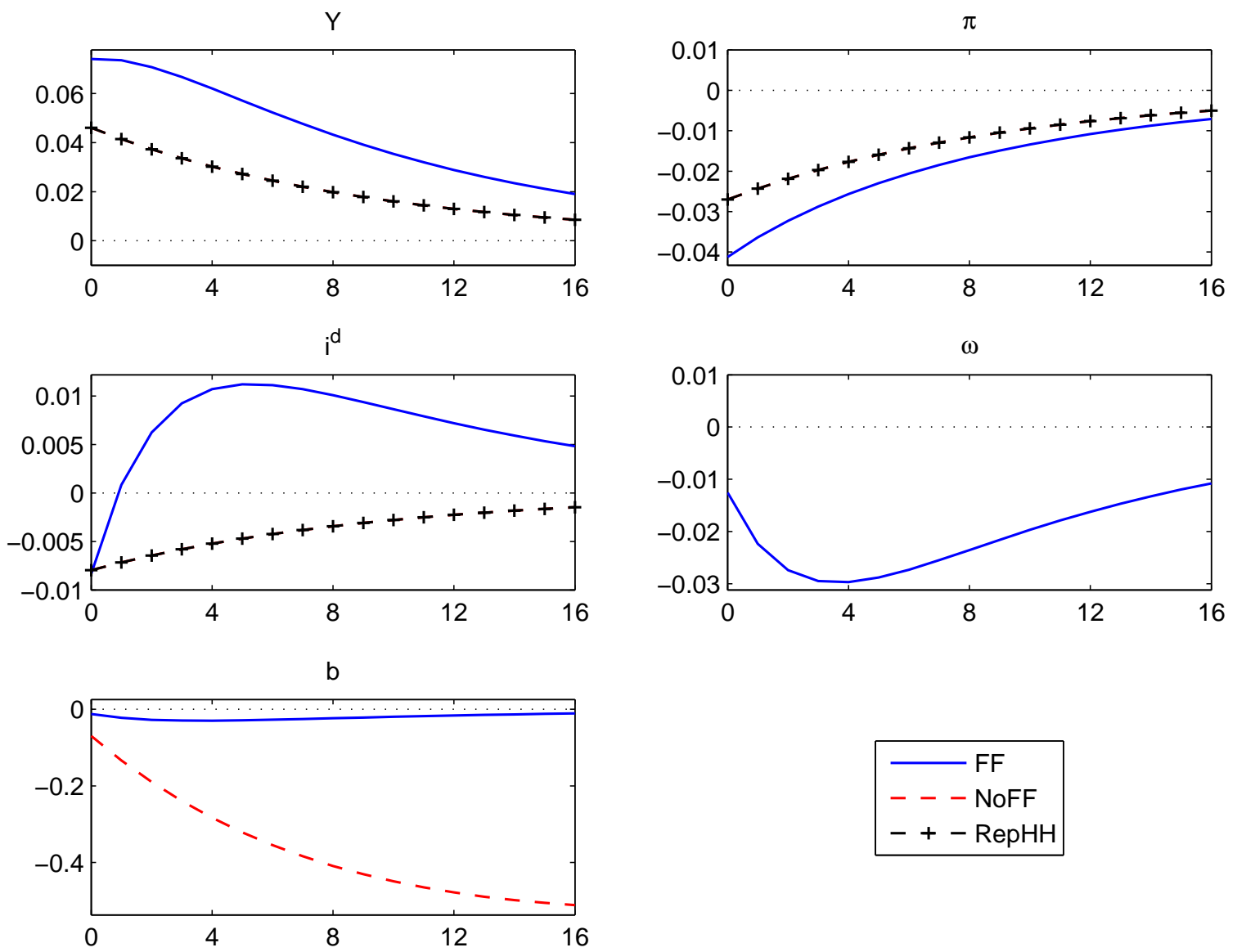

Figure 8: Impulse responses to a 1 percent shock to type $s$ expenditure, in three different models with a convex intermediation technology. 


\section{Credit Frictions and Optimal Monetary Policy}
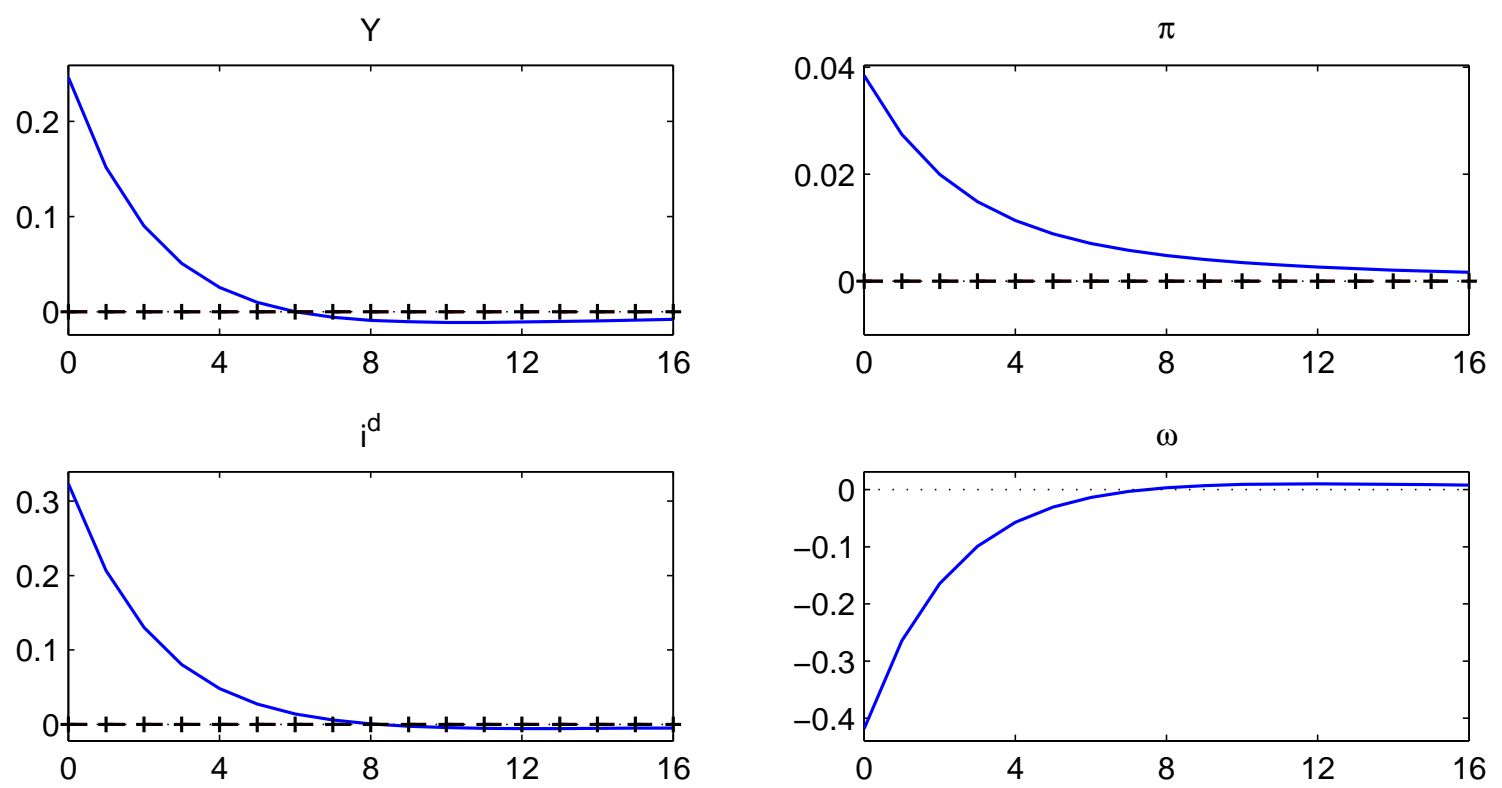

b
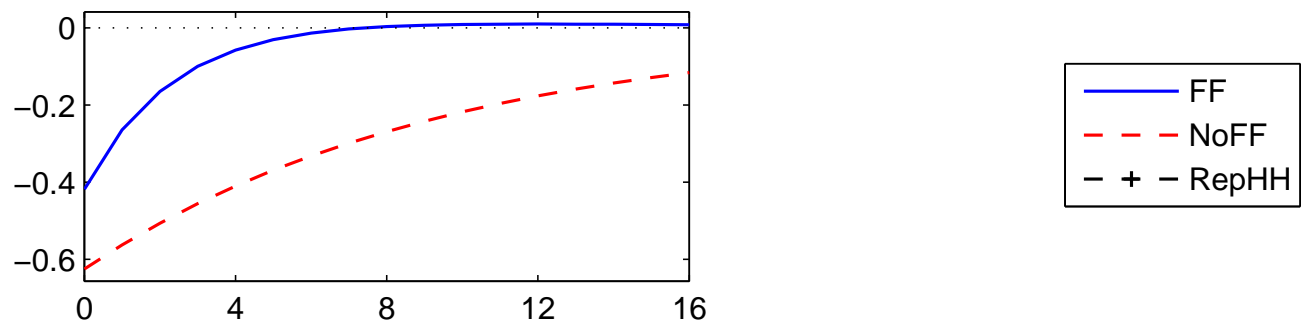

Figure 9: Impulse responses to a shock to $b_{t}^{g}$ equal to 1 percent of steady-state output, in three different models with a convex intermediation technology. 


\section{Credit Frictions and Optimal Monetary Policy}
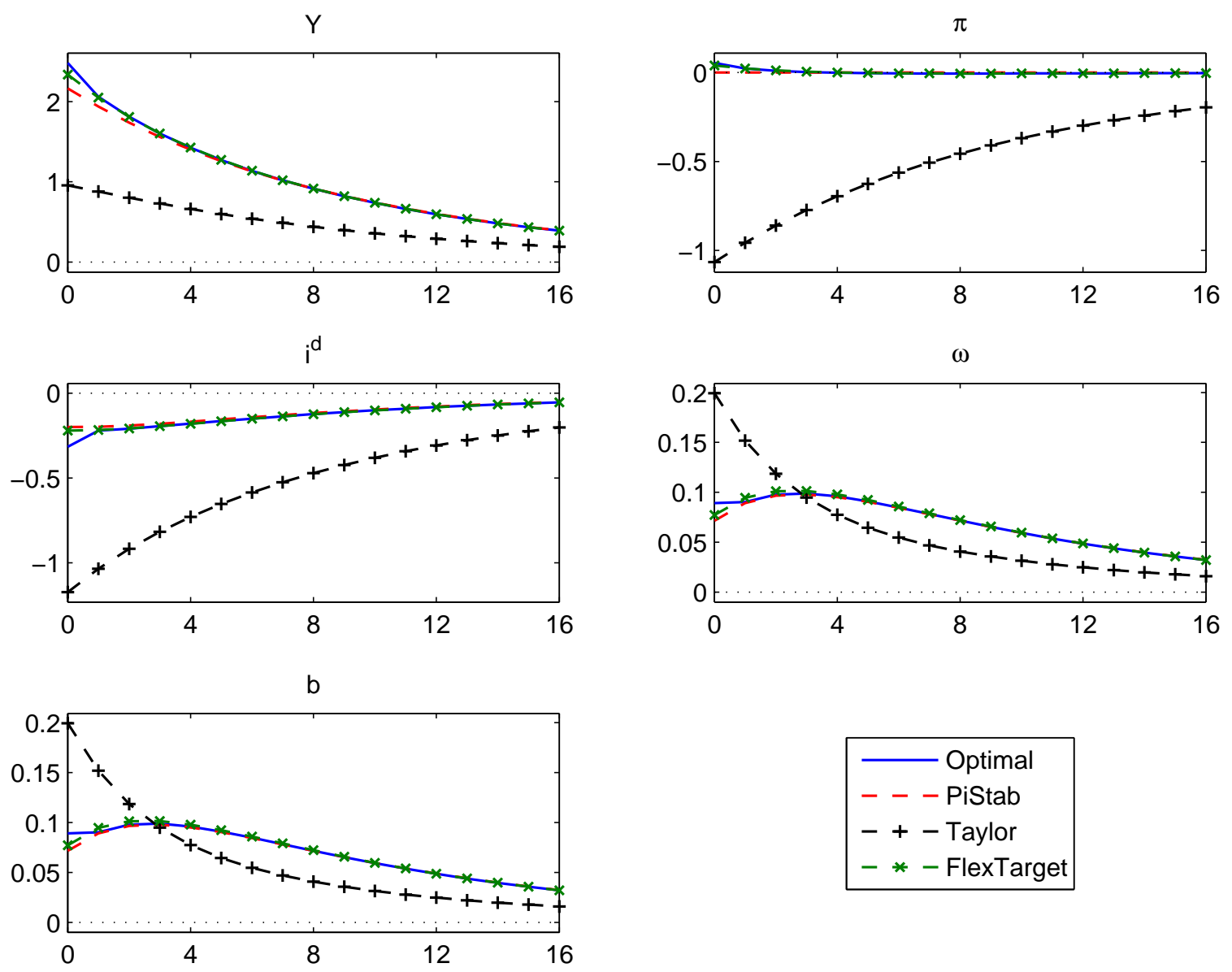

Figure 10: Impulse responses to a 1 percent shock to $Z_{t}$, under four alternative monetary policies. 


\section{Credit Frictions and Optimal Monetary Policy}
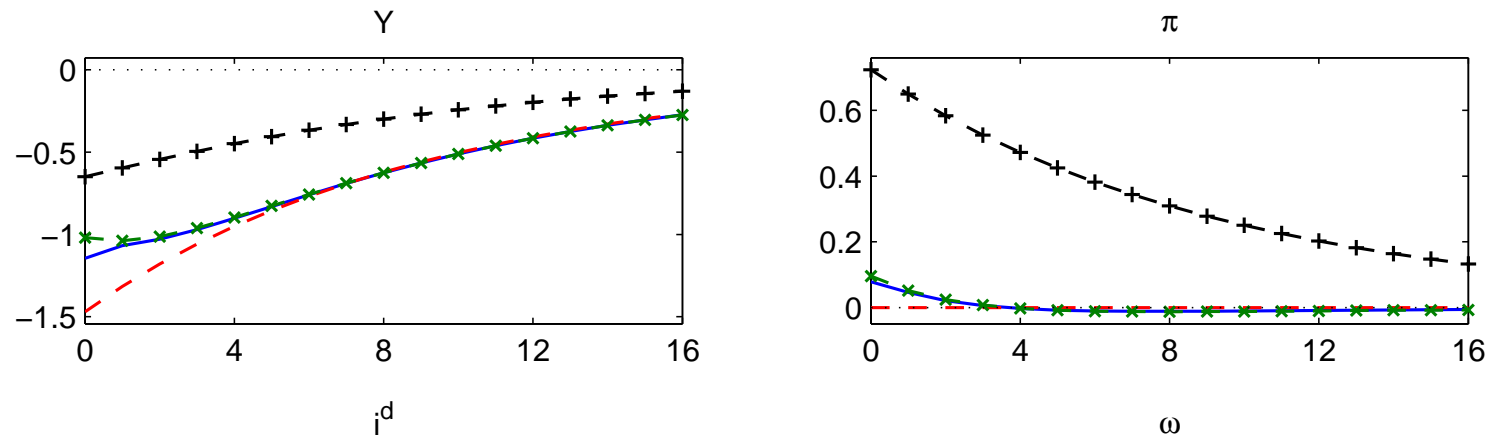

$\omega$
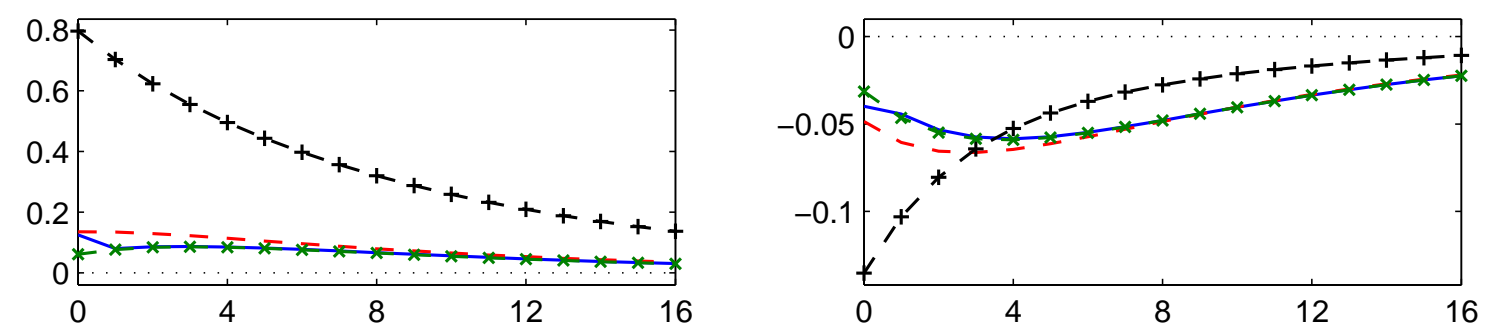

b

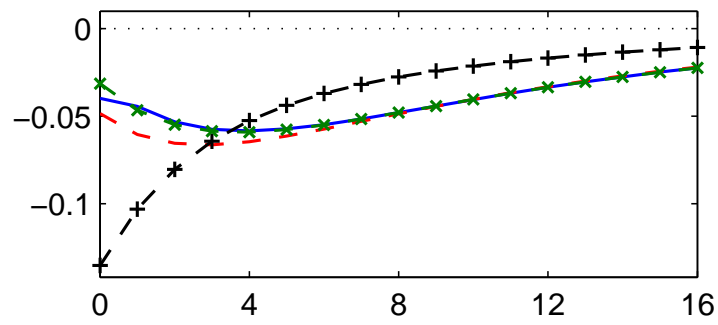

$$
\begin{aligned}
& \text { - Optimal } \\
& -\ldots-\text { PiStab } \\
& -+- \text { Taylor } \\
& -*-\text { FlexTarget }
\end{aligned}
$$

Figure 11: Impulse responses to a 1 percent shock to $\mu_{t}^{w}$, under four alternative monetary policies. 


\section{Credit Frictions and Optimal Monetary Policy}

Y
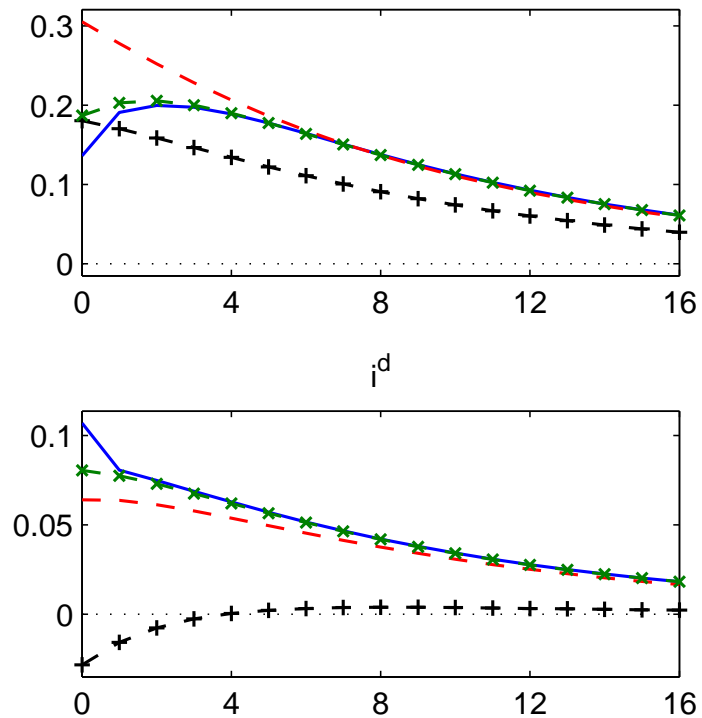

b

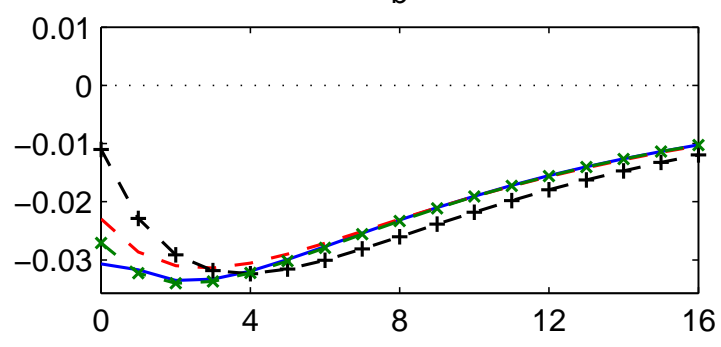

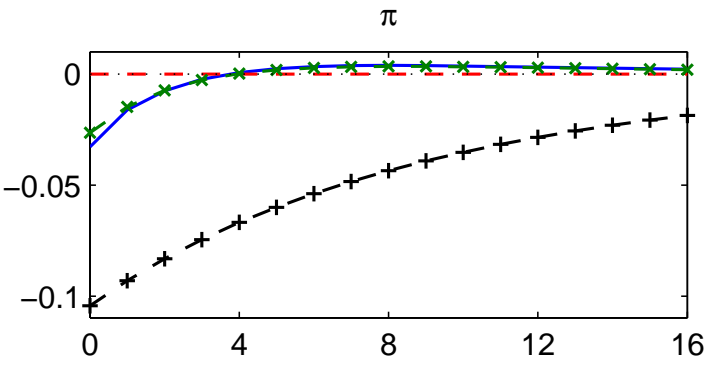

$\omega$

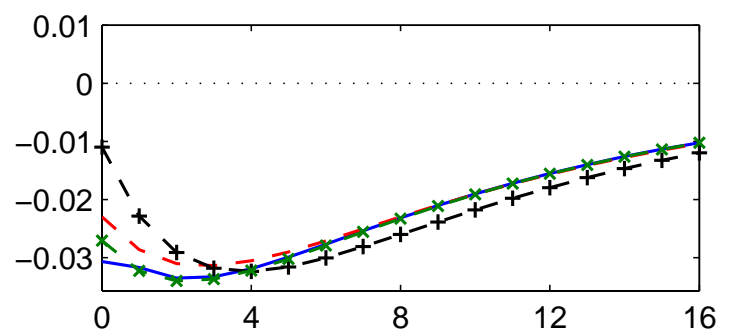

Figure 12: Impulse responses to a shock to $G_{t}$ equal to 1 percent of steady-state output, under four alternative monetary policies. 


\section{Credit Frictions and Optimal Monetary Policy}
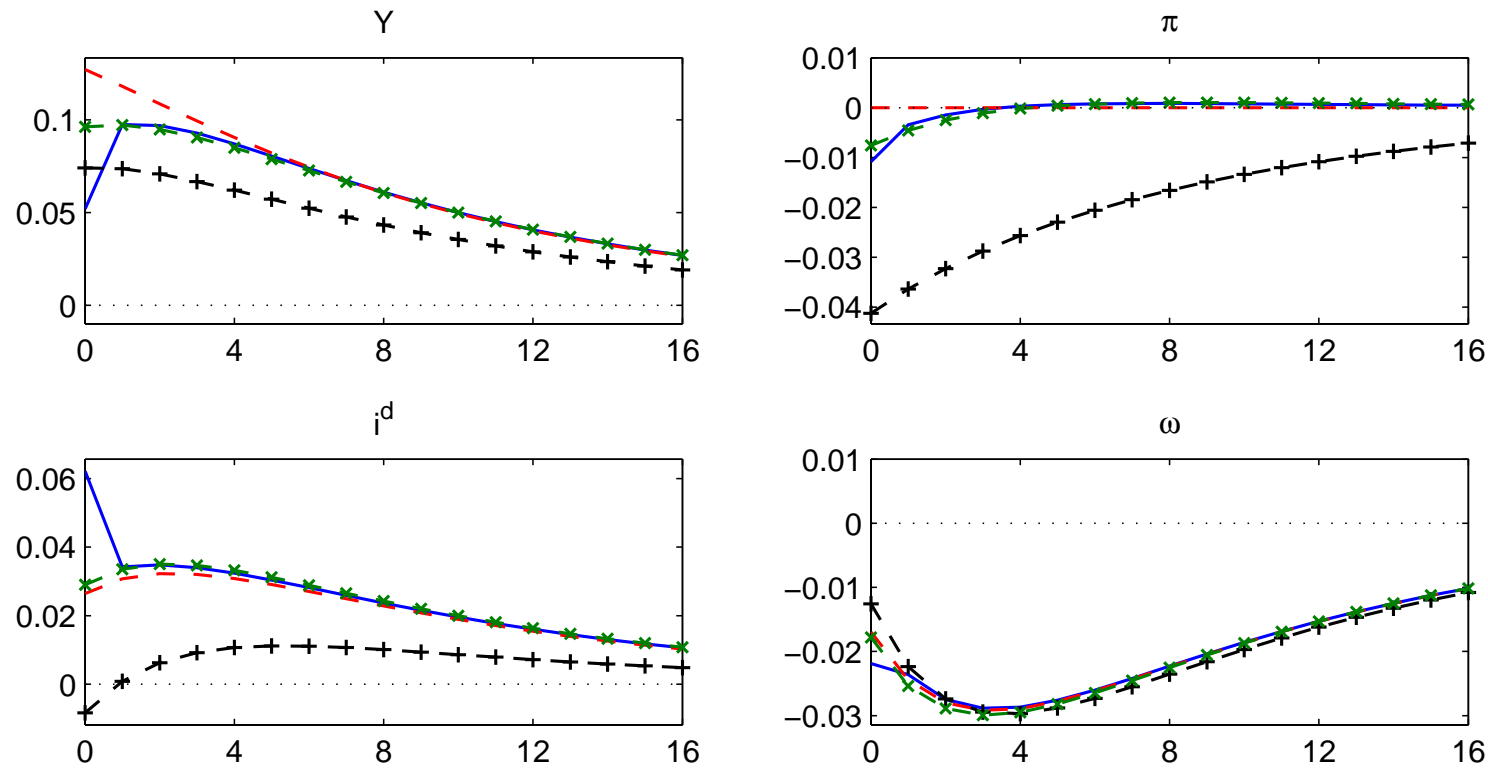

b

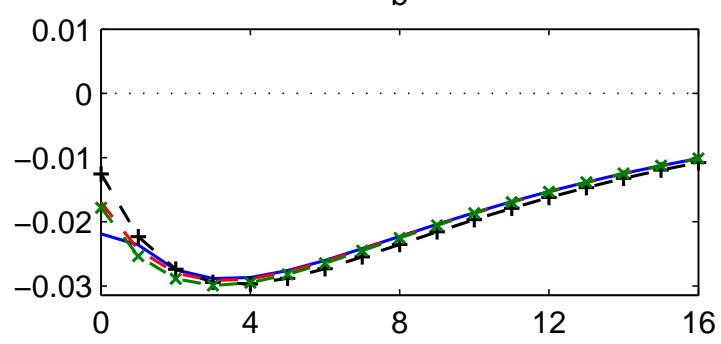

$$
\begin{aligned}
& - \text { Optimal } \\
& --- \text { PiStab } \\
& -+- \text { Taylor } \\
& -*-\text { FlexTarget }
\end{aligned}
$$

Figure 13: Impulse responses to a 1 percent shock to type $s$ expenditure, under four alternative monetary policies. 


\section{Credit Frictions and Optimal Monetary Policy}
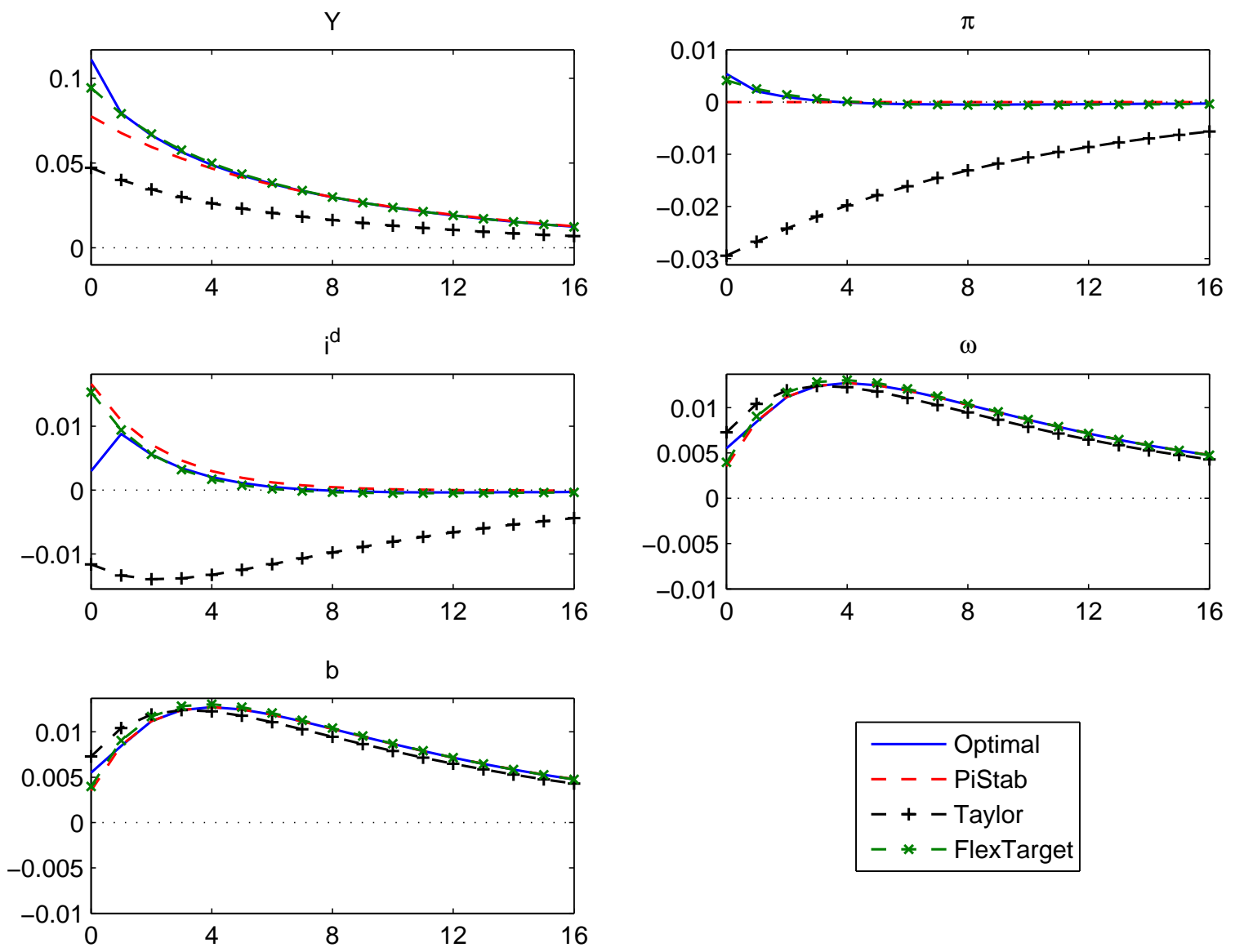

Figure 14: Impulse responses to a 1 percent shock to type $b$ expenditure, under four alternative monetary policies. 


\section{Credit Frictions and Optimal Monetary Policy}
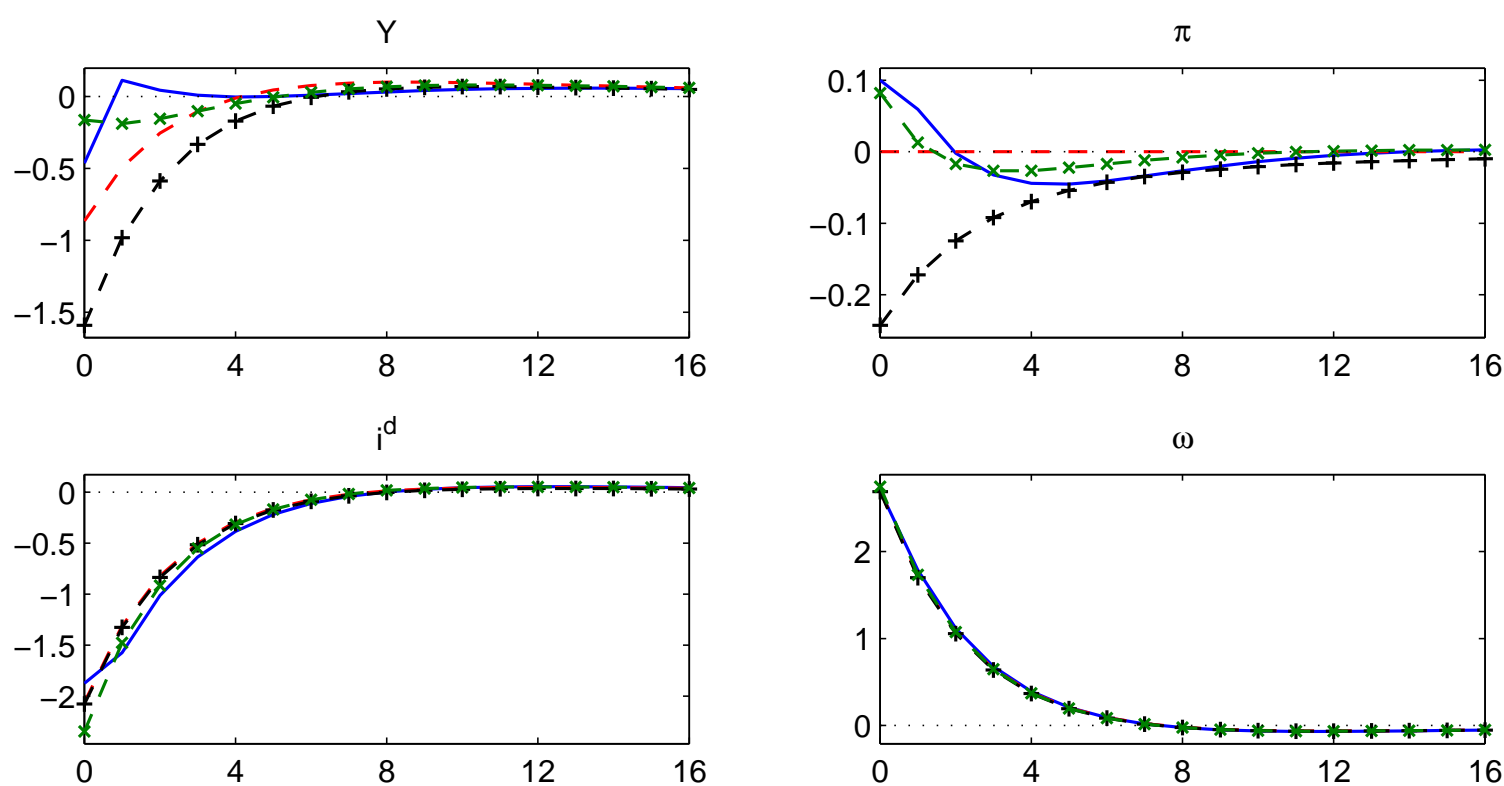

b
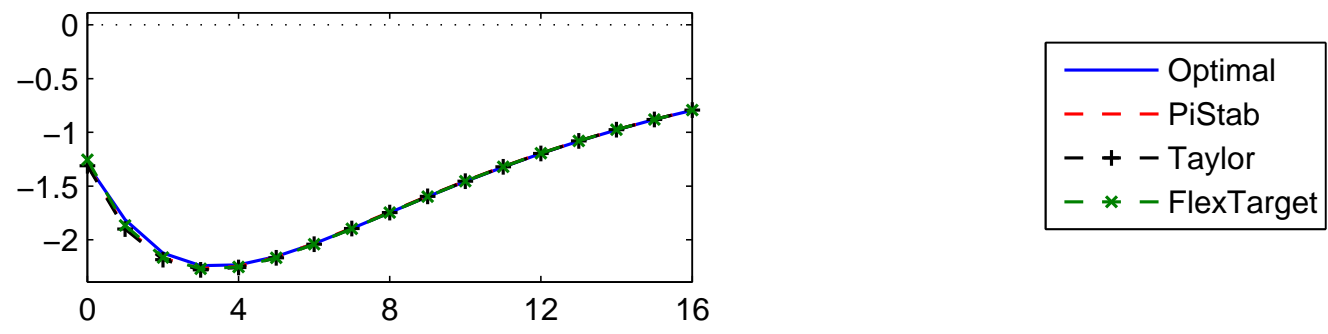

Figure 15: Impulse responses to a shock to $\tilde{\chi}_{t}$ that increases $\omega_{t}(b)$ by 4 percentage points (annualized) for each value of $b$, under four alternative monetary policies. 